\title{
Preliminary Evaluation of
} PSCM and BIPP Melter Design and Operating Conditions Using Physical Modeling
R. J. Skarda
S. G. Hauser
J. A. Fort

May 1985

Prepared for the U.S. Department of Energy under Contract DE-AC06-76RLO 1830

Pacific Northwest Laboratory Operated for the U.S. Department of Energy by Battelle Memorial Institute 


\title{
DISCLAIMER
}

This report was prepared as an account of work sponsored by an agency of the United States Government. Neither the United States Government nor any agency thereof, nor any of their employees, makes any warranty, express or implied, or assumes any legal liability or responsibility for the accuracy, completeness, or usefulness of any information, apparatus, product, or process disclosed, or represents that its use would not infringe privately owned rights. Reference herein to any specific commercial product, process, or service by trade name, trademark, manufacturer, or otherwise, does not necessarily constitute or imply its endorsement, recommendation, or favoring by the United States Government or any agency thereof. The views and opinions of authors expressed herein do not necessarily state or reflect those of the United States Government or any agency thereof.

\author{
PACIFIC NORTHWEST LABORATORY \\ operated by \\ BATTELLE \\ for the \\ UNITED STATES DEPARTMENT OF ENERGY \\ under Contract DE-AC06-76RLO 1830
}

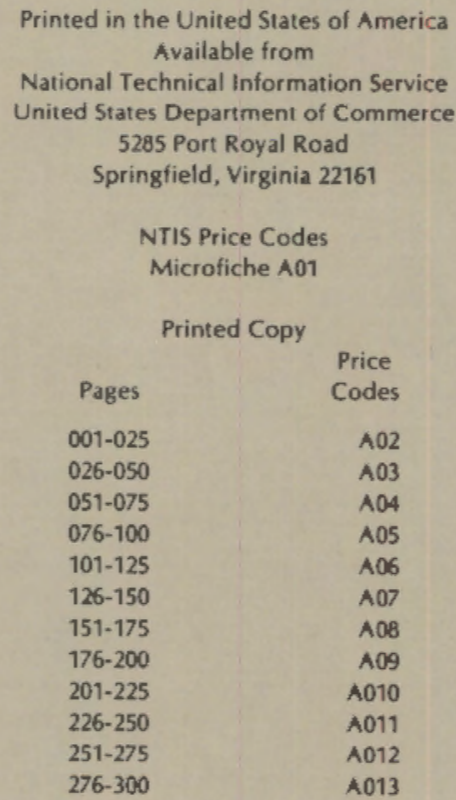


PRELIMINARY EVALUATION OF PSCM! AND BIPP MELTER DESIGN AND OPERATING CONDITIONS USING PHYSICAL MODELING

R. J. Skarda

S. G. Hauser

J. A. Fort (a)

May 1985

Prepared for

the U.S. Department of Energy

under Contract DE-AC06-76RLO 1830

Pacific Northwest Laboratory

Richland, Washington 99352

(a) Flow Industries, Kent, Washington 


\section{ACKNOWLEDGMENTS}

This work was funded by the U.S. Department of Energy in support of the Hanford Waste Vitrification Program managed by Rockwell Hanford Operations. The effort was performed as part of PNL's role in the Hanford Waste Vitrification Program under the direction of S. M. Barnes and M. S. Hanson directed the effort and provided considerable assistance in obtaining available melter data. The authors also wish to express their appreciation to: W. J. Apley and W. C. Cliff for management support, J. M. Bates for considerable technical guidance, C. R. Reid and K. K. Nomura for data reduction assistance, E. J. Eschbach for technical review of the report, and $P$. C. Young for word processing and report assembly. 

SUMMARY

The Glass Melter Physical Modeling investigation was initiated to support Pacific Northwest Laboratory (PNL) Hanford Waste Vitrification Program. Specifically, results discussed herein are those of the modeled B-Plant Immobilization Pilot Plant (BIPP) and Pilot Scale Ceramic Melter (PSCM) designs. The purpose of this study was to evaluate various melter design features using laboratory scale models. Hydrodynamic, thermal, and electrical similarity between the modeling fluid and the molten glass were primary objectives. Stroboscopic velocity measurements (flow visualization), temperature measurements, and electrical potential measurements were used to investigate the molten glass behavior. Results from this effort are to provide input to melter design and proposed operation in addition to providing a data base for verifying numerical models.

The approach used in the current glass melter modeling investigation was to obtain similarity parameters by nondimensionalizing the governing differential equations (i.e., mass, momentum, and energy equations) and the corresponding boundary conditions. Similarity of the four dimensionless groups: Peclet number, Pe, Raleigh number, Ra, Nusselt number, Nu, and the Power number, $\tilde{\phi}_{S}$ was required. For the convenience of determining scaling factors, Ra was regrouped into two dimensionless groups, $\beta \Delta T$ and GaPr. Model to prototype scaling factors were then derived from the relevant dimensionless groups. Determination of scaling factors was required because they provide a systematic method of determining modeling fluid properties and model operating conditions that correspond to the desired prototype operating conditions.

A modeling fluid was desired that could simultaneously be scaled to the glass kinematic viscosity and electrical resistivity for a given melter operating configuration. Model fluid criteria was satisfied by Glycerin-Lithium Chloride mixtures which were prepared using an iterative procedure. The $1 / 3$ scale PSCM model was fabricated from plexiglass, while a $1 / 4$ scale BIPP model was fabricated from glass. Plexiglass cooling jackets for both models were

- Rohm \& Hass Co. 
constructed on all sides of the models to maintain the proper wall temperatures, however, heat loss from the botton occurred by natural convection. Water cooled plate electrodes were fabricated from copper to simulate the PSCM prototype Inconel® electrodes. The BIPP water cooled electrode configuration, an upper and lower copper plate electrode pair simulated the BIPP Inconel@ electrode configuration. Power was supplied to the electrodes, in both configurations by phase angle forced SCR-power controllers. Lastly, a molten crust or "cold cap" which exists at the surface of the molten glass was simulated with a water cooled "cold cap."

An Argon ion laser was the source of a $1 / 8$ " thick vertical light sheet which was required for the stroboscopic velocity measurements. Neutrally buoyant glassy carbon particles which were developed at PNL were used as flow tracers/1ight scatters for flow visualization. Data was collected using the Integrated Systeln for Automated ACquisition and Control, ISAAC, which provided data with 12 bit binary resolution to an Apple IIE PC. Temperature measure ments were taken of the model walls, bottom \& top and modeling fluid. Cooling jacket temperatures and flows as well as electrode, power current, vol tage, and temperature were also monitored and recorded. Measurement and result accuracies were determined using the $\mathrm{K} t i$ ne and AcClintock uncertainty nethod.

The objectives of both the BIPP and PSCM studies were to minimize glass temperature gradients and increase fluid velocities by promoting stable convective cells in the fluid which increase fluid mixing. Fluid regions with low velocities promote particle settling. Large temperature gradients within the glass are undesirable because large variations of both viscosity and electrical conductivity occur. Large electrical conductivity variations produce nonuniform current densities which could result in excess electrode corrosion due to high local current densities. Nonuniform electrical conductivity in the BIPP melter could also lead to crossfiring of the electrodes. Cooler regions in the melter can also provide regions of crystallization due to the tendency of the glass to devitrify at lower temperatures [11]. High viscosity in cooler regions also promotes settling of nonsoluble particles which creates nucleation

(9) Carborundum $\mathrm{CO}$. 
sites for crystallization formation. The sludge formation could potentially lead to blockage of the throat or riser over longer periods of operation [11]. In addition, the formation of a conductive sludge could lead to shorting of electrodes.

Specific objectives of the BIPP model investigation were to measure the effects of electrode spacing and upper/lower Electrode Power Ratio (U/L EPR) on model operating performance. Preliminary BIPP tests at $U / L$ EPR's of 1.0:0.0, $0.5: 0.5$, and $0.26: 0.74$ were completed, although no effects of electrode spacing were examined. Additional BIPP model testing is scheduled to address botn objectives in greater detail. Preliminary testing revealed that fluid is divided into two flow regions for operation at a U/L EPR of 1.0:0.0. Fluid velocities are faster and fluid temperatures warmer in the upper half of the model and between the powered upper electrodes, relative to the fluid in the lower portion of the melter. A more uniform temperature was obtained for a $\mathrm{U} / \mathrm{L}$ EPR of 0.5:0.5 as compared to 1.0:0.0 U/L EPR. We11 defined convective cells were observed to penetrate through roughiy the full fluid depth for a U/L EPR of 0.26:0.74. During U/L EPR 1.0:0.0 testing, unstable convective cells were observed in the upper portion of the model while no convective cells appeared in the lower fluid regions.

During PSCM testing, large temperature gradients existed in the vertical direction and across the horizontal length of the model when bubbler induced mixing was not provided. The temperature differential in the model was reduced from $12^{\circ} \mathrm{C}$ to $2^{\circ} \mathrm{C}\left(55^{\circ} \mathrm{C}\right.$ to $9^{\circ} \mathrm{C}$ in the melter) by implementation of bubblers. Less mixing occurred near the electrodes where the temperature profiles were also increasingly stratified. During bubbler mixing, two counter rotating eddies, symmetric about the melter center were observed. Bubblers increased the speed at which these eddies rotated and also induced secondary eddies near the electrodes. Fluid velocities in the laminar flow regions near boundaries were also increased by bubbler induced mixing.

In a11 BIPP and PSCM test runs, large temperature gradients existed in the inmediate region of the cold cap. The flow field was symmetric about the melter center with the top completely cooled. However, cooling only an offset portion $(60 \%)$ of the top resulted in a distorted or nonsymmetrical fiow-field 
about the melter center. The flow field was skewed in the direction of the cold cap. Cold cap orientation, bubbler flow rates, and number of bubblers produced no observable change in potential field.

BIPP testing suggests that varying the power density of fluid layers is a viable means of enhancing fluid mixing, however, these preliminary results are not sufficient to recommend an electrode operating configuration. As expected, a $U / L$ EPR of 1.0:0.0 was a poor operating configuration. The $U / L$ EPR of $0.26: 0.74$ provided better overall mixing and may be a possible operating configuration. The effects of upper to lower electrode spacing need to be considered in addition to the possibility of electrode crossfiring.

Use of bubblers in the PSCM model ennances mixing which results in a more uniform temperature. Bubblers not only provide greater mixing in the center of the melter but also increase fluid velocities in laminar flow regions near the model floor. The smaller temperature variations and higher fluid velocities are believed to minimize the opportunity for crystallization and particle settling in the melter. Scaling criteria were not sufficiently developed to provide relative bubbler sizes and bubbler gas flow rates for the operating melter. These scaling criteria should be developed for present PSCM modeling results and future modeling efforts. Installation of bubblers in the PSCM should be considered to improve fluid mixing. 
CONTENTS

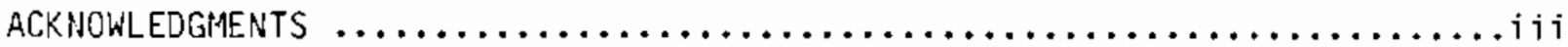

SUMMARY $\ldots \ldots \ldots \ldots \ldots \ldots \ldots \ldots \ldots \ldots \ldots \ldots \ldots \ldots \ldots \ldots \ldots \ldots \ldots \ldots \ldots \ldots$

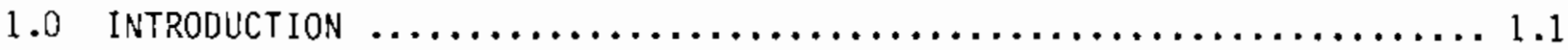

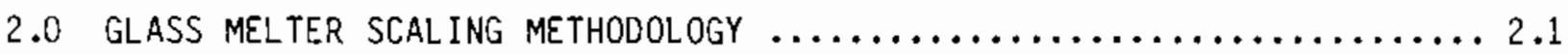

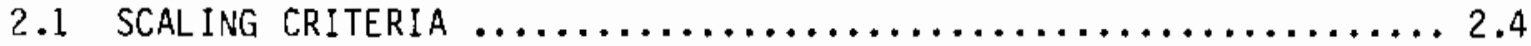

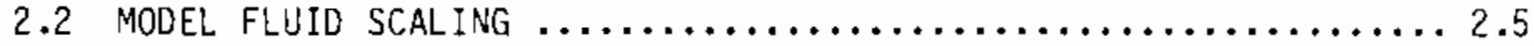

2.2.1 BIPP Model Fluid Scaling $\ldots \ldots \ldots \ldots \ldots \ldots \ldots \ldots \ldots . . \ldots \ldots$

2.2 .2 PSCM Model Fluid Scaling .............................

2.2 .3 Temperature Scaling $\ldots \ldots \ldots \ldots \ldots \ldots \ldots \ldots \ldots \ldots \ldots \ldots \ldots \ldots$

3.0 DESCRIPTION OF EXPERIMENTAL APPARATUS AND PROCEDURE;

MODEL FLUID PREPARATION AND PROPERTIES RESULTS $\ldots \ldots \ldots \ldots \ldots \ldots \ldots \ldots .1$

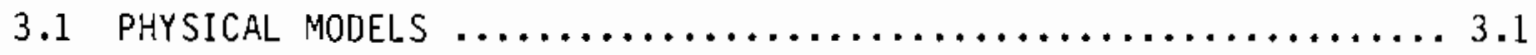

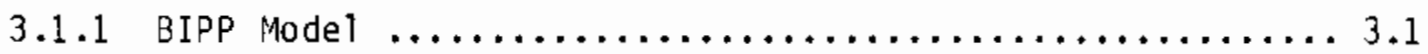

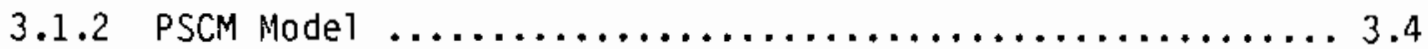

3.2 InSTRUMENTATION AND DATA AQUISITION $\ldots \ldots \ldots \ldots \ldots \ldots \ldots \ldots \ldots \ldots .4$

3.3 TEST MEASUREMENT PROCEDURES $\ldots \ldots \ldots \ldots \ldots \ldots \ldots \ldots \ldots \ldots \ldots \ldots \ldots \ldots \ldots$

3.4 MODELING FlUId PREPARATION $\ldots \ldots \ldots \ldots \ldots \ldots \ldots \ldots \ldots \ldots \ldots \ldots \ldots \ldots$

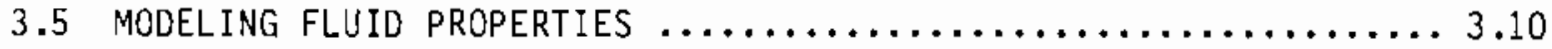

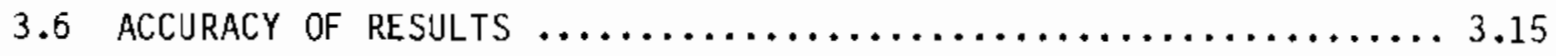

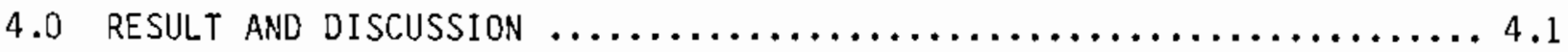

4.1 BIPP TEMPERATURE RESULTS $\ldots \ldots \ldots \ldots \ldots \ldots \ldots \ldots \ldots \ldots \ldots \ldots \ldots \ldots \ldots \ldots$

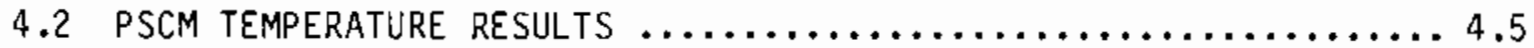

4.2.1 BIPP Flow and Velocity Measurements ................16

4.2.2 PSCM Flow and Velocity Measurements .............. 4.20

4.3 PSCM POTEnTIAL MEASUREMEnTS $\ldots \ldots \ldots \ldots \ldots \ldots \ldots \ldots \ldots \ldots \ldots \ldots \ldots \ldots \ldots \ldots$ 


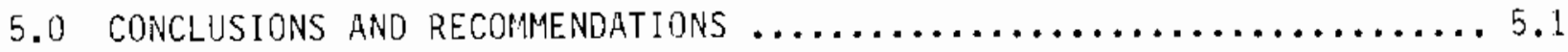
5.1 .1 Conclusions - BIPP Testing $\ldots \ldots \ldots \ldots \ldots \ldots \ldots \ldots \ldots \ldots \ldots \ldots \ldots \ldots \ldots \ldots$

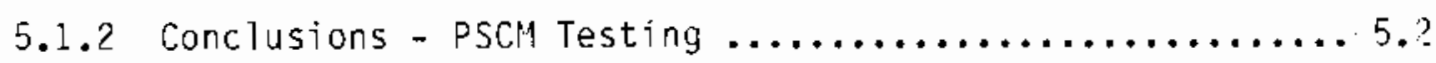

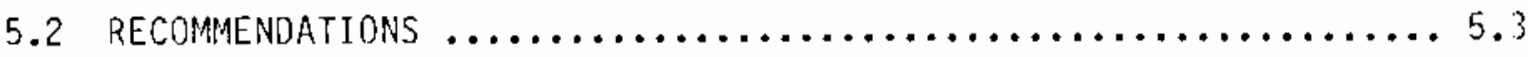

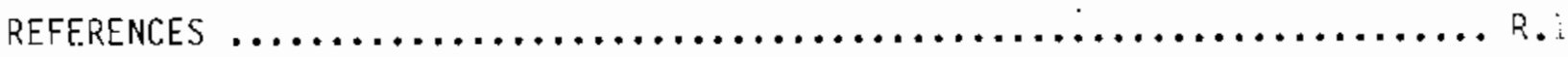

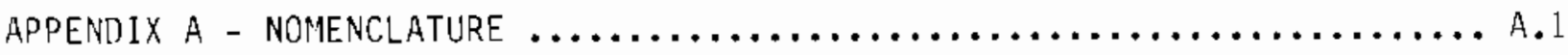

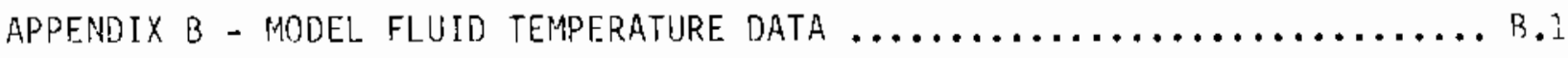
APPENDIX C - BIPP BOUNDARY CONDITIONS - FOR STROBOSCOPIC, PHOTOGRAPHS .....c. c. APPENDIX D - PSCM MODEL DATA FLUID ELECTRICAL POTENTIAL $\ldots \ldots \ldots \ldots \ldots \ldots$.

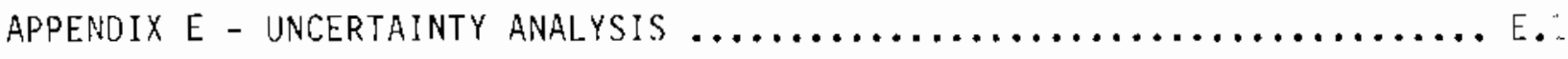
APPENDIX F - PSCM MODEL HEAT LOSS ANALYSIS ....................... F... 


\section{FIGURES}

3.1 B-Plant Immobilization Pilot Plant Model Configuration ........... 3.2

3.2 BIPP Model Fluid Temperature and Potential Measurement Locations

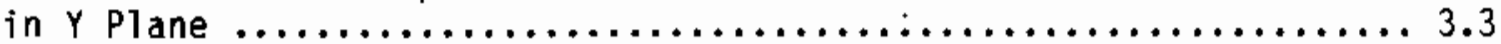

3.3 Pilot Scale Ceranic Melter Model Configuration ................ 3.5

3.4 PSCM Model Fluid Temperature and Potential Measurement Locations

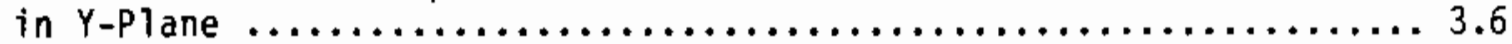

3.5 Instrumentation and Data Acquisition for BIPP Model .......... 3.8

3.6 Argon Laser and Optics Configuration for Flow Visualization

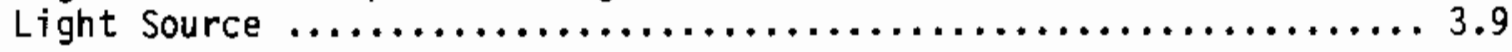

3.7 Dynamic and Kinematic Viscosities vs Temperature for Modeling

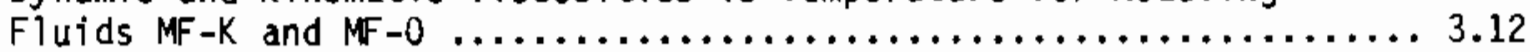

3.8 Electrical Conductivity and Resistivity for Modeling Fluids

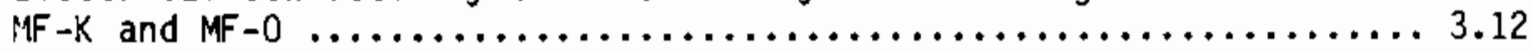

3.9 Specific, $\mathrm{C}_{\mathrm{p}}$ and Density, $\mathrm{C}$, vs Temperature for Modeling

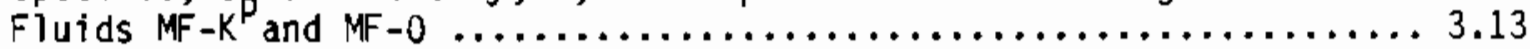

3.10 Thermal Conductivity, $K$, and Thermal Diffusivity, $\alpha$, vs

Temperature for Modeling Fluids, MF-K and MF $-0 \ldots \ldots \ldots \ldots \ldots . \ldots \ldots$

3.11 Modeling Fluid, MF-K, Scale Factor Variation with Temperature ..... 3.16

3.12 Modeling Fluid, MF-0, Scale Factor Variation with Temperature ..... 3.16

4.1 Horizontal Temperature Profile at Me1ter Center - BIPP Mode1 ...... 4.4

4.2 Horizontal Temperature Profile at Melter Center - BIPP ........4.4

4.3 Vertical Temperature Profile Near Front Wal1 .............. 4.6

4.4 Vertical Temperature Profile Near Front Wall $\ldots \ldots \ldots \ldots \ldots \ldots \ldots \ldots .6$

4.5 Vertical Temperature Profjle Near Front Wall $\ldots \ldots \ldots \ldots \ldots \ldots \ldots . \ldots 4$

4.6 Vertical Temperature Profile at Model Center ................ 4.7

4.7 Vertical Temperature Profile at Model Center ................ 4.8

4.8 Vertical Temperature Profile at Model Center $\ldots \ldots \ldots \ldots \ldots \ldots \ldots$

4.9 Vertical Temperature Profile Between Model Center and Back Wal1 .... 4.9 
4.10 Vertical Temperature Profile Between Model Center and Back Wall ... 4.9

4.11 Vertical Temperature Profile Between Model Center and Back Wall ... 4.10

4.12 Vertical Temperature Profile Near Back Wall ................ 4.10

4.13 Vertical Temperature Profile Near Back Wall ................. 4.11

4.14 Vertical Temperature Profile Near Back Wall $\ldots . . \ldots \ldots \ldots \ldots \ldots \ldots . . .4 .11$

4.15 Horizontal Temperature Profile at Model Center .............. 4.13

4.16 Horizontal Temperature Profile at Model Center ............... 4.13

4.17 Horizontal Temperature Profile at Model Center ............... 4.14

4.18 Horizontal Temperature Profile Near Back Wall ............... 4.14

4.19 Horizontal Temperature Profile Near Back Wa11 .............. 4.15

4.20 Horizontal Temperature Profile Near Back Wall .............. 4.15

4.21 BPRUN-1 Flow Field, U/R EPR $=1.0: 0.0, \gamma^{\star}=0.310 \ldots \ldots \ldots \ldots \ldots .17$

4.22 BPRUN-2 Flow Field, $U / R$ EPR $=1.0: 0, \gamma^{\star}=0.467 \ldots \ldots \ldots \ldots \ldots . .4 .18$

4.23 BPRUN-3 Flow Field, U/R EPR $=0.26: 74 \gamma^{\star}=0.423 \ldots \ldots \ldots \ldots \ldots . . \ldots 49$

4.24 Bubbler Flow Rate $=0.0$ SCFH; Strobed Photographs, $t=1.0 \mathrm{sec}$, $\Delta t=5.0 \mathrm{sec}, \gamma^{\star}=0.518$; Boundary Temperatures: $\mathrm{T}_{\mathrm{ele}}=39^{\circ} \mathrm{C}$, $\mathrm{T}_{\text {walls }}=43^{\circ} \mathrm{C}, \mathrm{T}_{\text {top }}=39^{\circ} \mathrm{C}$

4.25 Vector Plots Bubbler Flow Rate $=0.0$ SCFH; $y^{\star}=0.518 \ldots \ldots \ldots \ldots . .23$

4.26 Bubbler Flow Rate $=0.2$ SCFH; Strobed Photograph, $t=1.0 \mathrm{sec}$, $\Delta t=5.0 \mathrm{sec} ; Y^{\star}=0.600$, Three Bubblers $\ldots \ldots \ldots \ldots \ldots \ldots \ldots \ldots \ldots .25$

4.27 Bubbler Flow Rate $=0.5 \mathrm{SCFH}$; Strobed Photograph, $t=1.0 \mathrm{sec}$, $\Delta t=5.0 \mathrm{sec} ; \gamma^{\star}=0.600$, Three Bubblers $\ldots \ldots \ldots \ldots \ldots \ldots \ldots \ldots \ldots .25$

4.28 Bubbler Flow Rate $=1.0 \mathrm{SCFH}$; Strobed Photograph, $t=1.0 \mathrm{sec}$, $\Delta t=5.0 \mathrm{sec} ; \gamma^{\star}=0.600$, Three Bubblers $\ldots \ldots \ldots \ldots \ldots \ldots \ldots \ldots . . \ldots 4.26$

4.29 Bubbler Flow Rate $=0.5$ SCFH; Strobed Photograph, $t=1.0 \mathrm{sec}$, $\Delta t=5.0 \mathrm{sec} ; Y^{\star}=0.600$, Four Bubblers

4.30 Bubbler Flow Rate $=0.2$ SCFH; Three Bubblers; $t=1.0 \mathrm{sec}$, $\Delta t=5.0 \mathrm{sec} ; Y^{\star}=0.276 ;$ Power $=190 \mathrm{~W} ; \mathrm{T}_{\text {top }}=9.0^{\circ} \mathrm{C}$, $\mathrm{T}_{\text {walls }}=41.0^{\circ} \mathrm{C}, \mathrm{T}_{\text {ele }}=37.0^{\circ} \mathrm{C}$ 
4.31 Bubbler Flow Rate $=0.2 \mathrm{SCFH}$; Three Bubblers; $t=1.0 \mathrm{sec}$, $\Delta \mathbf{t}=5.0 \mathrm{sec} ; Y^{\star}=0.171 ;$ Power $=195 \mathrm{~W} ; \mathrm{T}_{\text {top }}=9.0^{\circ} \mathrm{C}$, $\mathrm{T}_{\text {walls }}=41.0^{\circ} \mathrm{C}, \mathrm{T}_{\text {ele }}=37^{\circ} \mathrm{C} \ldots \ldots \ldots \ldots \ldots \ldots \ldots \ldots \ldots \ldots \ldots \ldots \ldots \ldots \ldots \ldots \ldots \ldots \ldots \ldots \ldots .27$

4.32 Bubbler Flow Rate $=0.5 \mathrm{SCFH}$; Three Bubblers; $t=1.0 \mathrm{sec}$, $\Delta t=5.0 \mathrm{sec} ; Y^{\star}=0.171 ;$ Power $=171 \mathrm{~W} ; \mathrm{T}_{\text {top }}=8.0^{\circ} \mathrm{C}$, $\mathrm{T}_{\text {walls }}=46^{\circ} \mathrm{C}, \mathrm{T}_{\text {ele }}=36.4^{\circ} \mathrm{C}$.

4.33 Bubbler Flow Rate $=1.0 \mathrm{SCFH}$; Three Bubblers; $t=1.0 \mathrm{sec}$, $\Delta t=5.0 \mathrm{sec} ; Y^{\star}=0.276 ;$ Power $=171 \mathrm{~W} ; \mathrm{T}_{\text {top }}=8.0^{\circ} \mathrm{C}$, $\mathrm{T}_{\text {walls }}=46^{\circ} \mathrm{C}, \mathrm{T}_{\text {ele }}=38^{\circ} \mathrm{C}$

C.1 Temperature Measurement Locations on Model Bottom ...............

F.1 Maximum Heat Loss from Uncooled Portion of Model Top ...............

F.2 Maximum Heat Loss from PSCM Model Bottom $\ldots \ldots \ldots \ldots \ldots \ldots \ldots \ldots \ldots$ 


\section{$\underline{\text { TABLES }}$}

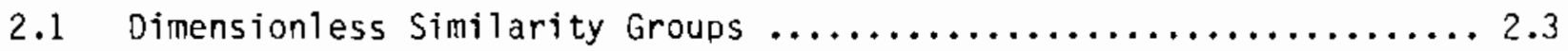

2.2 Scaling Relationshios Derived from Similarity Criteria $\ldots \ldots \ldots \ldots .2 .6$

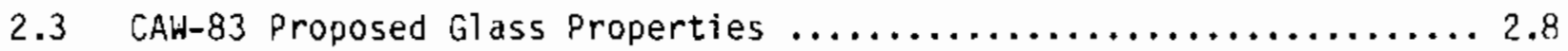

2.4 Glass Properties at Operating Bulk Glass Temperature $\ldots \ldots \ldots \ldots \ldots 2.9$

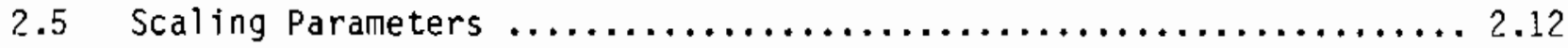

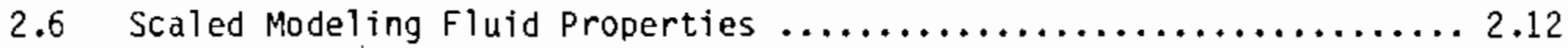

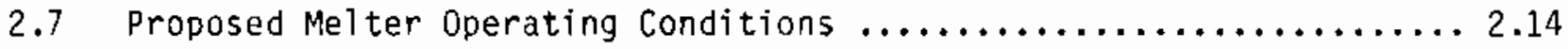

2.8 Scaled Model Operating Conditions $\ldots \ldots \ldots \ldots \ldots \ldots \ldots \ldots \ldots \ldots \ldots, 2.14$

3.1 Model Fluid Properties at Model Operating Temperature, $T_{\text {mo }} \ldots \ldots \ldots .3 .15$

B.1-1 Temperature Field Measurements $\gamma^{\star}=0.500$; Fluid Temperature ...... B.1

B.1-2 Temperature Field Measurements $\gamma^{\star}=0.500$; Fluid Temperature ..... B.2

B.2-1 Temperature Field Measurements Bubbler Flow Rate 0.0 SCFH; $y^{\star}=0.500$ Fluid Temperatures $\ldots \ldots \ldots \ldots \ldots \ldots \ldots \ldots \ldots \ldots \ldots \ldots \ldots \ldots \ldots \ldots \ldots$

B.2-2 Temperature Field Measurements Bubbler Flow Rate 0.2 SCFH;

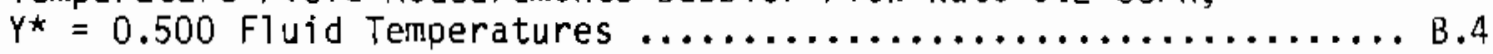

B.2-3 Temperature Field Measurements Bubbler Flow Rate 0.5 SCFH; $\gamma^{\star}=0.500$ Fluid Temperatures $\ldots \ldots \ldots \ldots \ldots \ldots \ldots \ldots \ldots \ldots \ldots \ldots . . .6$

B.2-4 Temperature Field Measurements Bubbler Flow Rate 1.0 SCFH;

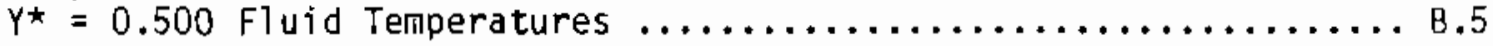

C.1 BPRUN-1 Boundary Conditions $\ldots \ldots \ldots \ldots \ldots \ldots \ldots \ldots \ldots \ldots \ldots \ldots \ldots, \ldots \ldots \ldots$

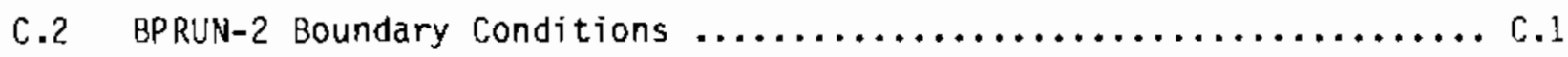

C.3 BPRUN-3 Boundary Conditions $\ldots \ldots \ldots \ldots \ldots \ldots \ldots \ldots \ldots \ldots \ldots \ldots, \ldots, 2$

D.1 Potential Field Measurements Bubbler Flow Rate 0.0 SCFH; $Y^{*}=0.500$ Fluid Potential Traverses $\ldots \ldots \ldots \ldots \ldots \ldots \ldots \ldots \ldots . .1$

D.2 Potential Field Measurements Bubbler Flow Rate 0.2 SCFH; $Y^{*}=0.500$ Fluid Potential Traverses $\ldots \ldots \ldots \ldots \ldots \ldots \ldots \ldots \ldots . . .2$

D.3 Potential Field Measurements Bubbler Flow Rate 0.5 SCFH; $Y^{\star}=0.500$ Fluid Potential Traverses $\ldots \ldots \ldots \ldots \ldots \ldots \ldots \ldots \ldots \ldots . .2$ 
F.1 Air Gap Properties $\ldots \ldots \ldots \ldots \ldots \ldots \ldots \ldots \ldots \ldots \ldots \ldots \ldots \ldots \ldots \ldots \ldots \ldots$

F.2 Temperature and Property Values Used to Determine $h_{2} \ldots \ldots \ldots \ldots \ldots$. . .

F.3 Temperature and Property Values IJsed to Determine $h_{3} \ldots \ldots \ldots \ldots . . .7$ 



\subsection{INTRODUCTION}

The Glass Melter Physical Modeling task was initiated in June 1983 to provide support to PNL's Hanford Haste Vitrification Program (HWV). The work was a continuation of previous physical modeling of glass melters done at PNL prior to 1980 (see PNL-2809; Physical Modeling of Joule Heated Ceramic Glass Melters for High Level Waste Immobilization). The purpose of this task was to use laboratory scale physical models to evaluate various glass melter design features and parameters. Temperature distributions, potential distributions, and flow patterns of the glass were modeled to accomplish the intended purpose.

The two systems that were modeled in this investigation are the B-Plant Immobilization Pilot Plant (BIPP) Melter and the Pilot Scale Ceramic Melter (PSCM). The PSCM is an experimental melter having a melt surface area of $0.75 \mathrm{~m}^{2}$. It is operated to provide developmental support to various Department of Energy (DOE) Waste Management programs, including HWV. The HWvP is a program providing ceramic melter technology for use in vitrification of various high-level waste streams at Hanford, WA. The BIPP is a pilot plant which was proposed to demonstrate vitrification of Hanford high-level wastes.

Objectives of the HWV modeling were to measure the effects of electrode positioning, and electrode power skewing. The PSCM modeling objectives were to lieasure the effects of using nitrogen bubblers as flow stabilizers and measure the effect of cold cap size and location. Results obtained from both PSCM and BIPP model testing would also serve in verification of numerical models. 



\subsection{GLASS MELTER SCALING PHETHODOLOGY}

The approach used in the current glass melter modeling investigation was to obtain similarity variables by nondimensionalizing the governing differential equations, (i.e., mass, momemtum and energy equations), and the corresponding boundary conditions. This approach was also adopted by quigley and Kreid(1) for the previous PNL glass melter physical modeling study. The general conservation equations may be written as:

Conservation of Mass

$$
\frac{D \rho}{D t}=-\rho(\nabla \cdot \vec{U})
$$

\section{Conservation of Momentum}

$$
\begin{gathered}
\circ \frac{D \vec{U}}{D t}=-\nabla P+\rho \vec{g}-\nabla \cdot \vec{\tau} \\
\text { Conservation of Energy } \\
\rho \frac{D E}{D t}=-\nabla \overrightarrow{0}-P(\nabla \cdot \vec{U})-\vec{\tau}: \vec{J}+\phi_{s}
\end{gathered}
$$

For the present study, the following assumptions are considered valid and are used to reduce the governing equations to a simpler form:

- steady state processes

- constant properties

- incompressible flow

- Boussinesq approximation is valid.

The boundary conditions are satisfied by Equation 4 which equates the convective heat losses to the fluid power dissipated. 


$$
\begin{gathered}
\frac{\text { Boundary Condition }}{Q_{i}=n A_{i}\left(T_{W}-T_{\infty}\right)=\delta_{i} \Delta A V}
\end{gathered}
$$

$\delta_{i}$ is the fractional fluid power dissipated at a given surface $i$.

Similarity parameters are obtained by nondimensionalizing Equations (1, 2, 3 , and 4). The nondimensionalization of the governing equations and boundary conditions is well documented and can be found in most heat transfer or fluid flow text books $[2,3,4,5]$. Reference [1] also devotes a detailed discussion to the nondimensionalization procedure as it applies to glass melter modeling. The resulting reduced and nondimensionalized governing equations and boundary conditions of Equations $(1,2,3$, and 4$)$ are given by Equations $(5,6,7$, and 8). The superscripted asterisk, *, denotes a nondimensionalized paraneter.

Nondimensionalized and Reduced Governing Equations

$$
\begin{gathered}
\nabla^{\star} \cdot \vec{U}^{\star}=0 \\
\operatorname{Re} \vec{U} \star \nabla \vec{U}^{\star}=\frac{\operatorname{Ra}}{\operatorname{Pe}} \frac{\vec{g}}{g}+\nabla^{2} U^{\star} \\
\operatorname{Pe} \vec{U} \cdot \nabla^{\star} T^{\star}=\nabla^{2} T^{\star}+\operatorname{EcPr} \tilde{\phi}_{V}+\widetilde{\Phi}_{S}
\end{gathered}
$$

Nondimensionalized Boundary Condition

$$
T^{*}=\delta_{i} \tilde{\phi}_{\mathrm{S}} \mathrm{Nu}^{-1}
$$

Equations (5, 6, 7 and 8) indicate that for proper scaling to nold, similarity is required of the following dimensionless groups: $\mathrm{Re}, \mathrm{Pe}, \mathrm{Ra}, \mathrm{Nu}, \mathrm{Ec}, \mathrm{Pr}$, and $\tilde{\phi}_{S}$. The relatively small velocjties occurring in the melter result in small Reynolds numbers, Re and Eckert numbers, EC. Therefore, these numbers and their associated terms drop out of Equations (6 and 7) respectively. The remaining dimensionless groups, $\mathrm{Pe}, \mathrm{Ra}, \mathrm{Nu}$, and $\widetilde{\phi}_{s}$ require similarity. The definitions of dimensionless groups relevant to this study are provided in Table 2.1. The choice of dimensionless groups used in the governing equations 
TABLE 2.1. Dinensioniess Similarity Groups

\begin{tabular}{|c|c|c|c|c|}
\hline & Parameter Name & Units & Interpretation & Equivalent Forms \\
\hline & Prandtl No. & $\mathrm{Pr}$ & $=\frac{\text { momentum diffusivity }}{\text { thermal diffusivity }}$ & $=\frac{\mu C}{K}-p=\frac{v}{q}$ \\
\hline & Reynolds No. & $\operatorname{Re}$ & $=\frac{\text { inertial forces }}{\text { viscous forces }}$ & $=\frac{\rho U L}{\mu}=\frac{U L}{\nu}$ \\
\hline & Peclet No. & $\mathrm{Pe}$ & $=\frac{\text { convection energy }}{\text { conduction energy }}$ & $=\frac{\rho^{C}{ }_{p} U L}{K}=\frac{U L}{\alpha}=\operatorname{RePr}$ \\
\hline & Grashof No. & $\mathrm{Gr}$ & $=\frac{\text { buoyancy forces (inertial forces) }}{(\text { viscous forces })^{2}}$ & $=\frac{g B L^{3} \Delta T}{v^{2}}$ \\
\hline & Rayleigh No. & $\mathrm{Ra}$ & $=\frac{\text { buoyant transport of energy }}{\text { conduction of energy }}$ & $=\frac{g \beta L^{3} \Delta T}{\alpha \nu}=\mathrm{GrPr}$ \\
\hline$\ddot{\omega}$ & Galileo No. & $\mathrm{Ga}$ & $=\frac{\text { buoyancy forces }}{\text { viscous forces }}$ & $=\frac{g^{3}}{v^{2}}=\frac{G r}{\beta \Delta T}$ \\
\hline & Nusselt No. & $\mathrm{Nu}$ & $=\frac{\text { convection neat flux }}{\text { conduction heat flux }}$ & $=\frac{\mathrm{hL}}{\mathrm{K}}$ \\
\hline & Eckert No. & $\mathrm{Ec}$ & $=\frac{\text { viscous energy dissipation }}{\text { convection energy flux }}$ & $=\frac{U^{2}}{C_{p} \Delta T}$ \\
\hline & Brinkman No. & $\mathrm{Br}$ & $\begin{aligned}= & \text { heat production by viscous } \\
& \text { dissipation }\end{aligned}$ & $=\frac{\mu(U / L)^{2}}{K \Delta T / L^{2}}$ \\
\hline & Power No. (a) & $\sim_{s}$ & $\begin{aligned} & \text { heat transport by conduction } \\
= & \frac{\text { source heat flux }}{\text { conductive heat flux }}\end{aligned}$ & $=\frac{\phi^{L^{2}}}{\mathrm{~K} \Delta \mathrm{T}}$ \\
\hline
\end{tabular}

(a) No commonly accepted name has been assigned to this paraineter. 
is partialiy dependent on the phenomena being modeled and in part, to the author's preference. For the convenience of scaling the dimensional quantities or properties which comprise the Rayleigh number, Ra is regrouped as:

$$
R a=\beta \Delta T \text { Ga } \mathrm{Pr}
$$

Substitution of the two dimensionless quantities $B \Delta T$ and GaPr results in the similarity of five dimensionless groups needed to accurately model the hydrodynamics and thermal phenomena of the Joule heated glass melter prototype. These five dimensionless yroups in terms of their dimensional quantities are:

$$
\begin{aligned}
\theta_{m} \Delta T_{m} & =\beta_{p} \Delta T_{p} \\
\frac{g L_{m}^{3}}{v_{m}^{\alpha}} & =\frac{g L_{p}^{3}}{v_{p}^{\alpha} \alpha_{p}} \\
\frac{U_{m} L_{m}}{x_{m}} & =\frac{U_{p} L_{p}}{\alpha_{p}} \\
\frac{\phi_{s m} L_{m}^{2}}{k_{m}^{\Delta T_{m}}} & =\frac{\phi_{s p} L_{p}^{2}}{k_{p} \Delta T_{p}} \\
\frac{n_{m} L_{m}}{k_{m}} & =\frac{h_{p} L_{p}}{k_{p}}
\end{aligned}
$$

\subsection{SCALING CRITERIA}

After determining the relevant dimensionless quantities required for modeling of the prototype, scaling factors $\left(\varepsilon_{i}\right)$ of the dimensional quantities must be determined. The purpose of the scaling factors is to provide a systematic method of determining modeling fluid properties and model operating 
conditions that correspond to desired prototype operating conditions and glass properties, (i.e., choose model properties and operating conditions that satisfy similarity criteria, Equations (9-13) for specific operating conditions of the prototypes). The scaling factors are derived from Equations (9-13) where the scaling factor, $\varepsilon_{i}$, is defined as $\varepsilon_{i}=i_{m} / i_{p}$. The variable, $i$, is the dimensional quantity or property being scaled, while the subscript, m, corresponds to model properties, and subscript $p$ corresponds to prototype properties. For example, a relationship for the scaling factors, $\varepsilon_{L}, \varepsilon_{v}$, $\varepsilon_{\alpha}$ can be determined by rewriting Equation (10) as:

$$
\frac{v_{m}}{v_{p}}=\frac{g_{m}}{g_{p}} \frac{L_{m}^{3}}{L_{p}^{3}} \frac{\alpha_{p}}{a_{m}}
$$

The gravity term drops out, yielding the following scaling factor relationship:

$$
\varepsilon_{\nu}=\varepsilon_{L}^{3} \varepsilon_{\alpha}
$$

Likewise Equation (11) can be written in terms of scaling factors: $\varepsilon_{u}=\varepsilon_{\alpha}$ $\varepsilon_{L^{-1}}$. As indicated in Table 2.2, scaling factor relationships can be manipulated and defined in a number of ways.

\subsection{MODEL FLUID SCALING}

Glycerine/Lithium Chloride mixtures were chosen to model the candidate vitrification glass. Advantages of LiCl/Glycerine mixtures include: transparency (for flow visualization techniques), chemical stability, and nonvolatility at model operating temperatures. Stanek [2] devotes a reasonably comprehensive discussion to the topics of model fluid selection and evaluation. Thermophysical properties and electrical properties for various LiCL/Glycerine mixtures are provided for comparison in both Quigley and kreid [1] and stanek [2]. Additional discussion concerning the effects of preparation method on mixture properties is presented in Section 3.3 of this report. Prior to model 
TABLE 2.2. Scaling Relationships Derived from Similarity Criteria

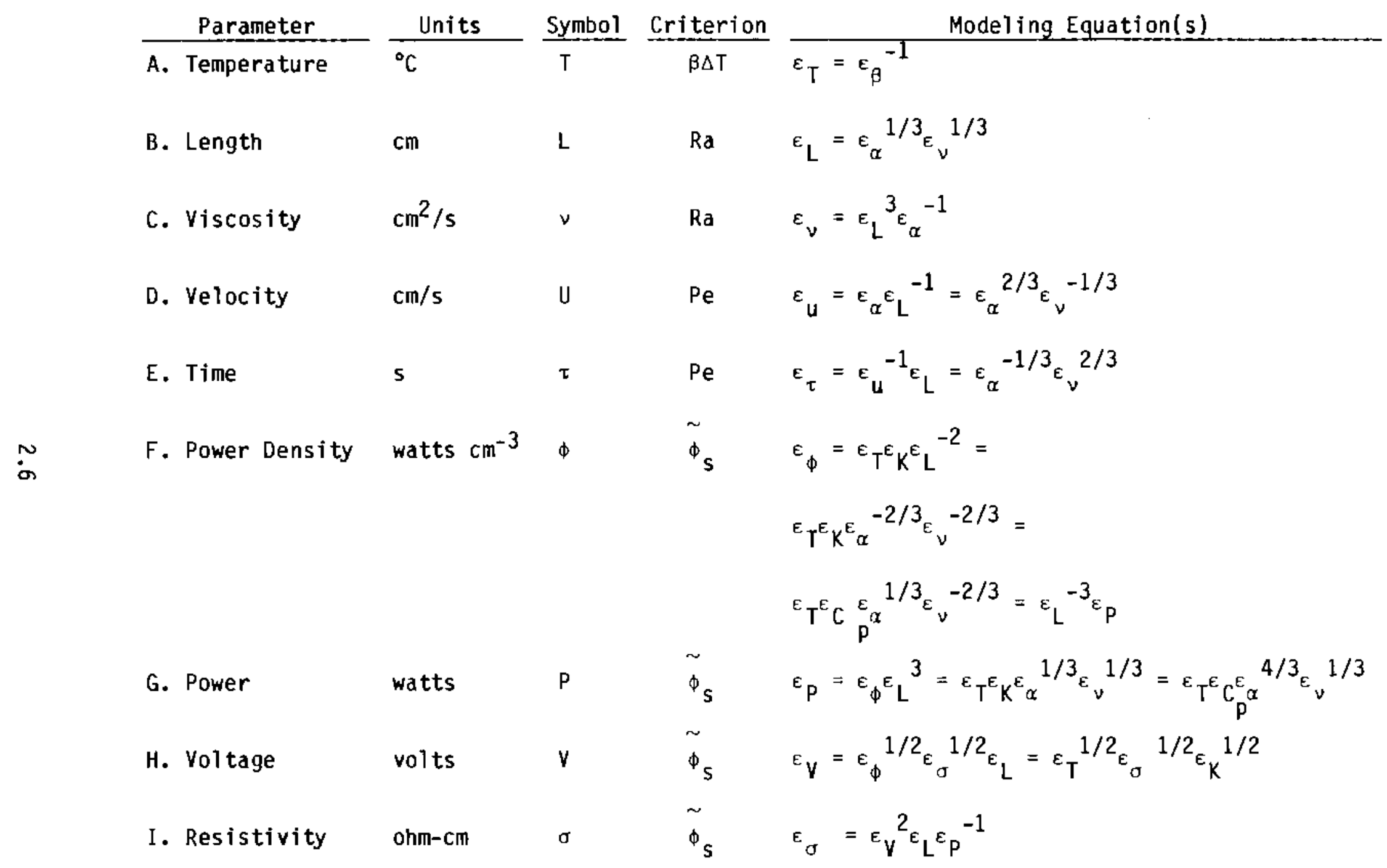


fluid preparation, property values for these mixtures were taken from References [1] and [2] to determine which LiC1/G1ycerine mixtures if any, were acceptable for modeling the candidate molten waste glass. In addition to similarity requirements, the following criteria were also applied to determine the acceptability of a modeling fluid:

- The modeling fluid must be compatible with the desired length scale, $\varepsilon_{L}$, as determined by Equation $B$, Table 2.2.

- The modeling fluid temperature must not exceed the model thermal limit. This limit was designated as the maximum service temperature of the model (acrylic plastic) plexiglass ${ }^{(1)}$ and was $82^{\circ} \mathrm{C}$.

Simultaneous scaling of all modeling fluid properties with respect to molten glass properties, and at melter operating temperature is generally not possible. Because kinematic viscosity, $\mu$, and electrical resistivity, $\sigma$, are much more temperature dependent than other glass or modeling fluid physical properties, modeling fluid preparation was subject to the concurrent scaling of $\mu$ and $\sigma$. The modeling fluid temperature, where coincidental scaling of the glass viscosity and electrical resistivity occur, was designated the operating modeling fluid temperature. Computation of the BIPP and PSCM scale factors is discussed in Section 2.2.1 and 2.2.2 respectively. Temperature scaling is discussed in section 2.2.3.

\subsubsection{BIPP Model Fluid Scaling}

A BIPP melter to model length scale factor of $1 / 4$ was considered since it provided a convenient laboratory working model. Preliminary compatibility of LiCl/Glycerine mixtures with an $E_{L}$ of $1 / 4$ was verified through application of Equation $B$ from Table 2.2. Glass properties from Table 2.3 were used in Equation $B$ while the LiCL/Glycerine properties were obtained from References [1] and $[2]$.

Computation of the model kinematic viscosity is performed using Equation $C$ of Table 2.2. Since the $\varepsilon_{L}$ term of Equation $C$ was chosen as $1 / 4$, only $\varepsilon_{\alpha}$ hence $\alpha_{p}$ and $a_{m}$ need be detemined. Glass properties at a BIPP operating glass temperature of $1150^{\circ} \mathrm{C}$ which are summarized in Table 2.4 were used to calculate an I $\mathrm{p}$ of $4.61 \times 10^{-3} \mathrm{~cm}^{2} / \mathrm{s}$. Table 2.4 properties are interpolated or curve fit 
TABLE 2.3. CAW-83 Proposed G1ass Properties

\begin{tabular}{|c|c|c|c|c|c|c|c|c|c|c|}
\hline$\left({ }^{\circ} \mathrm{C}\right)$ & $\begin{array}{c}p^{(3)} \\
\left(\mathrm{gm} / \mathrm{cm}^{3}\right) \\
\end{array}$ & $\begin{array}{c}\mu(1) \\
(g m / c m-s) \\
\end{array}$ & $\begin{array}{c}\sigma^{(1)} \\
(\Omega-c m) \\
\end{array}$ & $\begin{array}{c}\mathrm{c}(2) \\
\left(\mathrm{cal} / \mathrm{gm}^{\circ} \mathrm{C}\right) \\
\end{array}$ & $\left(10^{-3}\right.$ & $\begin{array}{l}\mathrm{K}(2) \\
\left.\mathrm{Cal} / \mathrm{cm} \cdot \mathrm{s} \cdot{ }^{\circ} \mathrm{C}\right)\end{array}$ & $\left(\times 10^{-3^{\alpha}} \mathrm{cm}^{2} / \mathrm{s}\right)$ & $\left(\mathrm{cm}^{2} / \mathrm{s}\right)$ & $(\alpha v)^{1 / 3}$ & $\begin{array}{r}\operatorname{Pr} \\
\times 10^{3} \\
\end{array}$ \\
\hline 800 & 2.76 & 1012.5 & 15.9 & .359 & & 2.87 & 2.90 & 366.8 & 1.020 & 126 \\
\hline 900 & 2.74 & 436.5 & 5.01 & .385 & & 3.54 & 3.36 & 159.3 & 0.812 & 47.5 \\
\hline 1000 & 2.72 & 225.0 & 2.99 & .413 & & 4.37 & 3.89 & 82.7 & 0.685 & 21.2 \\
\hline 1100 & 2.71 & 100.45 & 2.13 & .449 & & 5.33 & 4.38 & 37.1 & 0.546 & 8.47 \\
\hline 1200 & 2.69 & 47.86 & 1.65 & .483 & & 6.26 & 4.81 & 17.8 & 0.441 & 3.69 \\
\hline 1300 & 2.67 & 22.57 & 1.35 & .516 & & 7.22 & 5.24 & 8.45 & 0.354 & 1.61 \\
\hline o $p r=$ & $=\frac{\nu}{\alpha}$ & & & & & & & & & \\
\hline
\end{tabular}

(1) CAH-83-1 measured properties.

(2) Properties obtained from SRL Comp-411 [8].

(3) Estimated property based on molten glass composition comparisons $[8,9,10]$. 
TABLE 2.4. Glass (CAW-83) Properties at Operating Bulk Glass Temperature

\begin{tabular}{|c|c|c|}
\hline Property & $\begin{array}{c}\text { BIPP } \\
\left(1150^{\circ} \mathrm{C}\right)\end{array}$ & $\begin{array}{c}\text { PSCM } \\
\left(1100^{\circ} \mathrm{C}\right)\end{array}$ \\
\hline$\rho_{p}\left(\mathrm{~g} / \mathrm{cm}^{3}\right)$ & 2.70 & 2.71 \\
\hline$\mu_{p}(g / c m \cdot s)$ & 66.2 & 100.45 \\
\hline$v_{p}\left(\mathrm{~cm}^{2} / \mathrm{s}\right)$ & 24.5 & 37.1 \\
\hline$C_{p_{p}}(J / g \cdot K)$ & 0.466 & 0.449 \\
\hline $\left.\mathrm{K}_{\mathrm{p}}(\mathrm{ca}) / \mathrm{cm} \cdot \mathrm{s} \cdot{ }^{\circ} \mathrm{C}\right)$ & $5.80 \times 10^{-3}$ & $5.33 \times 10^{-3}$ \\
\hline$\alpha_{p}\left(\mathrm{~cm}^{2} / \mathrm{s}\right)$ & $4.61 \times 10^{-3}$ & $4.38 \times 10^{-3}$ \\
\hline$\sigma_{p}(\Omega \cdot \mathrm{cm})$ & 1.89 & 2.13 \\
\hline$\beta_{p}\left({ }^{\circ} \mathrm{C}\right)^{-1}$ & $6.22 \times 10^{-5}$ & $9.07 \times 10^{-5}$ \\
\hline
\end{tabular}

values from the glass properties of Table 2.3. It should be noted that $\mu_{p}$ and $\sigma_{p}$ were the only measured properties of the CAW-83 glass while other properties had to be inferred from comparison with other similar glasses $[8,9,10]$. In addition variation of waste glass composition among batches compounds the difficulty of accurate representation of glass properties [1].

Properties to calculate the model fluid thermal diffusivity, $\alpha_{\text {m }}$ were not available in Stanek [2]. However, measured properties, ${ }_{0}, K_{m}$, and $C_{p_{m}}$ for different $\mathrm{LiCl} / \mathrm{Glycerine}$ mixtures did exist in Reference [1]. Quigley and Kreid also noted that these properties show little variation for different $\mathrm{LiCl} / \mathrm{Glycerine}$ mixtures [1]. For a temperature variation of $30^{\circ} \mathrm{C}$ to $80^{\circ} \mathrm{C},{ }^{\alpha} \mathrm{m}$ of these mixtures varied from $1.10 \times 10^{-3} \mathrm{~cm}^{2} / \mathrm{s}$ to $0.98 \times 10^{-3} \mathrm{~cm}^{2} / \mathrm{s}$ or a $10 \%$ change in $x_{m}$. Therefore, making the assumptions that $\alpha_{m}$ would show little variation for different $\mathrm{LiCl}$ mixture, as indicated by the Quigley and Kreid data, and that the desired viscosity, $v_{m}$, could be obtained within the $30^{\circ} \mathrm{C}$ to $80^{\circ} \mathrm{C}$ temperature range, $\alpha_{m}$ was estimated as $1.05 \times 10^{-3} \mathrm{~cm}^{2} / \mathrm{s}$. These assumptions were supported (after the fact) by comparison of the measured modeling fluid diffusivity shown in Figure 3.10 with $\alpha_{m}$ values given in Reference [1]. Substituting the aforementioned values of $\varepsilon_{L}, \alpha_{m}$ and $\alpha_{p}$ in Equation $C$ (Table 2.2) results in an $\varepsilon_{y}$ of 0.0685 . The required BIPP modeling fluid kinematic viscosity, $v_{m}$, is $1.68 \mathrm{~cm}^{2} / \mathrm{s}$ which corresponds to the $v_{p}$ of 
$24.5 \mathrm{~cm}^{2} / \mathrm{s}$ shown in Table 2.4. Following the scaling of the modeling fluid electrical resistivity, $v_{\text {mi }}$ and $\sigma_{m}$ were used to determine modeling fluid composition and model operating temperature.

Scaling of electrical resistivity is determined from the dimensionless group denoted as the Power number, $\tilde{\Phi}_{S}$, given in Table 2.1. A major consideration in determining a scaling relationship for $\varepsilon_{\sigma}$ is again, to obtain the scaling factor in terms of known or approximately known scaling factors. The computational procedure used in this investigation was to sequentially solve Equations 16 through 19 . These equations are scale factor relationships shown in Table 2.2 .

$$
\begin{aligned}
& \varepsilon_{T}=\left(\varepsilon_{B}\right)^{-1} \\
& \varepsilon_{\phi}=\varepsilon_{T} \varepsilon_{K} \varepsilon_{L}-2 \\
& \varepsilon_{P}=\varepsilon_{\phi} \varepsilon_{L}^{3} \\
& \varepsilon_{\sigma}=\varepsilon_{V} 2 \varepsilon_{L} \varepsilon_{P}-1
\end{aligned}
$$

Values for $K_{p}, K_{m}, \beta_{p}$, and $\beta_{m}$ were required before applying these equations. Values for $K_{p}$ and $B_{p}$ were obtained from the proposed glass properties given in Table 2.3. Thermal conductivity at $60^{\circ} \mathrm{C}$ was used to estimate $K_{m}$ while $B_{m}$ was obtained from Modeling Fluid $C$ of Quigley and Kreid. Values for $k_{m}$ and $\beta_{\pi}$ are given in Table 2.5. The scaling factors, which were detemined from Equations 16,17 and $18, \varepsilon_{T}, \varepsilon_{\phi}, \varepsilon_{p}$ were $.168, .196$, and $7.24 \times 10^{-3}$ respectively.

Prior to solving for $\varepsilon_{\sigma}$, a voltage scaling factor, $\varepsilon_{V}$ was needed. However, the determination of the voltage scaling factor was not straight forward and is discussed herein. The melter voltage was estinated using a nominal operating power of $200 \mathrm{~kW}$ for the BIPP me1ter and the following assumptions:

- uniform glass temperature of $1150^{\circ} \mathrm{C}$

- single pair of plate electrodes with spacing $L$

Voltage, .V, can be expressed by Equation (20)

$$
V=(P R)^{1 / 2}=\left(\frac{P d}{W D}\right)^{1 / 2}
$$




$$
\begin{aligned}
P & =\text { power watts } \\
\sigma & =f l u i d \text { electrical resistivity } \\
D & =\text { depth (fluid height) } \\
W & =\text { width, dimension in horizontal plane } \\
L & =\text { distance between electrodes, perpendicular to cross-sectional area. } \\
V_{p} & =85.8 \mathrm{Vac} \text { was determined from Equation (19) using the following values: } \\
P_{p} & =200 \times 10^{3} \mathrm{~W} \\
\sigma_{p} & =1.890-\mathrm{cm} \\
L_{p} & =152.4 \mathrm{~cm} \\
W_{p} & =111.8 \mathrm{~cm} \\
D_{p} & =70.0 \mathrm{~cm}
\end{aligned}
$$

The BIPP model voltage can be adjusted with reasonable ease within the range $50 \leqslant V_{\mathrm{m}} \leqslant 200 \mathrm{Vac}$. Therefore, $\varepsilon_{v}$ should be in the range $0.581 \leqslant \varepsilon_{v} \leqslant 2.33$ subject to the modeling fluid resistivity. Substituting the values for $\varepsilon_{L}$, $\varepsilon_{p}$, and $E_{V}$ into Equation (19), the resistivity scaling factor range is 21.7 $\leqslant E_{\sigma} \leqslant 350$. For $\sigma_{p}=1.89$ a-cm at a prototype bulk fluid operating temperature of $1150^{\circ} \mathrm{C}$, an acceptable modeling fluid resistivity range was calculated as

$$
41.0 \leq \sigma_{m} \leq 661 \Omega-c m .
$$

Simultaneous scaling of the BIPP glass kinematic viscosity and electrical resistivity for a glass temperature of $1150^{\circ} \mathrm{C}$ occurs when the modeling fluid kinematic viscosity is $1.68 \mathrm{~cm}^{2} / 5$ and the electrical resistivity is concurrently in the range $41.0 \Omega-\mathrm{cm} \leqslant \sigma_{\mathrm{m}} \leqslant 6610-\mathrm{cm}$. BIPP melter to model scale factors are summarized in Table 2.5. The modeling fluid thermophysical properties determined from the scaling relationships and waste glass properties are given in Table 2.6 .

\section{2 .2 PSCM Model Fluid Scaling}

The PSCM melting cavity dimensions are similar to the dimensions of an earlier melter design, the CFCM, which was modeled by Quigley and Kreid. While operating conditions and glass composition of the two melters is different, the $1 / 3$ CFCM melter was judged suitable for the PSCM investigation. Therefore, model fluid scaling was performed subject to an $\varepsilon_{L}$ of $1 / 3$. The scaling factors 
IABLE 2.5. Scaling Parameters

\begin{tabular}{c} 
Scale Factor \\
\hline$\varepsilon_{\mathrm{L}}$ \\
$\varepsilon_{\nu}$ \\
$\varepsilon_{\alpha}$ \\
$\varepsilon_{\Delta T}$ \\
$\varepsilon_{\beta}$ \\
$\varepsilon_{\mathrm{P}}$ \\
$\varepsilon_{V}$ \\
$\varepsilon_{\sigma}$
\end{tabular}

\begin{tabular}{l}
$\frac{1}{\text { BIPP }}$ \\
\hline 0.25 \\
0.0685 \\
0.228 \\
0.168 \\
5.95 \\
$3.88 \times 10^{-3}$ \\
$0.581<\varepsilon_{\gamma}<2.33$ \\
$21.7<\varepsilon_{\sigma}<350$
\end{tabular}

\begin{tabular}{l}
$\frac{1}{\text { PSCM }}$ \\
\hline 0.333 \\
0.155 \\
0.240 \\
0.168 \\
5.95 \\
$7.24 \times 10^{-3}$ \\
$0.71<\varepsilon_{Y} 2.91$ \\
$23.6 \varepsilon_{\gamma}<391$
\end{tabular}

TABLE 2.6. Scaled Modeling Fluid Properties

\begin{tabular}{|c|c|c|}
\hline Property & $\begin{array}{c}\text { BIPP } \\
\left(1150^{\circ} \mathrm{C}\right)\end{array}$ & $\begin{array}{c}\text { PSCM } \\
\left(1100^{\circ} \mathrm{C}\right)\end{array}$ \\
\hline$\rho_{m}\left(g / \mathrm{cm}^{3}\right)$ & $1.27^{(1,2)}$ & $1.27^{(1,2)}$ \\
\hline$\mu_{m}(\mathrm{~g} / \mathrm{cm} \cdot \mathrm{s})$ & 2.13 & 7.33 \\
\hline$v_{m}\left(\mathrm{~cm}^{2} / \mathrm{s}\right)$ & $1.68^{(3)}$ & $5.73^{(3)}$ \\
\hline$k_{m}(w / m \cdot k)$ & $0.002837^{(4)}$ & $0.002837^{(4)}$ \\
\hline$\alpha_{m}\left(\mathrm{~cm}^{2} / \mathrm{s}\right)$ & $1.05 \times 10^{-3(1)}$ & $1.05 \times 10^{-3(1)}$ \\
\hline$\sigma_{m}(\Omega \cdot c m)$ & $41.0<\sigma_{m}<661(3)$ & $49.4<\sigma<833^{(3)}$ \\
\hline$\beta_{m}\left({ }^{\circ} C^{-1}\right)$ & $5.34 \times 10^{-4(1)}$ & $5.34 \times 10^{-4(1)}$ \\
\hline
\end{tabular}

(1) Estimated from Quigley and Kreid [1]

(2) Estimated from Stanek [2]

(3) Determined from Similarity Analysis

(4) Determined from Holman [12]

derived in Section 2.1 and shown in Table 2.2 were also applicable to PSCM modeling. The same waste glass, CAW-83, used in the BIPP scaling was used for PSCM glass scaling. However, the PSCM glass properties which are shown in Table 2.4 are those for a melter operating temperature of $1100^{\circ} \mathrm{C}$.

Using the same approach outlined in Section 2.2.1, $\varepsilon_{v}$ was computed from Equation $C$ of Table 2.2. For the following values: 


$$
\begin{aligned}
& \varepsilon_{\mathrm{L}}=1 / 3 \\
& \alpha_{\mathrm{m}}=1.05 \times 10^{-3} \mathrm{~cm}^{2} / \mathrm{s} \\
& \alpha_{p}=4.38 \times 10^{-3} \mathrm{~cm}^{2} / \mathrm{s},
\end{aligned}
$$

an $\varepsilon_{\nu}$ of 0.155 was obtained. The resulting model fluid viscosity, $v_{\mathbb{R}}$ of $5.73 \mathrm{~cm}^{2} / \mathrm{s}$ corresponded to the glass $v_{p}$ of $37.1 \mathrm{~cm}^{2} / \mathrm{s}$. A PSCM modeling fluid electrical resistivity range of $49.4 \Omega-c m \leqslant \sigma_{m} \leqslant 833 \Omega-c m$ was obtained from Equation 19 using PSCM scale factors from Table 2.5 and for a $\sigma_{p}$ of $2.13 \Omega-\mathrm{cm}$. Property criteria for the PSCM modeling fluid is therefore:

- $v_{\mathrm{m}}=5.73 \mathrm{~cm}^{2} / \mathrm{s}$

- 49.4 a-cm $\leqslant \sigma_{m} \leqslant 833 \Omega-\mathrm{cm}$ concurrently with $v_{\text {fl }}$

- model fluid temperature between $50^{\circ} \mathrm{C}$ and $80^{\circ} \mathrm{C}$

PSCM scaling factors as well as BIPP scaling factors are shown in Table 2.5 while the scaled modeling fluid properties are given in Table 2.6.

\subsubsection{Temperature Scaling}

The melter to model scaling factor for glass temperature gradients and melter boundary temperature differentials are determined from the ratio of the modeling fluid to waste glass thermal expansion coefficients, ${ }^{3} \mathrm{~m}$ and ${ }^{3} \mathrm{p}$. The temperature differentials, $\Delta T_{p}$ and $\Delta T_{m}$ which were determined from Equation 2 of Table 2.2, are referenced with respect to the glass operating temperature, $T_{p o}$, and modeling fluid operating temperature, $\mathrm{T}_{\mathrm{mo}}$. $\mathrm{T}_{\mathrm{po}}$, shown in Table 2.7 as $\mathrm{T}_{\text {glass, }}$ is $1150^{\circ} \mathrm{C}$ and $1100^{\circ} \mathrm{C}$ for BIPP and PSCM operation, respectively. $T_{\text {pio }}$ is taken as the modeling fluid temperature corresponding to the simultaneously occurring $\nu_{m}$ and $\sigma_{m}$ as discussed in Sections 2.2.1 and 2.2.2.

LiCl/Glycerine mixture densities from Reference [8] were used to calculate ${ }^{3} \mathrm{~m}$ for both BIPP and PSCM modeling fluids. For the BIPP study, ${ }^{\beta}$ p was based on density changes from a waste glass designated as BNW 76-68 [9]. The PSCM waste glass ${ }^{\beta}$ p shown in Table 2.7 was determined from Reference [8] results of a waste glass denoted as SRL-411. The waste glass densities for both BIPP and PSCM modeling were taken from BNW 76-68 data. Proposed melter operating boundary temperatures for the BIPP and PSCIN are shown in Table 2.7, while the 
scaled model operating boundary temperatures are given in Table 2.8. Model fluid boundary temperatures were predicted from model fluid operating teinperatures deternined from property results of Section 3.5 .

TABLE 2.7. Proposed Melter Operating Conditions

\begin{tabular}{|c|c|c|}
\hline $\begin{array}{l}\text { Operating } \\
\text { Condition } \\
\end{array}$ & BIPP & PSCM \\
\hline Glass & CAW-83 & CAW-83 \\
\hline${ }^{\mathrm{T} g l a s s}\left({ }^{\circ} \mathrm{C}\right)$ & 1150 & 1100 \\
\hline$T_{e l e c t r o d e}\left({ }^{\circ} \mathrm{C}\right)$ & 1050 & 998 \\
\hline$T_{w a 11}\left({ }^{\circ} \mathrm{C}\right)$ & 1100 & 1065 \\
\hline $\mathrm{T}_{\operatorname{cold}} \operatorname{cap}\left({ }^{\circ} \mathrm{C}\right)$ & $700-800$ & 700 \\
\hline $\begin{array}{l}\text { Power (KH) } \\
\text { (max feed) }\end{array}$ & $\sim 300$ & 90 \\
\hline $\begin{array}{l}\text { Power (KW) } \\
\text { (idling) }\end{array}$ & - & 35 \\
\hline
\end{tabular}

TABLE 2.8. Scaled Hodel Operating Conditions

$\begin{array}{llll}\begin{array}{c}\text { Operating } \\ \text { Condition }\end{array} & & \begin{array}{c}\text { BIPP } \\ \text { (Model) }\end{array} & \begin{array}{c}\text { PSCM } \\ \text { (Mode1) }\end{array} \\ \mathrm{T}_{\text {fluid }}\left({ }^{\circ} \mathrm{C}\right) & 72.0 & 56.0 \\ \mathrm{~T}_{\text {electrode }}\left({ }^{\circ} \mathrm{C}\right) & & 64.5 & 32.7 \\ \mathrm{~T}_{\text {wa11s }}\left({ }^{\circ} \mathrm{C}\right) & & 64.5 & 47.3 \\ \mathrm{~T}_{\text {Cold cap }}\left({ }^{\circ} \mathrm{C}\right) & 15.1 & -26.4(1) \\ \text { Power }(\mathrm{W}) & \sim 300 \mathrm{~W} & \sim 165\end{array}$

(1) PSCM model cooling capability $5^{\circ} \mathrm{C}$. 


\subsection{DESCRIPTION OF EXPERIMENTAL APPARATUS AND PROCEDURE; MODEL FLUID PREPARATION AND PROPERTIES RESULTS}

A description of the melter models is given in the ensuing subsections. The experimental apparatus and procedures are also summarized including a description of measurement locations, techniques, and measurement uncertainties. In addition, modeling fluid preparation and its impact on fluid properties are discussed. Lastly, model fluid properties measurements are also presented.

\subsection{PHYSICAL MODELS}

Two melter designs the PSCM and BIPP were modeled during this study. A description of these two model configurations follows.

\subsubsection{BIPP Model}

The $1 / 4$ scale BIPP model is shown in Figure 3.1. The inner model dimensions corresponding to the coordinate specifications given in Figure 3.2 are $38.10 \mathrm{~cm}$ in $X$ by $27.94 \mathrm{~cm}$ in $Y$ by $36.83 \mathrm{~cm}$ in $Z\left(15^{\prime \prime} \times 11^{\prime \prime} \times 141 / 2^{\prime \prime}\right)$. The model bottom has a $5^{\circ} \mathrm{C}$ slope downward from both electrodes, to the melter center where a $2.54 \mathrm{~cm}\left(1^{\prime \prime}\right)$ deep trough is located. These details are shown in Figure 3.2. The actual melt dimension for the model are also bounded by modeling fluid height. For 8IPP model investigation, modeling fluid was maintained at a height of $13.34 \mathrm{~cm}\left(51 / 4^{\prime \prime}\right)$ as depicted in Figure 3.2. A cold cap at the fluid glass upper surface was simulated using a $60 \%$ offset water cooled top. Boundary temperatures of the front and back walls, electrodes, and cold cap were maintained using four independently controlled cooling jacket subsystems. Heat loss from the bottom occurred from natural convection to the air.

Power for two independently controlled pair of copper electrodes, the upper and lower pairs, was supplied by two Silicone Controlled Rectifiers (SCR) power controllers. The area of each upper electrode face is $10.16 \mathrm{~cm}$ high $X$ $27.61 \mathrm{~cm}$ wide $\left(4^{\prime \prime} \times 107 / 8^{\prime \prime}\right)$ while the dimensions of each lower electrode face is $3.81 \mathrm{~cm}$ high $\times 27.61 \mathrm{~cm}$ wide $\left(11 / 2^{\prime \prime} \times 107 / 8^{\prime \prime}\right)$. The electrode spacing 


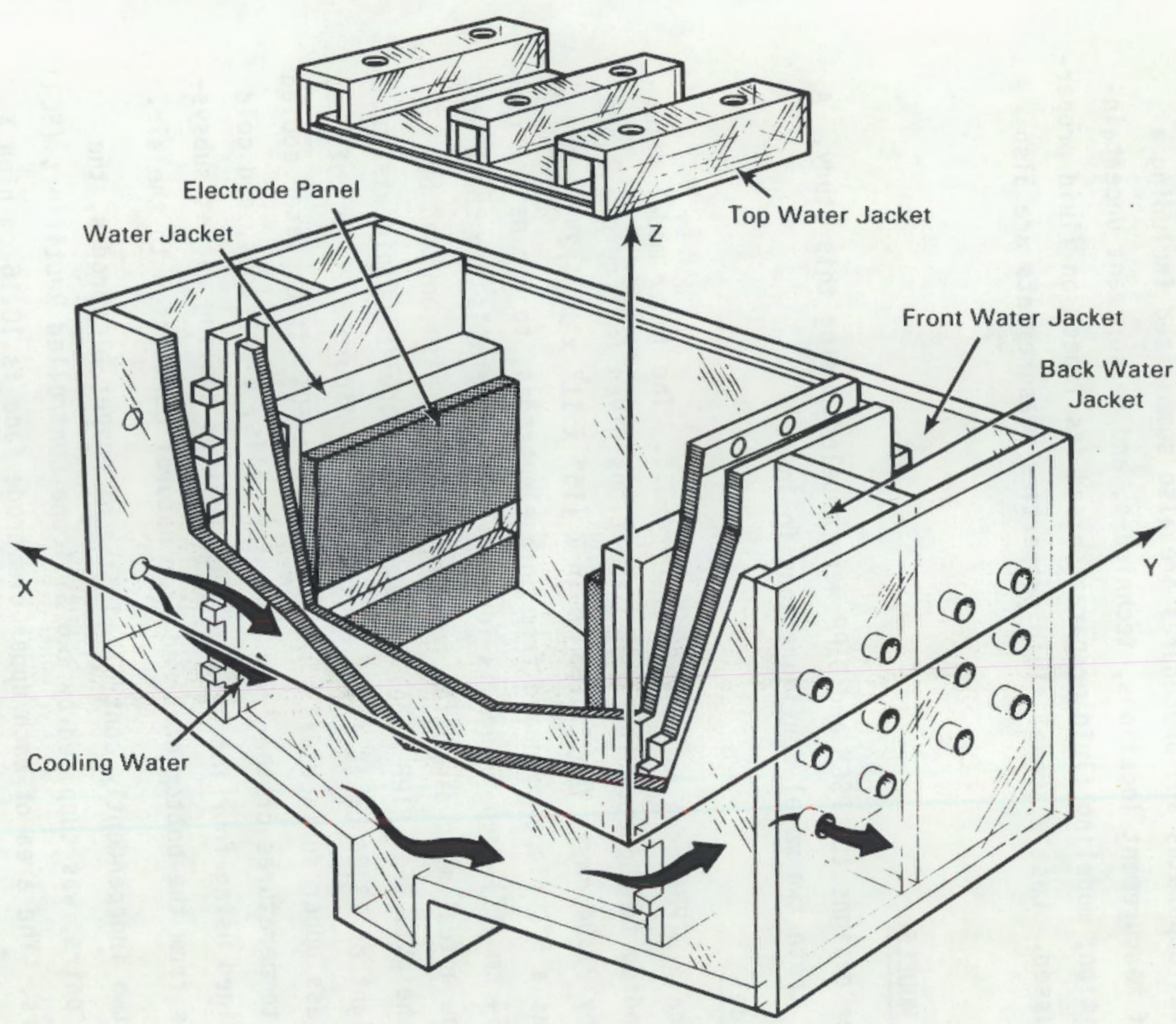

FIGURE 3.1. B-Plant Imnobilization Pilot Plant Model Configuration 


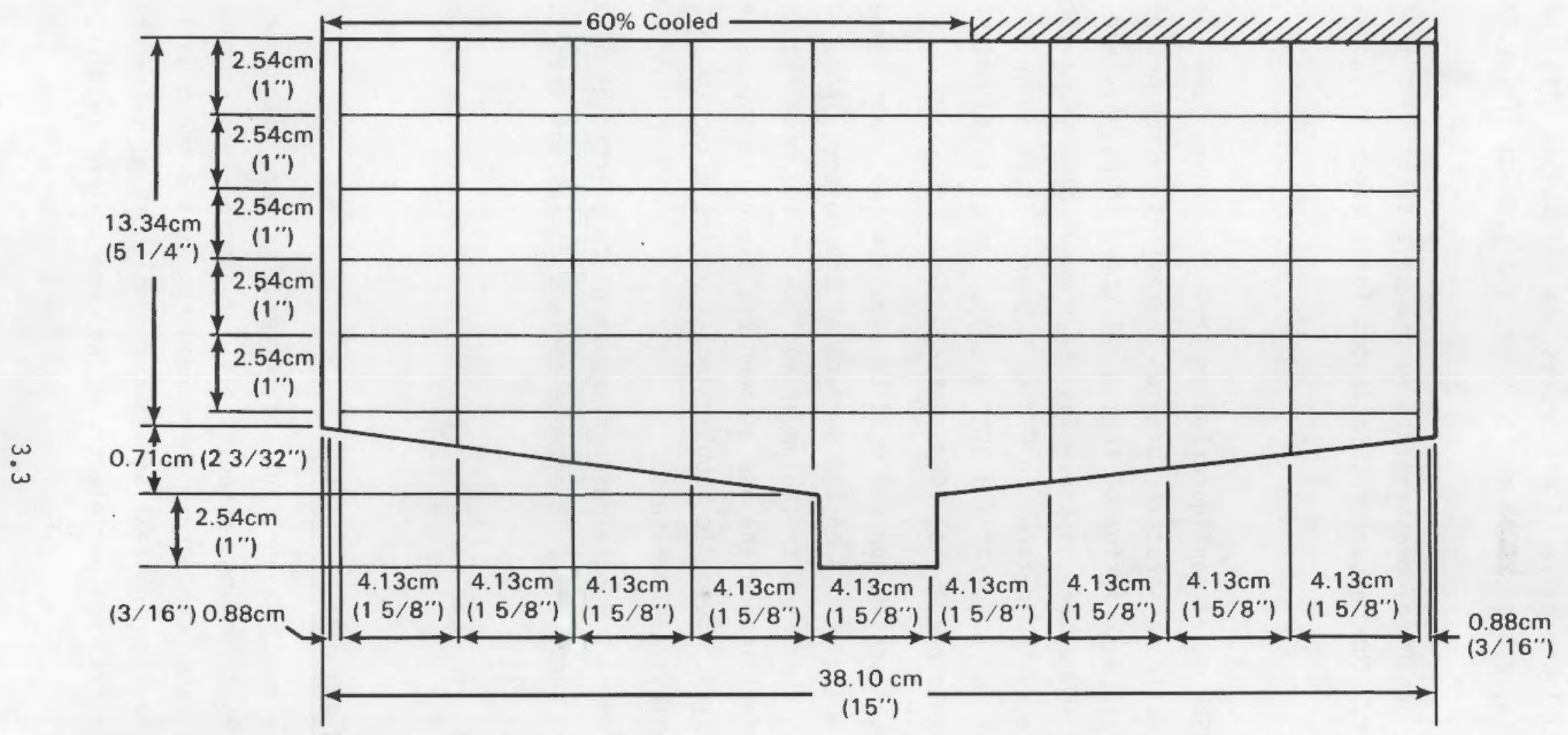

FIGURE 3.2. BIPP Model Fluid Temperature and Potential Measurement Locations in Y Plane 
between the upper and lower pairs of electrodes was adjustable with the following spacings available; $2.5 \mathrm{~cm}, 3.92 \mathrm{~cm}, 5.40 \mathrm{~cm}$, and $6.35 \mathrm{~cm}$ (1", $13 / 8$ ", $\left.21 / 8^{\prime \prime}, 21 / 2^{\prime \prime}\right)$

Temperature and potential measurements were always taken in a $Y$-plane as defined in Figure 3.1. The measurement locations for a given $Y$-plane are shown in Figure 3.2.

\subsubsection{PSCM Model}

The $1 / 3$ scale PSCM model configuration is shown in Figure 3.3. The PSCM model body was originally constructed to model a previous melter design, the CFCM [1]. The detailed description of this model given in Ouigley and Kreid [1] is briefly summarized herein. The inner model dimensions corresponding to the coordinate system defined in Figure 3.3 are, $35.56 \mathrm{~cm}$ in $x$ by $23.81 \mathrm{~cm}$ in $Y$ by $25.4 \mathrm{~cm}$ in $Z\left(14^{\prime \prime} \times 93 / 8^{\prime \prime} \times 10^{\prime \prime}\right)$. Model fluid height of $12.70 \mathrm{~cm}\left(5^{\prime \prime}\right)$ was maintained during PSCM testing.

A $60 \%$ offset water cooled top was used to simulate the upper temperature boundary due to the molten crust on the surface of the molten glass. The top was adjusted to be in contact with the upper surface of the modeling fluid. The cooled top also facilitated the use of bubblers along the top center (parallel to the $Y$ axis). Specific bubbler locations are given in Section 4.0 in terms of dimensionless coordinates.

Power was applied to a single pair of copper plate electrodes by a phase angle fired SCR power controller. Electrode surface dimensions are $22.86 \mathrm{~cm}$ wide by $20.32 \mathrm{~cm}$ high $\left(9^{\prime \prime} \times 8^{\prime \prime}\right)$.

Temperature and potential measurement locations for a given $Y$-plane are shown in Figure 3.4 .

\subsection{INSTRUMENTATION AND DATA AOUISITION}

A total of fifty readings and forty-seven readings were taken per scan during the BIPP and PSCM testing, respectively. Thermocouple measurements performed during a single scan were: three readings at the front wall, seven readings at the back wall, nine readings on the model bottom, six modeling fluid readings, three readings per electrode, and one ambient reading. Eight 


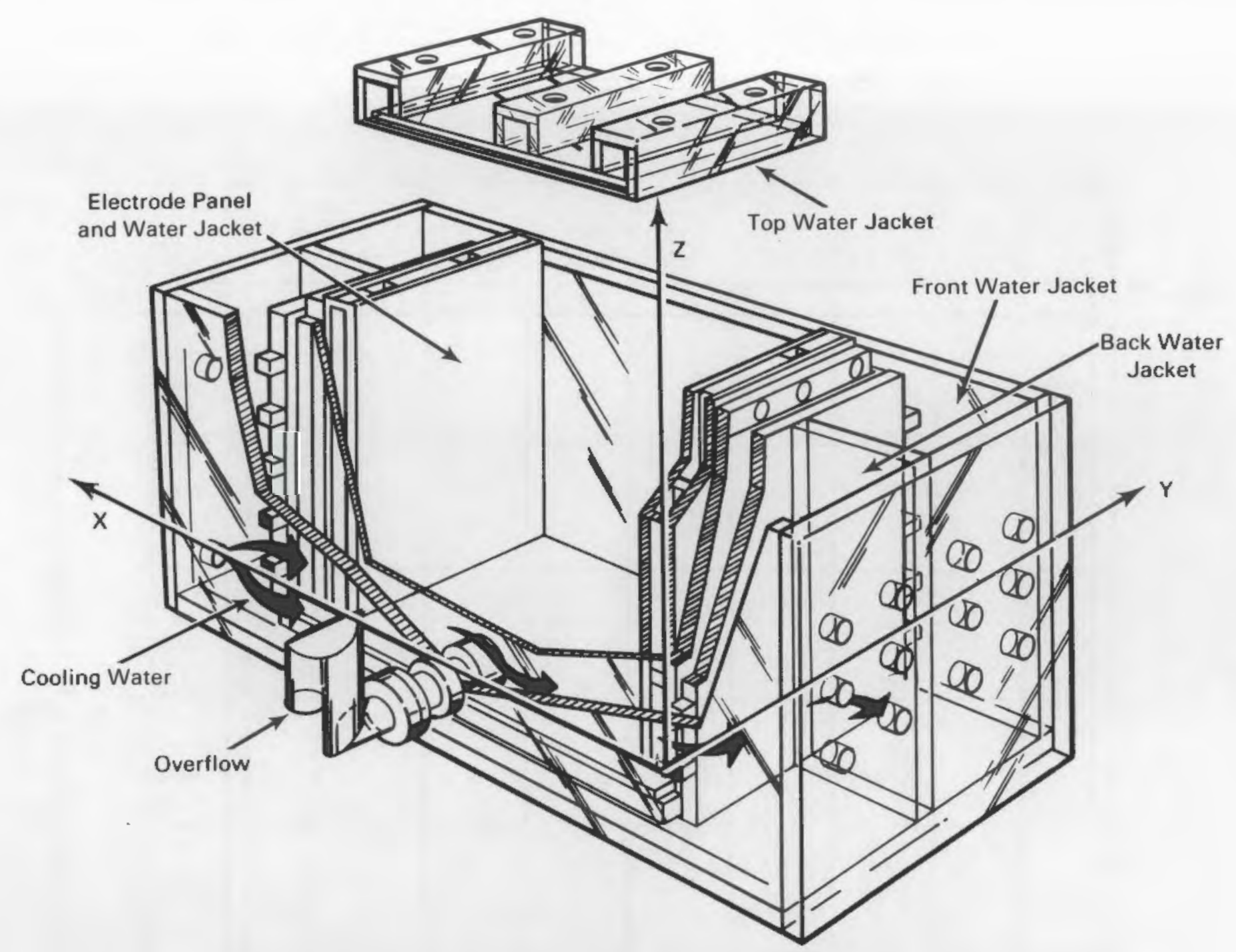

FIGURE 3.3. Pilot Scale Ceranic Melter Model Configuration 


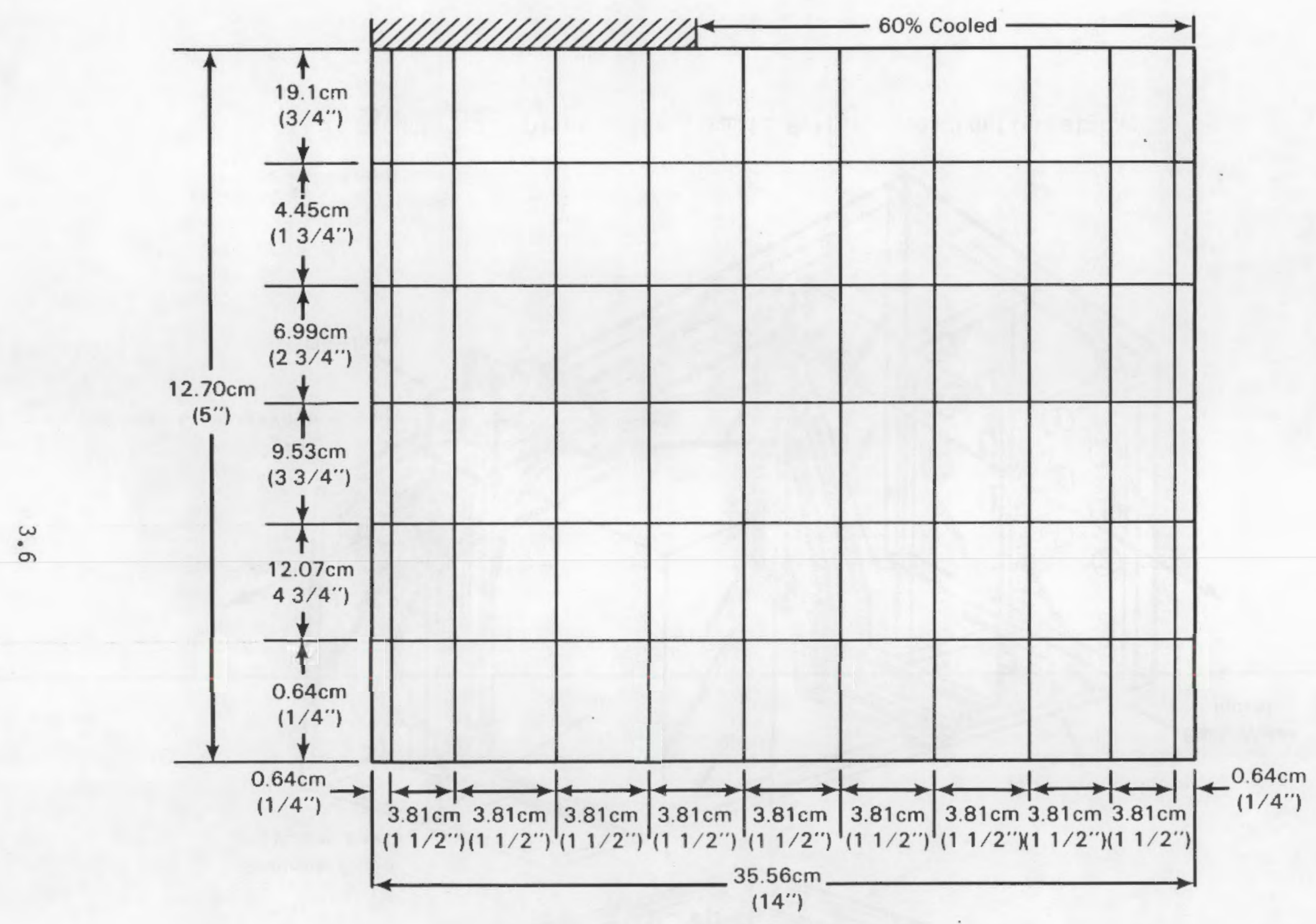

FIGURE 3.4. PSCM Model Fluid Temperature and Potential Measurement Locations in Y-Plane 
RTDs were used to take temperature readings at the inlet and outlet of each cooling jacket. Cooling jacket flow readings from four flow turbine meters were taken during each scan. Current, voltage, and power from the electrode power supply were also recorded and monitored. An additional three power supply readings were taken during the BIPP testing due to the additional electrode pair. Operating conditions were typically monitored and recorded every ten minutes during testing.

In Figure 3.5, the thermocouple extension wire are observed above and to the left of the BIPP model. The thermocouple extension wires connect to a data logger which is located to the left of the model. Power supply signals, as well as temperature and flow signals were directed to the Integrated System for Automated Aquisition and Control (ISAAC) module where the 0 to 5 volt analog signals were converted to digital signals. The digitized signals were then assigned a 12 bit binary values which were read by the data acquisition minicomputer (Apple IIE). Further processing of the signal was then user directed. The ISAAC $91 \mathrm{~A}$ is shown in Figure 3.5 on the desk and to the right of the Apple personal computer. The electrode power supply is located to the right of ISAAC module in Figure 3.5. Run conditions were displayed on a terminal, stored on disk and/or simultaneously printed during model operation.

\subsection{TEST MEASUREMENT PROCEDURES}

Modeling fluid temperature measurements were performed using six $1 / 16$ " diameter sheathed ungrounded Type $T$ thermocouples. The thermocouples were inserted into the modeling fluid through the drywells of the simulated cold cap (model top). The six thermocouples were simultaneously placed at the same fluid depth (level) of a given $Y$-plane during a set of measurement readings. Readings were recorded after 15 thermocouple time constants elapsed or approximately $11 / 2$ minutes. The procedure was then repeated at the next fluid level of the measuring plane.

Electrical potential measurements were accomplished using a probe cut from $1 / 16^{\prime \prime}$ diameter aluminum stock. The probe was electrically insulated with the 


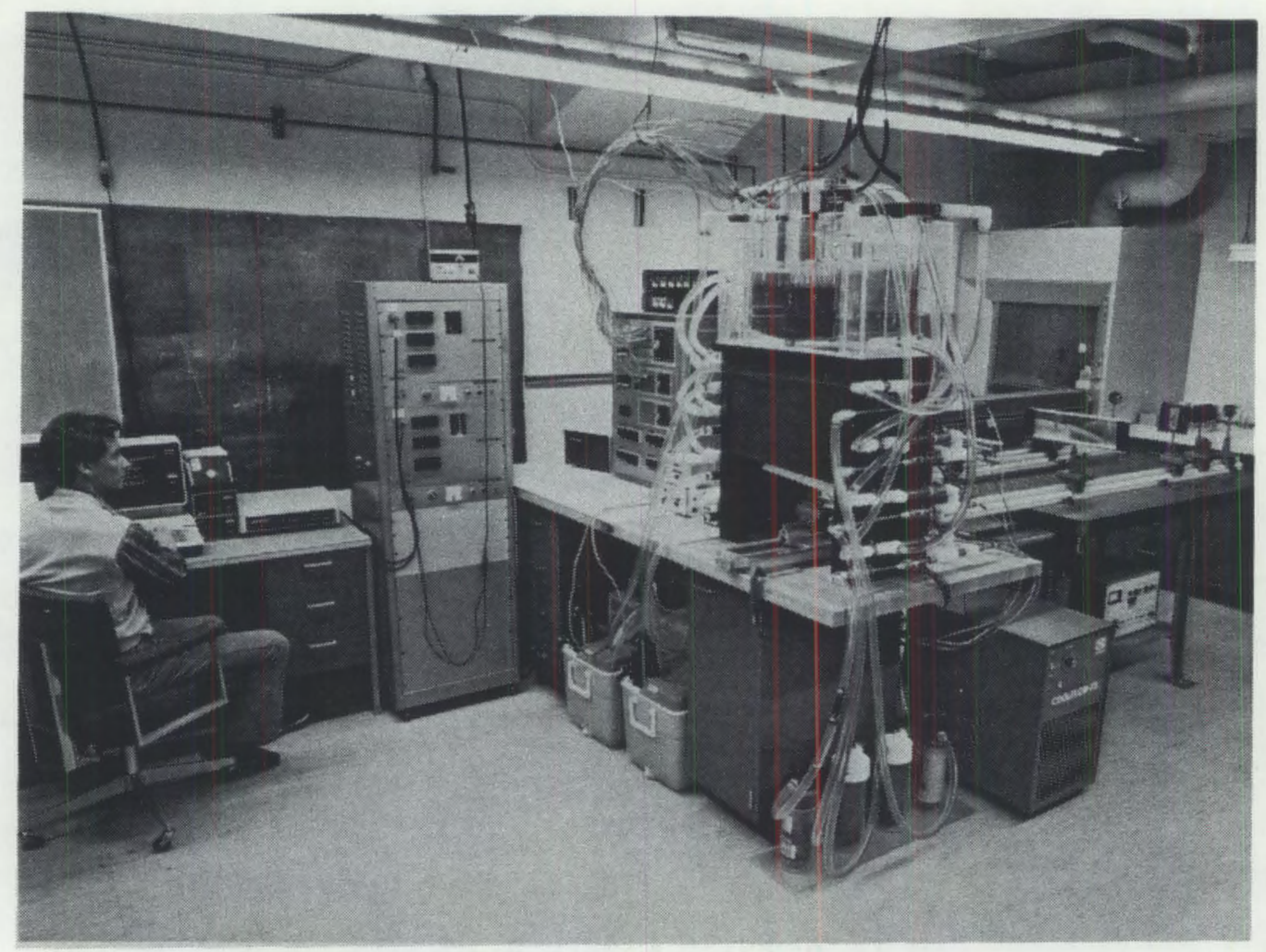

FIGURE 3.5. Instrumentation and Data Acquisition for BIPP Model

exception of a small area at the probe tip. Measurements were read from a true RMS voltmeter. One lead was attached to the probe while the other was grounded to an electrode.

The modeling fluid local flow patterns were characterized by taking time exposed photographs of light scattering particles following the flow. A light sheet, produced by a coherent light source (Argon ion 1aser), and optical configuration consisting of mirrors, beam expanders, and lenses is finally reflected upward into the vertical plane of the model. Some of the light from particles in the light sheet are reflected towards the camera. Qualitative flow streak photographs are taken by leaving the camera shutter open over a suitable time interval. Stroboscopic velocity measurements were made by strobing the shutter at a constant time interval. A five second strobe interval with a one second exposure time over a $21 / 2$ minutes was typical for the BIPP and PSCM stroboscopic velocity photographs. 
The optics configuration and laser used to produce the flow visualization light sheet are shown in Figure 3.6. The Argon ion laser was operated at a wavelength of $5145 \AA$ (angstrom), green line, during all testing. A $0.318 \mathrm{~cm}$ $(1 / 8$ in.) thick light sheet in the vertical plane of the fluid was used for flow visualization. A faint light sheet is observed in Figure 3.6 just beyond the Fresnel lens at center of. the photograph. Neutrally buoyant glassy carbon particles produced at PNL were used as the light scatterers/flow tracers.

\subsection{MODELING FLUID PREPARATION}

The modeling fluid preparation procedure used to obtain the coincidental $v_{m}$ and $\sigma_{m}$ discussed in Sections 2.2.1 and 2.2.2 is discussed below. Because modeling fluid preparation is an iterative procedure, the following discussion may help to avoid unnecessary iterations in future investigations.

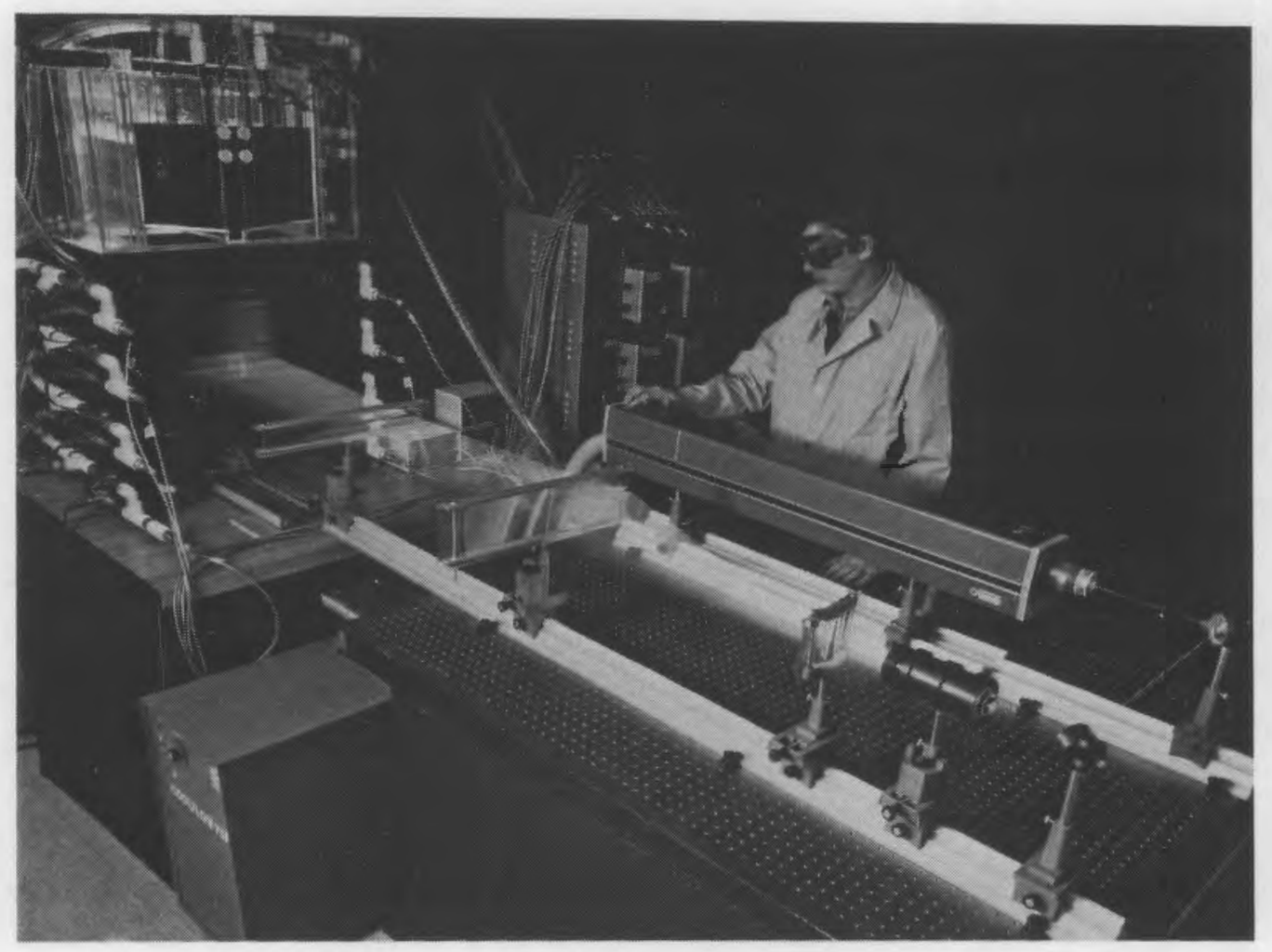

FIGURE 3.6. Argon Laser and Optics Configuration for Flow Visualization Light Source 
Modeling fluid preparation was initiated after the modeling fluid properties were determined from the scaling factor relationships. The initial modeling fluid sample was Fluid 20 of Stanek's recipes [2]. This solution most nearly matched the desired kinematic viscosities and electrical resistivities indicated in Sections 2.2.1 and 2.2.2. Measured properties of the initial fluid sample were not in good agreement with those properties predicted in Table 2.6. Therefore, new sample mixtures, based on the previous mixture properties were processed until the scaled kinematic viscosity and electrical resistivity were obtained near a desired operating model temperature of approximately $75^{\circ} \mathrm{C}$.

Observations from BIPP and PSCM fluid preparation are briefly summarized since the preparation equipment and procedure used are believed to influence $\mathrm{LiCl/Glycerine} \mathrm{mixture} \mathrm{properties} \mathrm{in} \mathrm{addition} \mathrm{to} \mathrm{LiCl}$ concentration, bake time, and bake temperature. During the addition of $\mathrm{LiCl}$, an exothermic reaction occurred which resulted in a $25^{\circ} \mathrm{C}$ to $30^{\circ} \mathrm{C}$ rise in solution temperature. The temperature rise resulting from the exothermic reaction remained above the proposed bake temperature for the duration of the bake time. Since the mixture was heated in well insulated heating mantels, the heat generated during the $\mathrm{LiCl/Glycerine} \mathrm{reaction} \mathrm{dissipated} \mathrm{slowly} \mathrm{which} \mathrm{resulted} \mathrm{in} \mathrm{prolonged} \mathrm{exposure}$ of the mixture to increased temperatures. An exothermic reaction during fluid preparation was noted during previous work [1], however, the magnitude of temperature rise or duration of prolonged exposure at excessively high temperatures was not indicated. Mixture properties' differences were also observed from using different batches of Technical Grade Glycerine. The time and cost in obtaining desired mixture properties is dependent on the above influences. It should be emphasized that property measurements were performed after a modeling fluid was prepared, hence final modeling fluid property accuracies were unaffected by the preparation variations discussed above.

\subsection{MODELING FLUID PROPERTIES}

Modeling fluids denoted as MF-K and MF-0 were used for BIPP modeling and PSCM modeling, respectively. MF-K was a $12 \% \mathrm{LiCL}$ mixture by weight heated at $165^{\circ} \mathrm{C}$ for 40 minutes, while MF-0 was a $13 \%$ mixture by weight heated at $180^{\circ} \mathrm{C}$ 
for 90 minutes. Viscosity and electrical conductivity measurements were performed at PNL while density, thermal conductivity, and specific heat measurements were made by the Thermophysical Properties Research Laboratory at the University of Purdue. Results of the property measurements of MF-K and MF-O are shown in Figures 3.7 through 3.10 .

Model operating temperatures were determined from the viscosity and electrical resistivity scaling criteria specified in Sections 2.2 .1 and 2.2.2. The property data were curve fit as functions of modeling fluid temperatures. The kinematic viscosity and electrical resistivity empirical relationships were then solved for model fluid operating temperatures. BIPP and PSCM model operating temperatures of $72.1^{\circ} \mathrm{C}$ and $55^{\circ} \mathrm{C}$, respectively, were calculated. Model fluid properties for these operating conditions are shown in Table 3.1.

Temperature dependence of scale factors is shown in Figures 3.11 and 3.12 for BIPP and PSCM modeling respectively. Modeling fluid and glass temperature correspondence was determined from the temperature scaling criteria outlined in Section 2.2.3. Scale factor curves were then generated by computing scale factors at the corresponding melter/model temperatures as: $\varepsilon_{i}=i\left(T_{m}\right) / i\left(T_{p}\right)$.

Scale factors in general, show little variation with temperature. Previous melter operations indicate that the temperature gradients within the me1ters cover only a small portion of the temperature ranges shown in Figures 3.11 and 3.12. Therefore, scale factors were assumed independent of temperature with the exception of $\varepsilon_{\sigma}$. Equations 21 and 22 were used to compute $\varepsilon_{\sigma}$ as functions of model temperature for MF-K and MF -0 respectively. A consequence of

$$
\begin{array}{ll}
\varepsilon_{\sigma}=1.73 \times 10^{4} \mathrm{~T}_{\mathrm{m}}^{-1.72} & \text { (MF-K) } \\
\varepsilon_{\sigma}=8.24 \times 10^{6} \mathrm{~T}_{\mathrm{m}}^{-2.51} & \text { (MF-0) }
\end{array}
$$

Temperature Range: $50^{\circ} \mathrm{C}<\mathrm{T}_{\mathrm{m}}<80^{\circ} \mathrm{C}$

the $\varepsilon_{\sigma}$ temperature dependence is that a similarity error occurs for the Power number, $\tilde{\phi}$ where the model temperature deviates from $T_{m o}$. The relative 


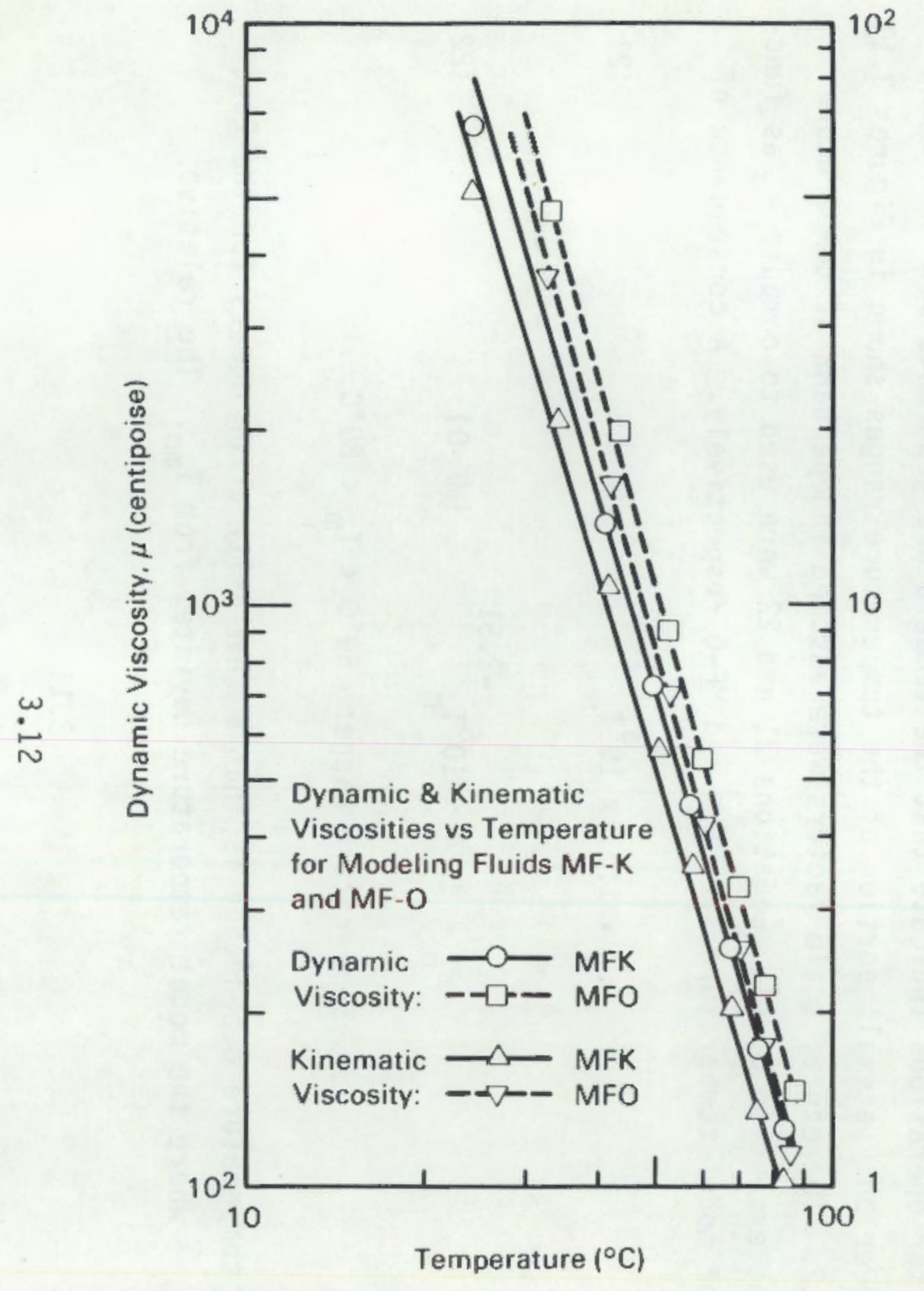

FIGURE 3.7. Dynamic and Kinematic Viscosities vs Temperature for Modeling Fluids MF-K and MF -0

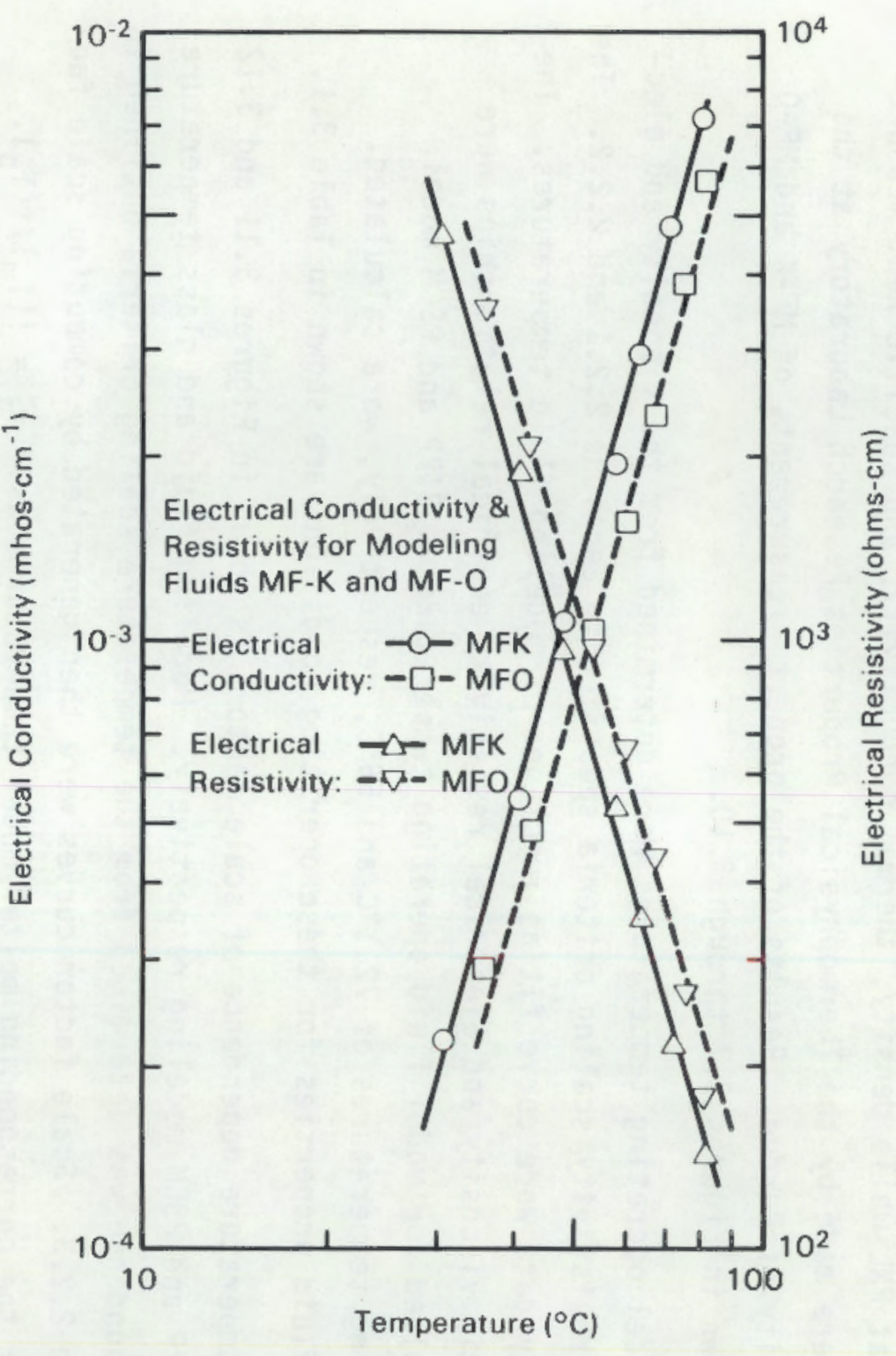

FIGURE 3.8. Electrical Conductivity and Resistivity for Modeling Fluids MF-K and $\mathrm{MF}-0$ 


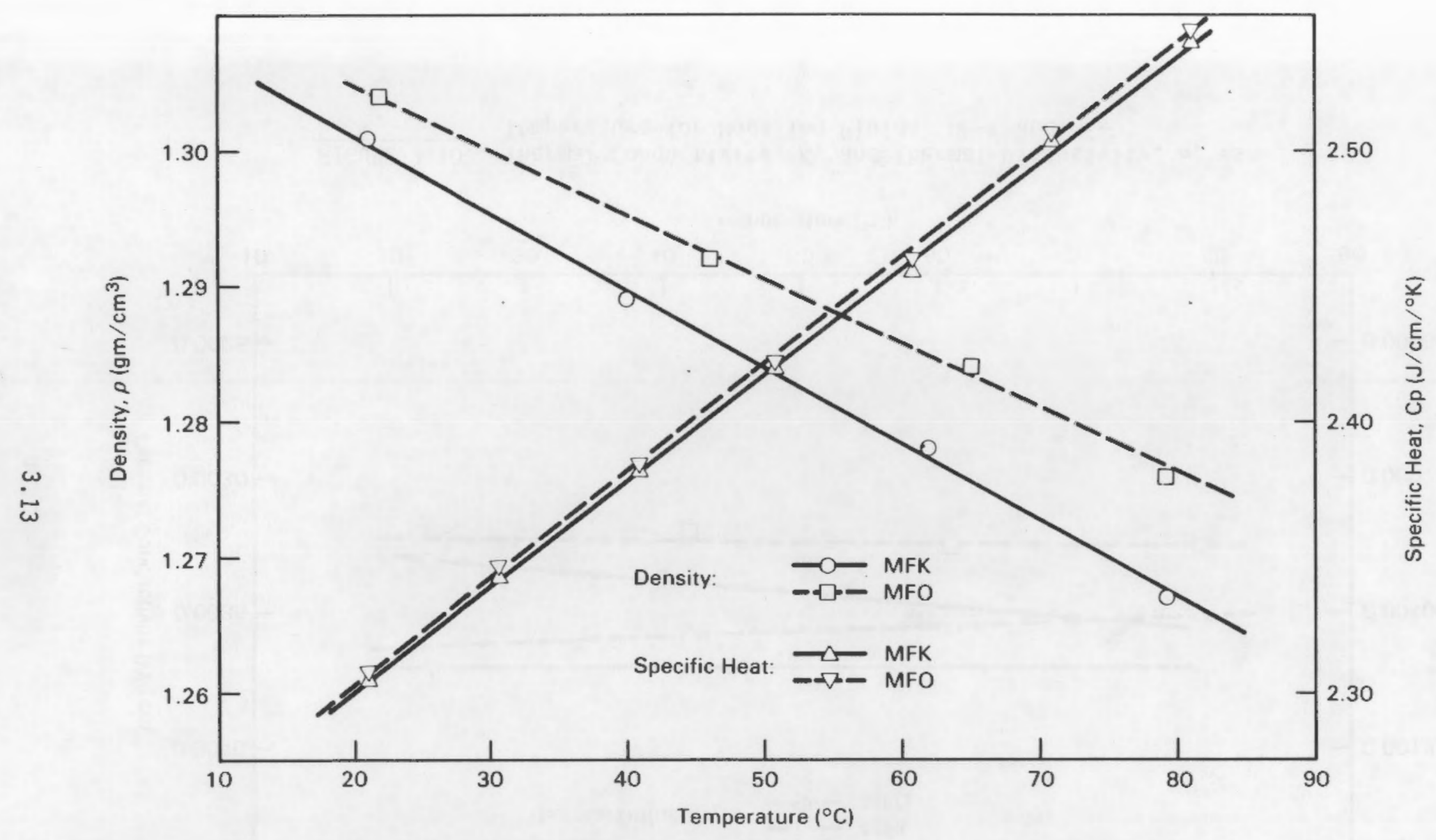

FIGURE 3.9. Specific, $C_{p}$ and Density, $\rho$, vs Temperature for Modeling Fluids MF-K and MF-0 


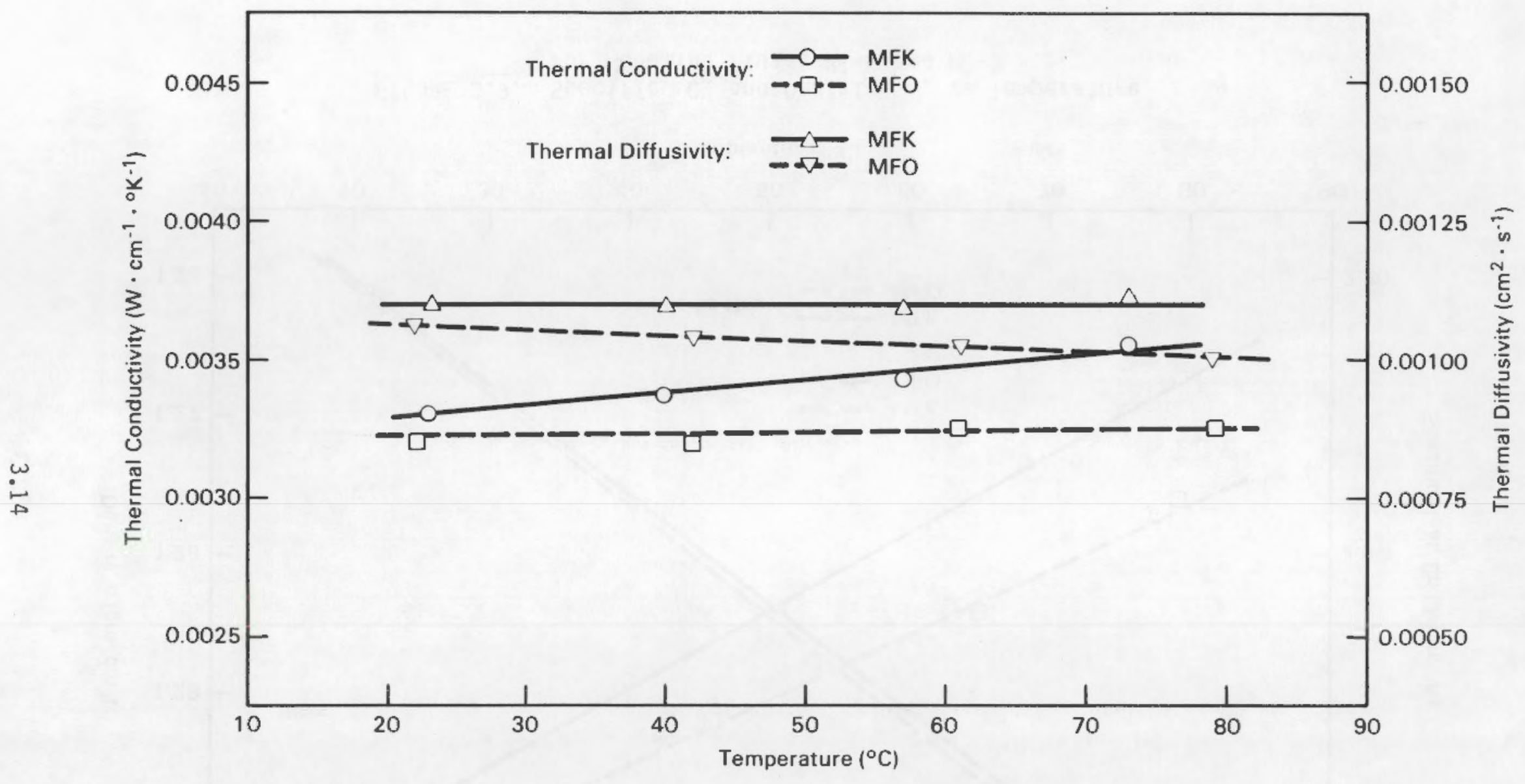

FIGURE 3.10. Thermal Conductivity, $K$, and Thermal Diffusivity, $\alpha$, vs Temperature for Modeling Fluids, MF $-K$ and MF -0 
TABLE 3.1. Model Fluid Properties at Model Operating Temperature, $T_{\text {mo }}$

\begin{tabular}{|c|c|c|}
\hline Property & BIPP & PSCM \\
\hline$T_{\mathrm{mon}}\left({ }^{\circ} \mathrm{C}\right)$ & 72.1 & 56 \\
\hline$\rho_{m}\left(g / \mathrm{cm}^{3}\right)$ & 1.27 & 1.28 \\
\hline$\mu_{m}(\mathrm{~g} / \mathrm{cm} \cdot \mathrm{s})$ & 2.15 & 7.41 \\
\hline$\nu_{m}\left(\mathrm{~cm}^{2} / \mathrm{s}\right)$ & 1.68 & 5.76 \\
\hline$K_{\mathrm{rn}}(\mathrm{W} / \mathrm{cm} \cdot \mathrm{K})$ & $3.53 \times 10^{-3}$ & $3.23 \times 10^{-3}$ \\
\hline$c_{p m}(J / g m \cdot k)$ & 2.50 & 2.44 \\
\hline$\alpha_{m}\left(\mathrm{~cm}^{2} / \mathrm{s}\right)$ & $1.11 \times 10^{-3}$ & $1.03 \times 10^{-3}$ \\
\hline$\sigma_{m}(\Omega \cdot c m)$ & 216 & 785 \\
\hline${ }^{\beta_{m}}\left({ }^{\circ} \mathrm{C}^{-1}\right)$ & $4.38 \times 10^{-4}$ & $3.78 \times 10^{-4}$ \\
\hline
\end{tabular}

deviation of model Power number to the intended melter Power number can be determined from $\left(\sigma_{m}-\left(\varepsilon_{\sigma} \times \sigma_{p}\right)\right) / \sigma_{m}$. Actual melter operating data are needed to examine the effects of estimated to actual glass properties error, Power number deviations, and other possible similarity incongruities.

\subsection{ACCURACY OF RESULTS}

An uncertainty analysis using the $\mathrm{Kline}$ and $\mathrm{McCl}$ intock uncertainty method as outlined by Schenck [6], is presented in Appendix E. The accuracies of the power supply measurements; voltage, current, and power as well as cooling jacket flow rates were calculated in this analysis. Errors and uncertainties in the measurements and computation of results in addition to those determined in Appendix E, are summarized below. Modeling fluid temperature measurements were made using ungrounded copper/Constantan thermocouples with an accuracy of $\pm 0.5^{\circ} \mathrm{C}$. The accuracy of the thermocouples embedded in the model walls, model bottom, and electrodes was $\pm 1.2^{\circ} \mathrm{C}$ at $21^{\circ} \mathrm{C}$. Accuracy of the embedded thermocouples was determined from a one point calibration against a NBSI calibrated type $T$ thermocouple at a room temperature of $21^{\circ} \mathrm{C}$. The percent uncertainty of the RTD's which were used to measure the cooling jacket temperatures was $0.2 \%$.

Viscosity and electrical conductivity measurements were accurate within $1.0 \%$. The MF-K and MF- 0 thermophysical properties uncertainties of $k, C_{p}$, and 0 were $3.0 \%, 3.0 \%$, and $0.1 \%$ respectively. Measurement devices with the exception of thermocouples embedded in the PSCM model were calibrated against instruments traceable to the National Bureau of Standards. 


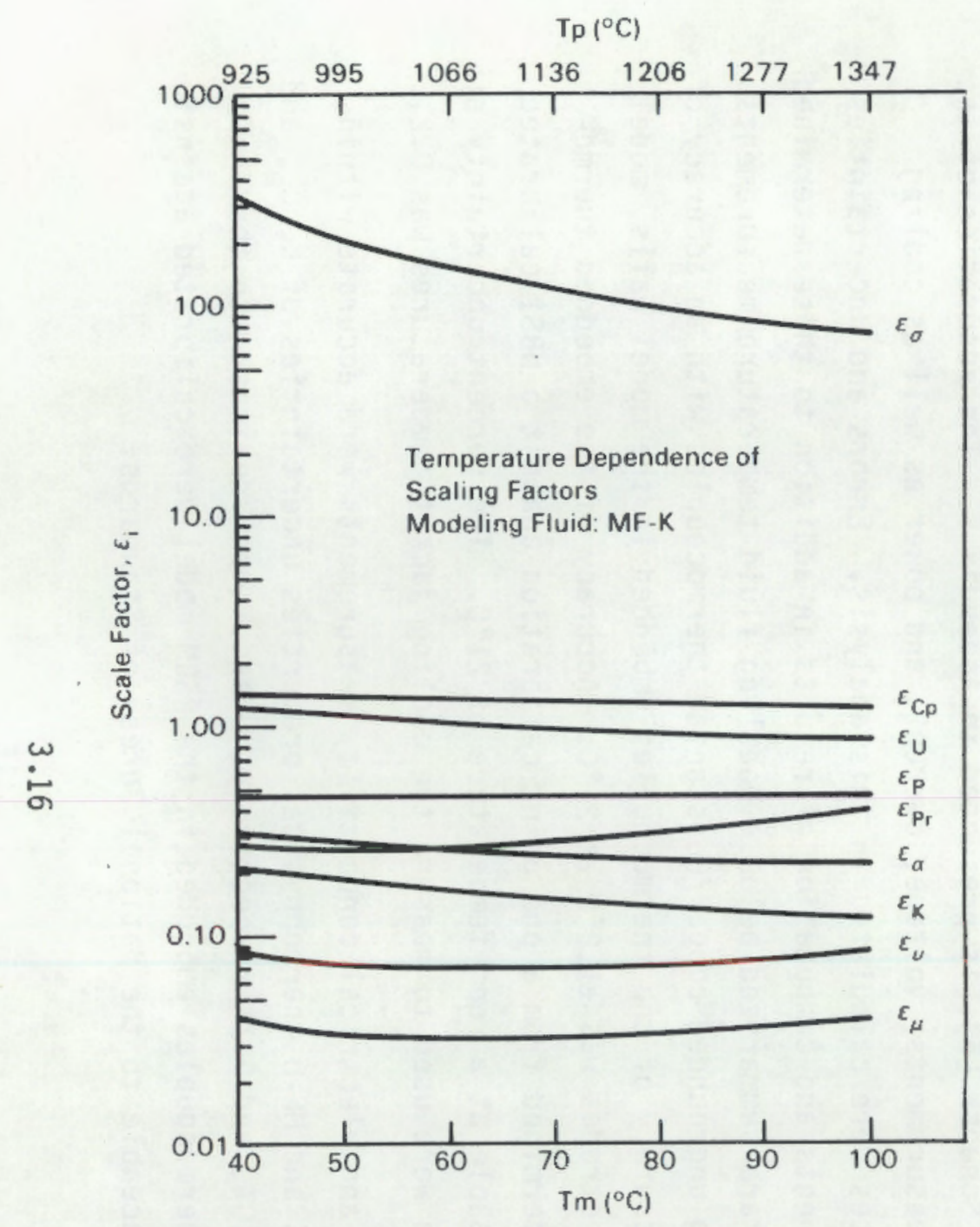

FIGURE 3.11. Modeling Fluid, MF-K, Scale Factor Variation with Temperature

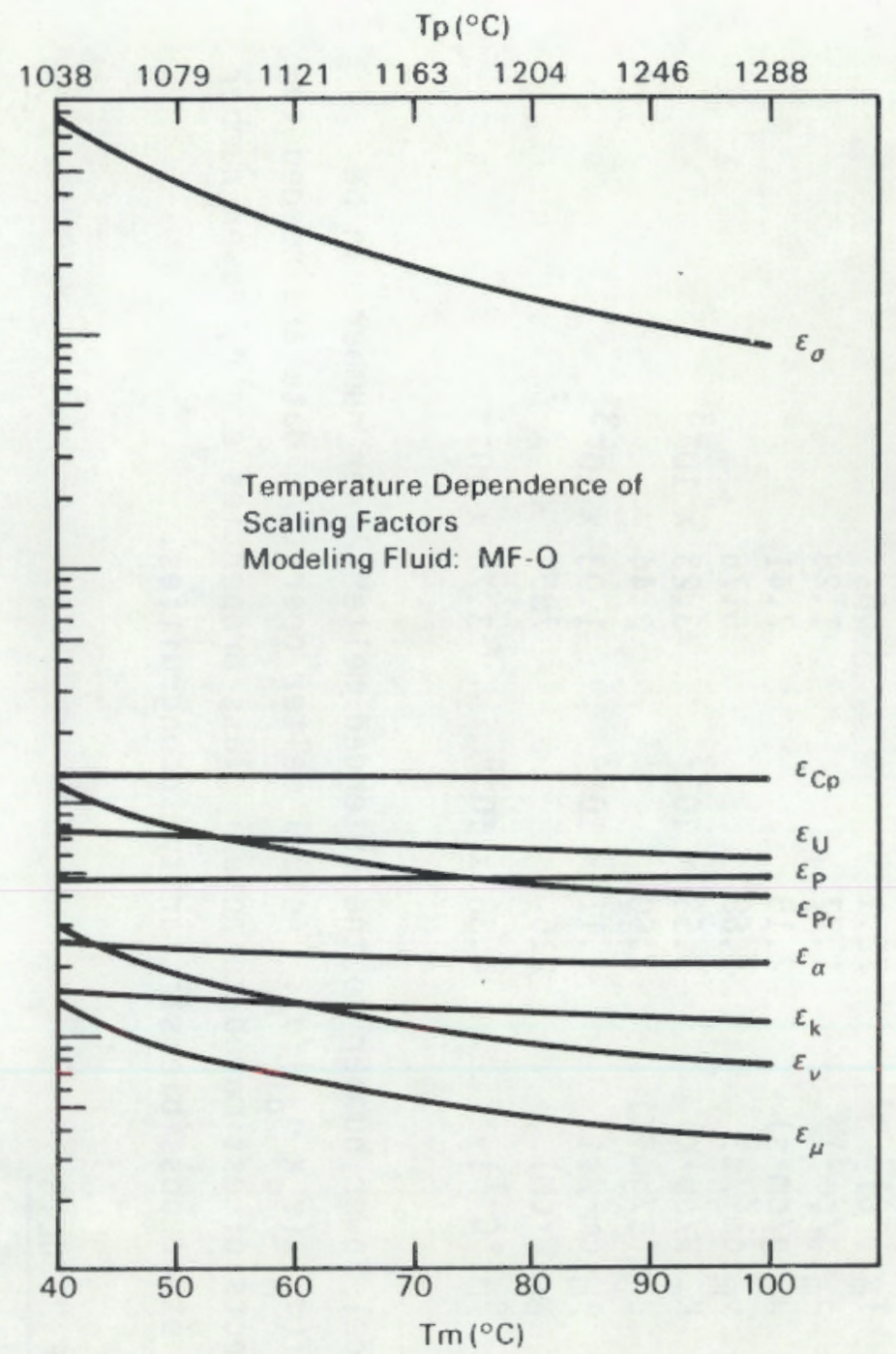

FIGURE 3.12. Modeling Fluid, MF-0, Scale Factor Variation with Temperature 


\subsection{RESULT AND DISCUSSION}

Results from the B-Plant Immobilization Pilot Plant (BIPP) model and the Pilot Scale Ceramic Melter (PSCM) model tests are presented in this section. The objectives of both studies were to minimize glass temperature gradients and increase fluid velocities by promoting stable convective cells in the fluid. Fluid regions with low velocities are more susceptible to particle settling. Large temperature gradients within the glass are undesirable because large variations of both viscosity and electrical conductivity occur. Large electrical conductivity variations produce nonuniform current densities which could result in excess electrode corrosion due to high local current densities. Nonuniform electrical conductivity in the BIPP melter could also lead to crossfiring of the electrode. Cooler regions in the melter can also provide regions of crystallization due to the tendency of the glass to devitrify at lower temperatures [11]. The high viscosity in cooler regions also promotes settling of nonsoluble particles which creates nucleation sites for crystallization formation. This crystallization sludge formation could potentially lead to blockage of the throat or riser over longer periods of operation [11]. In addition, the formation of a conductive sludge could lead to shorting of electrodes.

The influences of different electrode spacings and different upper/lower electrode power ratios (skews) were to be examined during BIPP testing. However, only preliminary BIPP results were obtained prior to a change in program direction. Additional BIPP testing is anticipated to complete the intended test objectives. Preliminary temperature results are presented from test runs BRUN-3 and BRUN-4 for upper/lower electrode power ratios (U/L EPR) of $100 \% / 0 \%$ and $50 \% / 50 \%$ respectively. Preliminary flow results of test BRUN-1, BRUN-2, and BRUN-3, are given for U/L EPR of $100 \% / 0 \%, 100 \% / 0 \%$, and $33 \% / 66 \%$ respectively. These results were obtained at an electrode spacing of $3.49 \mathrm{~cm}\left(13 / 8^{\prime \prime}\right)$.

The primary purpose of the PSCM model testing was to evaluate the use of bubblers to promote stable fluid mixing. Specifically, location, number and 
rate of unreactive bubbling were investigated. A preliminary and qualitative comparison of cold cap location and orientation is also provided for the PSCM model study.

Heat losses through the cold cap were to be calculated, however, the temperature differential across the tops of both models during test was too small to provide reliable heat rate results. This was due to an excessive cooling jacket flow rate. Heat loss calculations shown in Appendix $F$ indicate less than $4 \%$ of the heat generated in the modeling fluid was dissipated from the noncooled surfaces of the PSCM model.

Fluid temperature measurements, electrical potential measurements, and streaked/strobed photography were performed at selected locations in the models to investigate the influences of the various model(s) operating configurations on the fluid temperature profile, electric field, and flow field. Measurement locations are shown in Figures 3.2 and 3.4 while tabulated results are presented in terms of dimensionless coordinates $X^{\star}, Y^{\star}$, and $Z^{\star}$ in Appendices $B, C$, and D. A $60 \%$ offset cold cap was used during all PSCM and BIPP testing. The cooled portions of the BIPP and PSCM model cold caps in contact with upper fluid surface, occupied the areas defined by:

\begin{tabular}{|c|c|}
\hline BIPP & PSCM \\
\hline $0.000<x^{\star}<0.600$ & $0.400<x^{\star}<1.000$ \\
\hline $\begin{array}{l}0.000<Y^{\star}<1.000 \\
Z^{\star}=1.000\end{array}$ & $\begin{array}{l}0.000<Y^{\star}<1.000 \\
Z^{\star}=1.000\end{array}$ \\
\hline
\end{tabular}

During PSCM tésting, the bubble (nitrogen gas flow) rate was defined and measured as the overall volumetric flow to all bubbler tubes. The $0.476 \mathrm{~cm}$ (3/16") I.D. glass tubes (bubblers) were installed $1.27 \mathrm{~cm}\left(1 / 2^{\prime \prime}\right)$ from the model bottom, $Z^{\star}=0.10$. The tubes were inserted into the fluid through model top drywells located at $x^{\star}=0.500$. The tubes' $\gamma^{\star}$ locations were $0.263,0.500$, and 0.737 for the three bubbler tests and $0.263,0.421,0.579$, and 0.737 for the four bubbler tests. Nitrogen flow rate tests were performed using three bubblers at flow rates of $0.0 \mathrm{SCFH}, 0.2 \mathrm{SCFH}, 0.5 \mathrm{SCFH}$, and 1.0SCFH. Tests using zero, three, and four bubbler tubes were made to examine the effects of bubble 
number. Melter to model scaling was not sufficiently developed to predict corresponding bubbler flow rates in the melter.

\subsection{BIPP TEMPERATURE RESULTS}

Model fluid temperature results from two of the preliminary BIPP test runs, BPRUN-4 and BPRUN-5 are presented and briefly discussed in this subsection. BPRUN-4 and BPRUN-5 tests were performed at upper/lower (U/L) electrode power ratios (EPR) of 1.0:0.0 and 0.5:0.5 respectively. Model fluid temperature profiles in the $X^{*}$ direction are shown for BPRUN-4 and BPRUN-5 in Figures 4.1 and 4.2. Each curve in these figures correspond to the horizontal $\left(X^{*}\right)$ temperature profile at a constant fluid depth ( $Z^{*}$-direction). The temperature data for these two runs are tabulated in Appendix B.1.

BPRUN-4 results in Figure 4.1 show much greater temperature stratification relative to the BPRUN-5 results of Figure 4.2 . Model fluid temperature differentials calculated using average temperatures at $Z^{\star}=0.05$ and $Z^{\star}=0.81$ were $23^{\circ} \mathrm{C}$ and $9.1^{\circ} \mathrm{C}$ respectively for BPRUN-4 and BPRUN-5 results. These model temperature differentials scale to $150^{\circ} \mathrm{C}$ and $64.1^{\circ} \mathrm{C}$ glass temperature differential between the corresponding glass depths. The large temperature gradients during the BPRUN-4 testing are undesirable due to the possible crystallization and electrode wear complications mentioned in Section 4.0. A $64.1^{\circ} \mathrm{C}$ glass temperature differential is considered sufficiently small to avoid these problems $[9,10,11]$.

With only the upper electrode pair in operation, as in the BPRUN-4 test, less Joule heating occurs in the cooler, denser, and more electrically resistive fluid beneath these electrodes. Therefore, as expected, mixing between the fluid in the upper and lower regions is deterred and results in large temperature stratification of these fluid layers. When the lower electrode pair is also in operation, additional heat is generated in the lower fluid regions which increase the buoyancy induced mixing of these regions. Hence, operation of both electrode pairs provide greater mixing which reduces temperature stratification. 


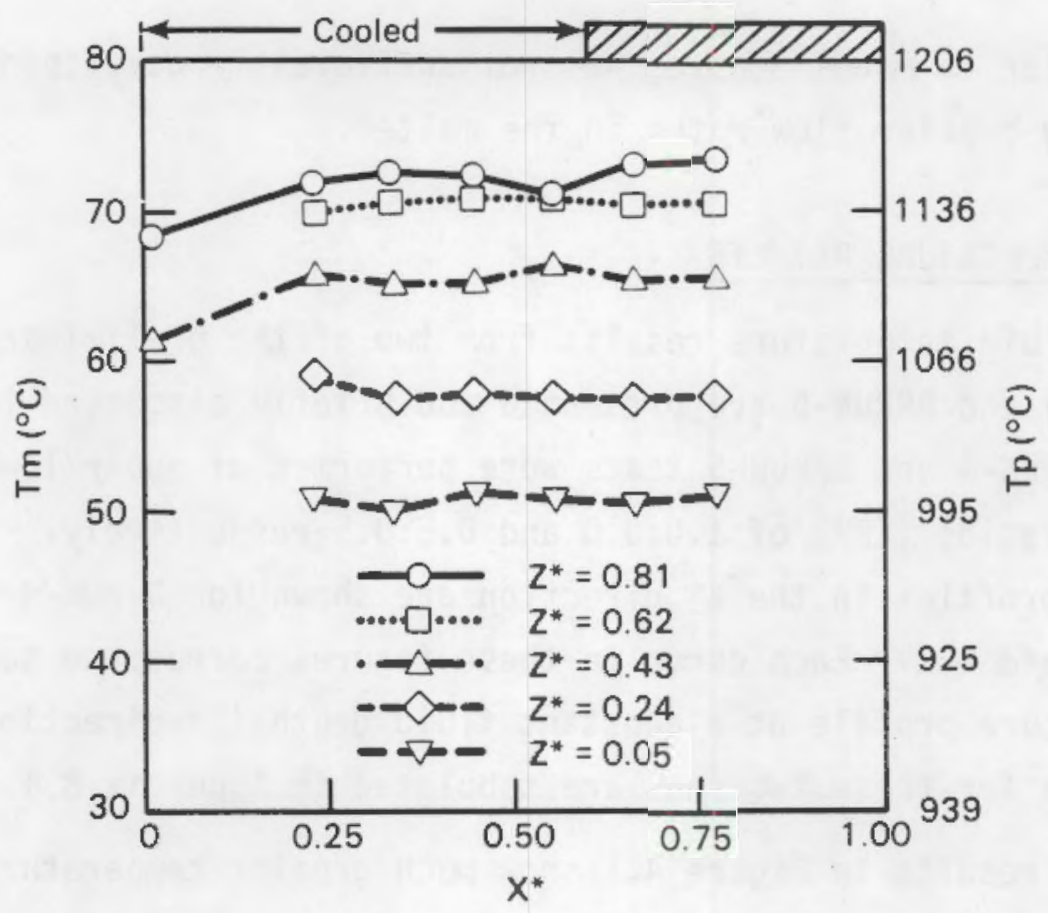

FIGURE 4.1. Horizontal Temperature Profile at Melter Center - BIPP Model

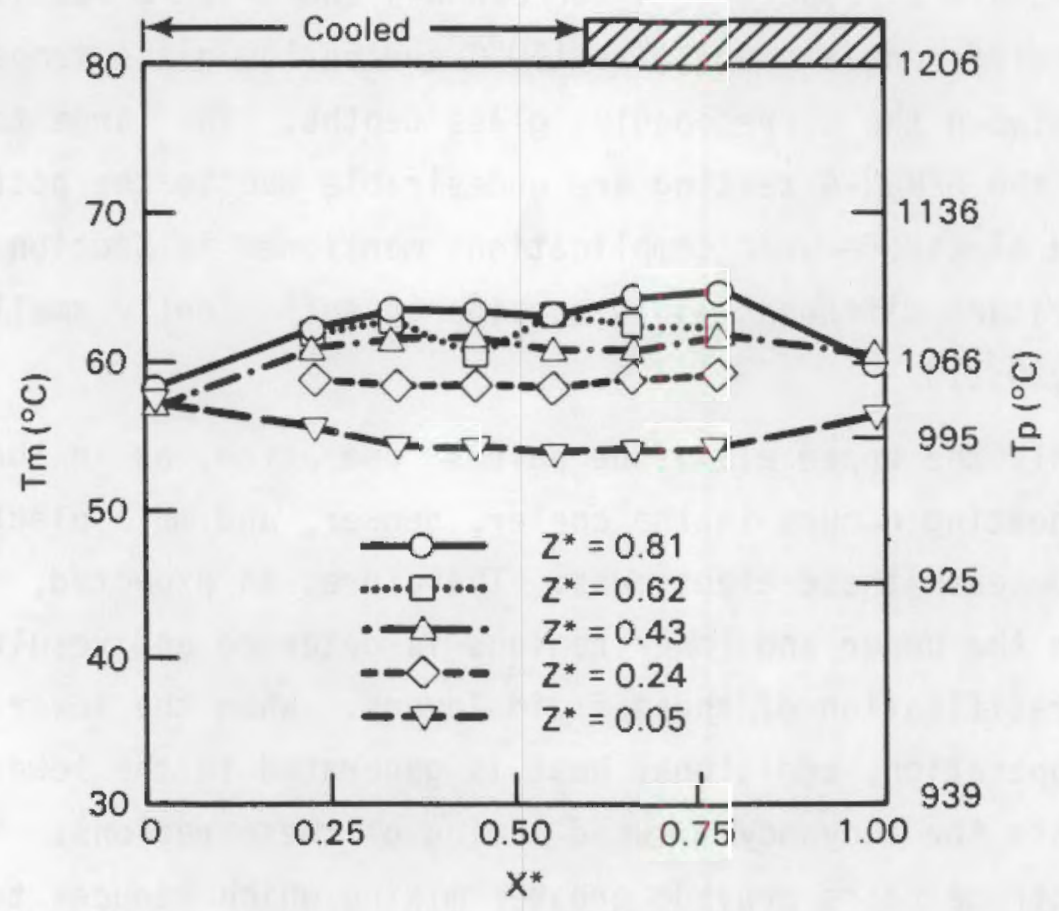

FIGURE 4.2. Horizontal Temperature Profile at Melter Center - BIPP 
The ability of the BIPP two electrode pair configuration to vary the upper to lower fluid layer heat addition, provides additional control over fluid mixing and temperature stratification not possible with a single electrode pair. Electrode spacing and U/L EPR need to be considered in more detail to determining the optimum operating configuration as well as investigate the possible complications of electrode crossfiring.

\subsection{PSCM TEMPERATURE RESULTS}

Fluid temperature profiles in the vertical direction of four different bubbling flow rates are shown in Figures 4.3 through 4.14 at selected $X^{*}$ and $Y^{*}$ locations. Figures 4.3 through 4.5 and Figures 4.12 through 4.14 show the vertical temperature profiles near the front and back wall respectively. Figure 4.8 and Figures 4.9 through 4.11 are temperature profiles at the center vertical plane of the melter and at $Y^{*}=0.263$, respectively. Fluid below the uncooled portions of the cold cap at $X^{\star}<0.34$, exhibited smaller vertical temperature gradients with increasing bubbler flow rates. Figures $4.3,4.6,4.9$ and 4.12 show temperature profiles at $X^{*}=0.338$. Stratified temperatures typical of buoyancy induced flows are observed for the no bubbler runs beneath the uncooled portion of the cold cap. The resulting vertical temperature differences for the no bubbler case is $12^{\circ} \mathrm{C}$ in the model which corresponds to $55^{\circ} \mathrm{C}$ in the prototype. Temperature differences of $\Delta T_{m}=4^{\circ} \mathrm{C}\left(\Delta T_{p}=18^{\circ} \mathrm{C}\right)$ were obtained for a nitrogen flow rate of 0.2 SCFH at $X^{*}<0.34$. Temperature differences for nitrogen flow rates of 0.5 SCFH and 1.0 SCFH at $x^{*} \leqslant 0.35$ are approximately $2^{\circ} \mathrm{C}$ and $9^{\circ} \mathrm{C}$ for model and prototype respectively.

The vertical temperature profiles for $X^{\star}<0.400$ are shown in Figures 4.4 , $4.5,4.7,4.8,4.10,4.11,4.13$ and 4.14. Maximum temperature differences for the bubbler runs in the region of the cold cap are $20^{\circ} \mathrm{C}$ to $24^{\circ} \mathrm{C}$ in the model, which scale to prototype temperatures between $92^{\circ} \mathrm{C}$ and $110^{\circ} \mathrm{C}$. The largest ternperature gradients occur directly beneath the cooled portion of the cold cap, in the region $Z^{\star}>0.75$. The vertical temperature differences also increase in the $x *$ direction, moving towards the electrodes from the center of the model. As shown in the flow field photographs, Figures 4.21 through 4.25 , 


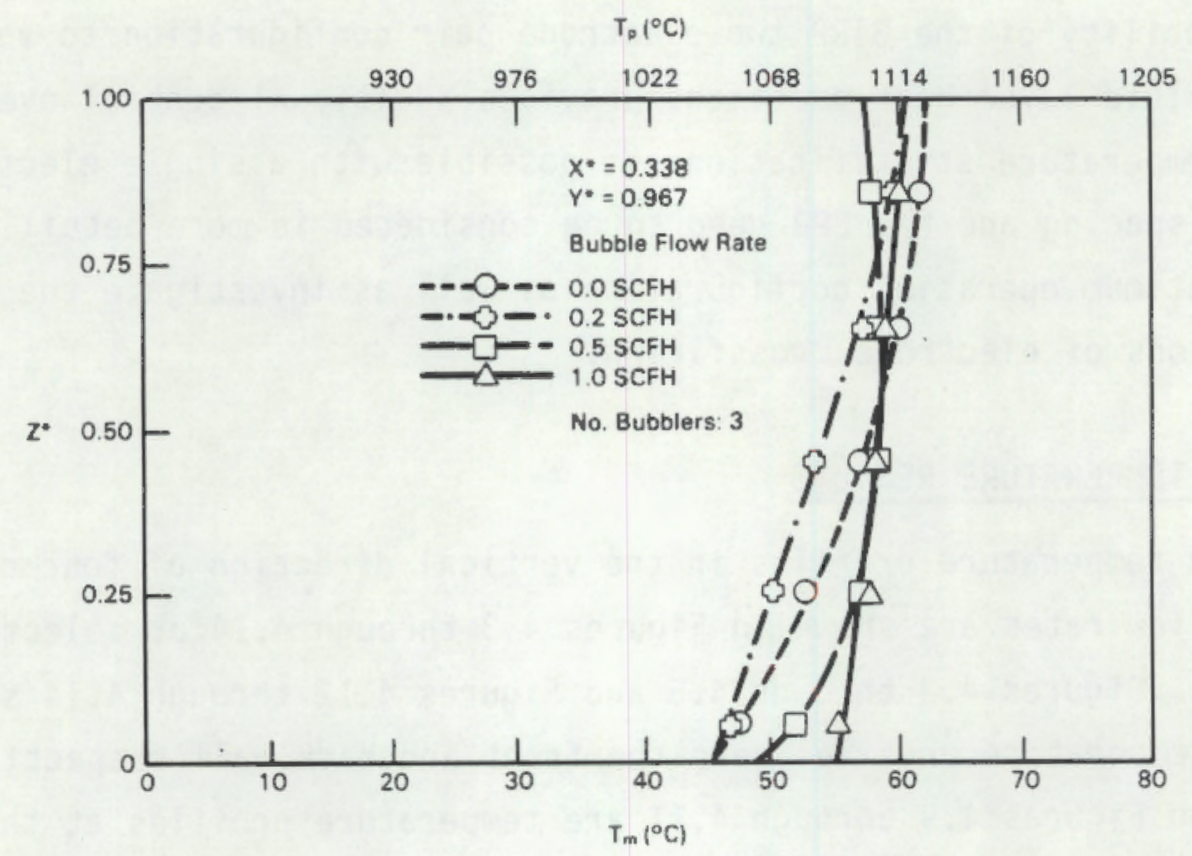

FIGURE 4.3. Vertical Temperature Profile Near Front Wall

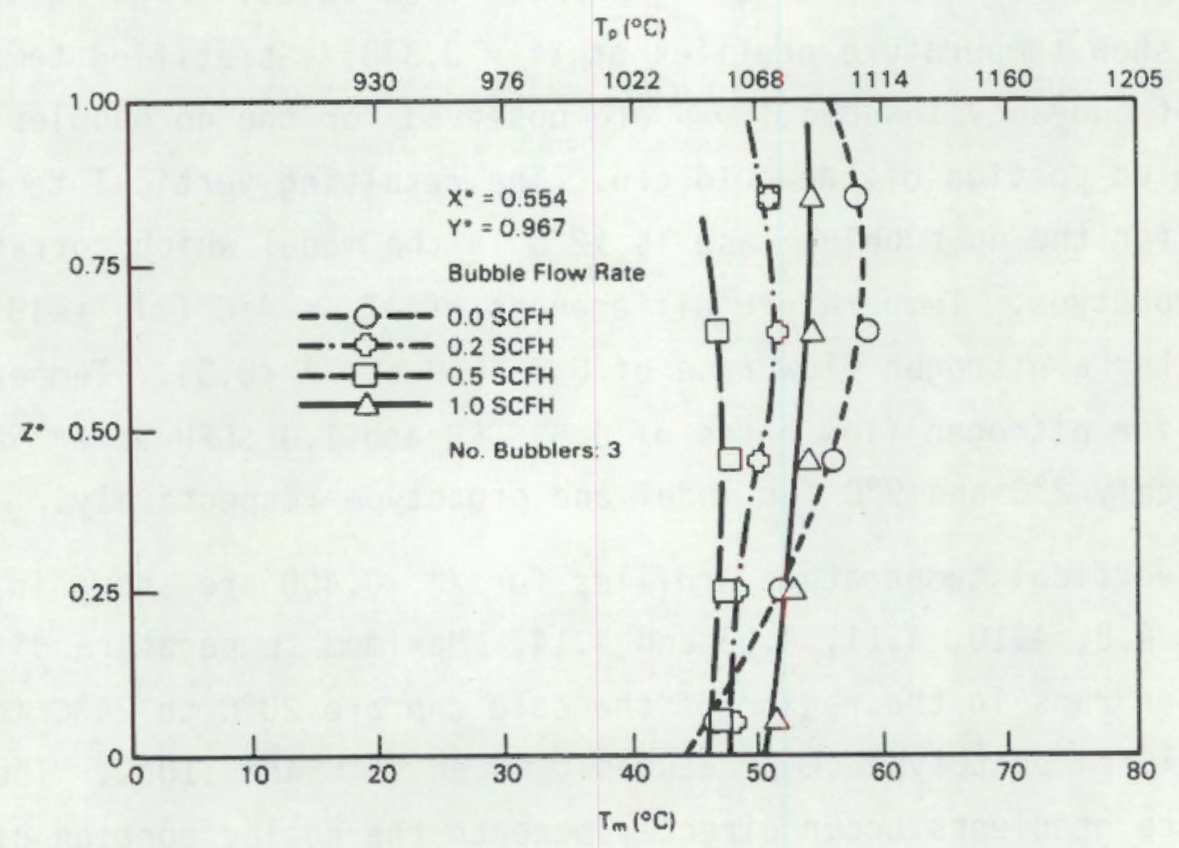

FIGURE 4.4. Vertical Temperature Profile Near Front Wall 


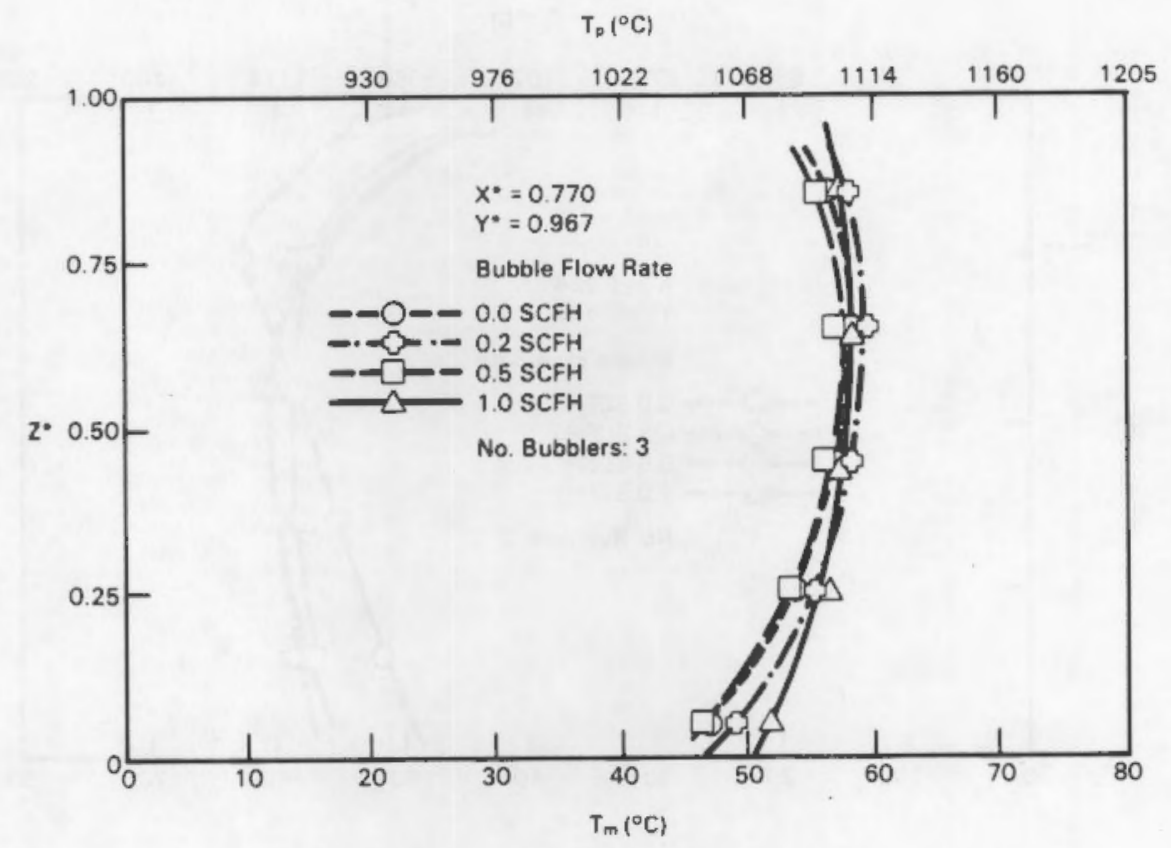

FIGURE 4.5. Vertical Temperature Profile Near Front Wall

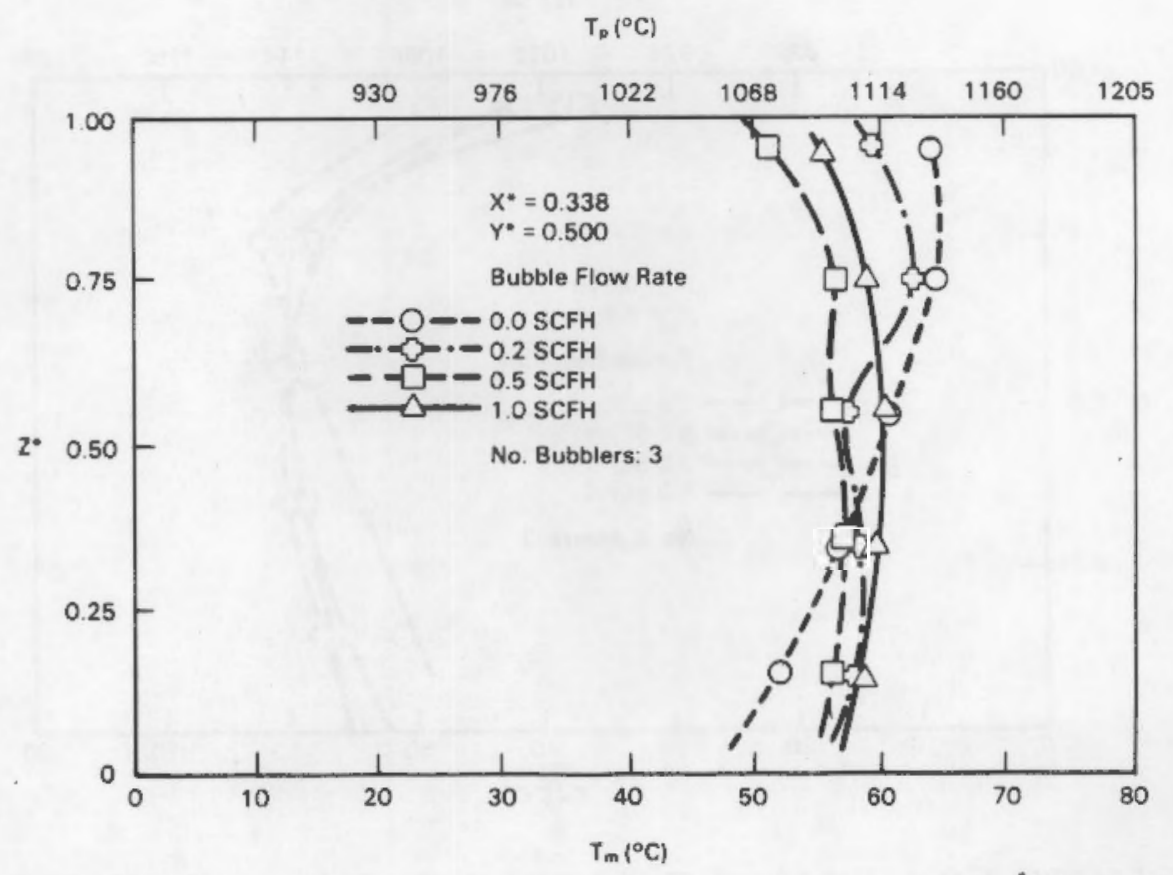

FIGURE 4.6. Vertical Temperature Profile at Model Center 


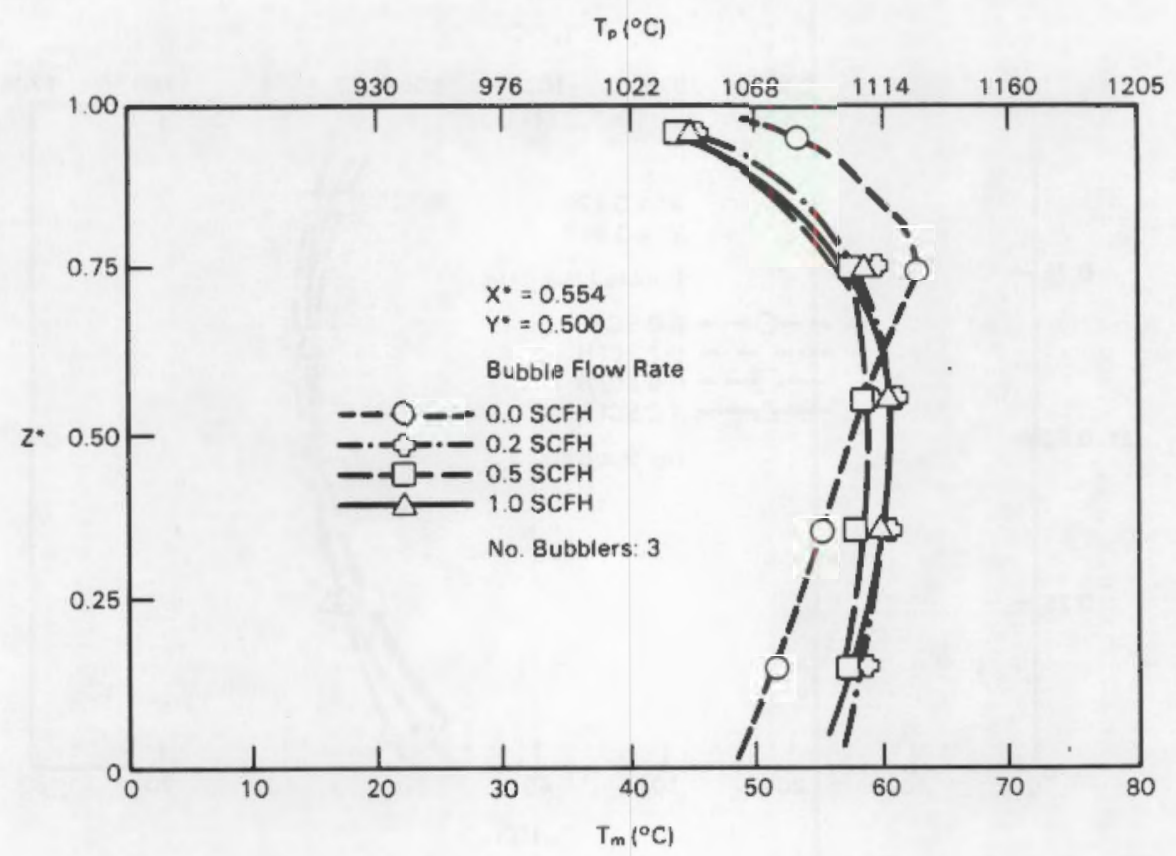

FIGURE 4.7. Vertical Temperature Profile at Model Center

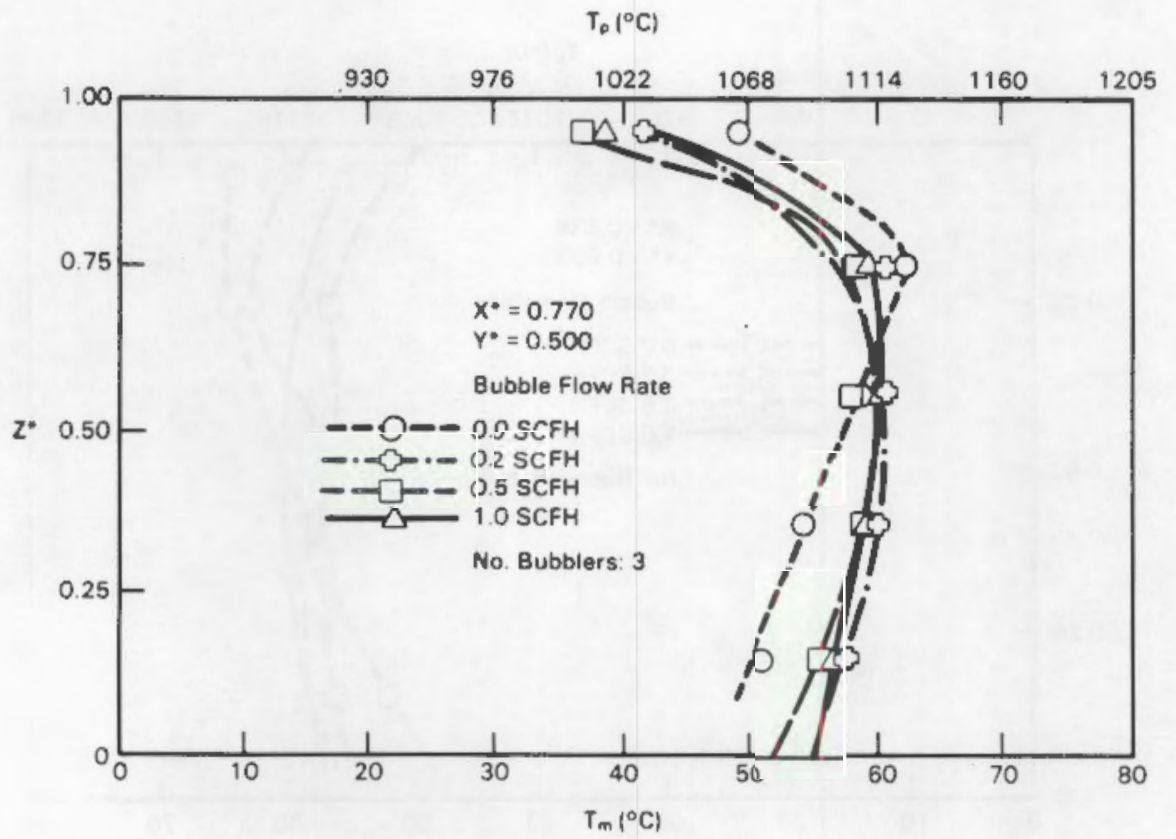

FIGURE 4.8. Vertical Temperature Profile at Model Center 


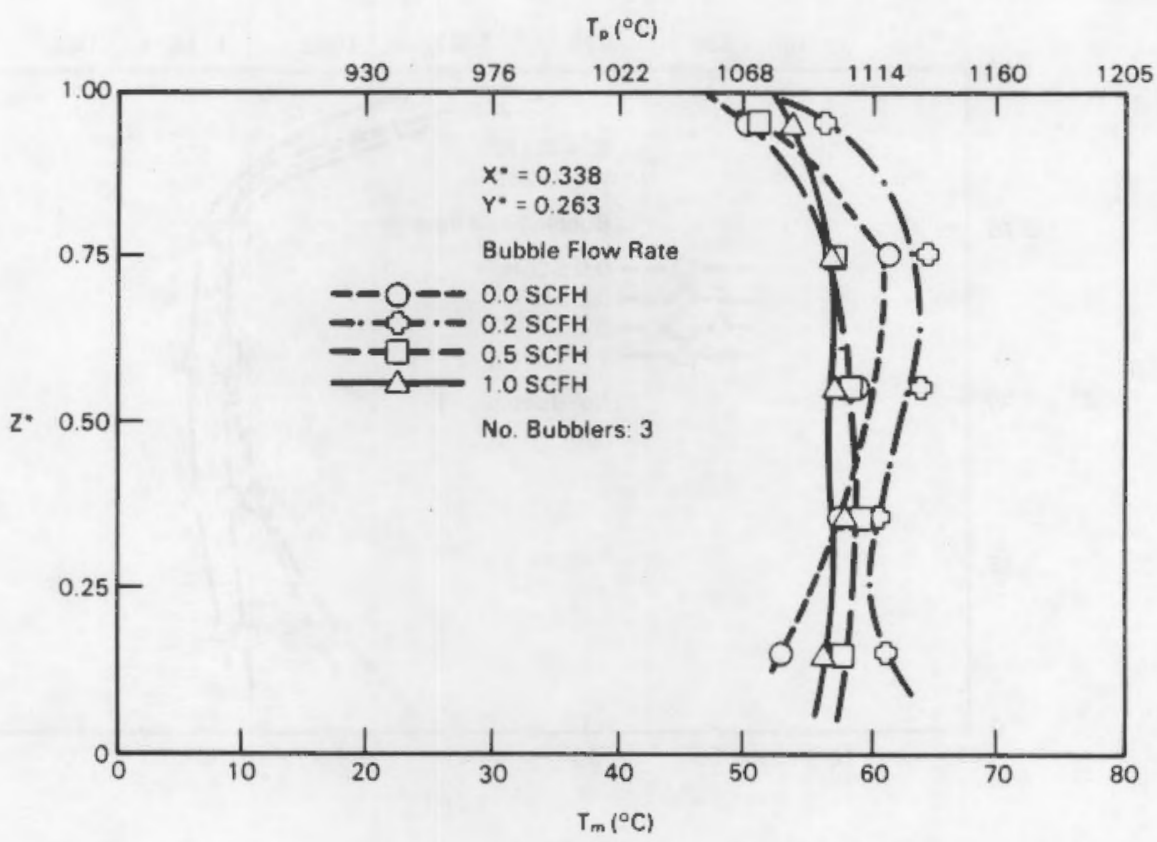

FIGURE 4.9. Vertical Temperature Profile Between Model Center and Back Wall

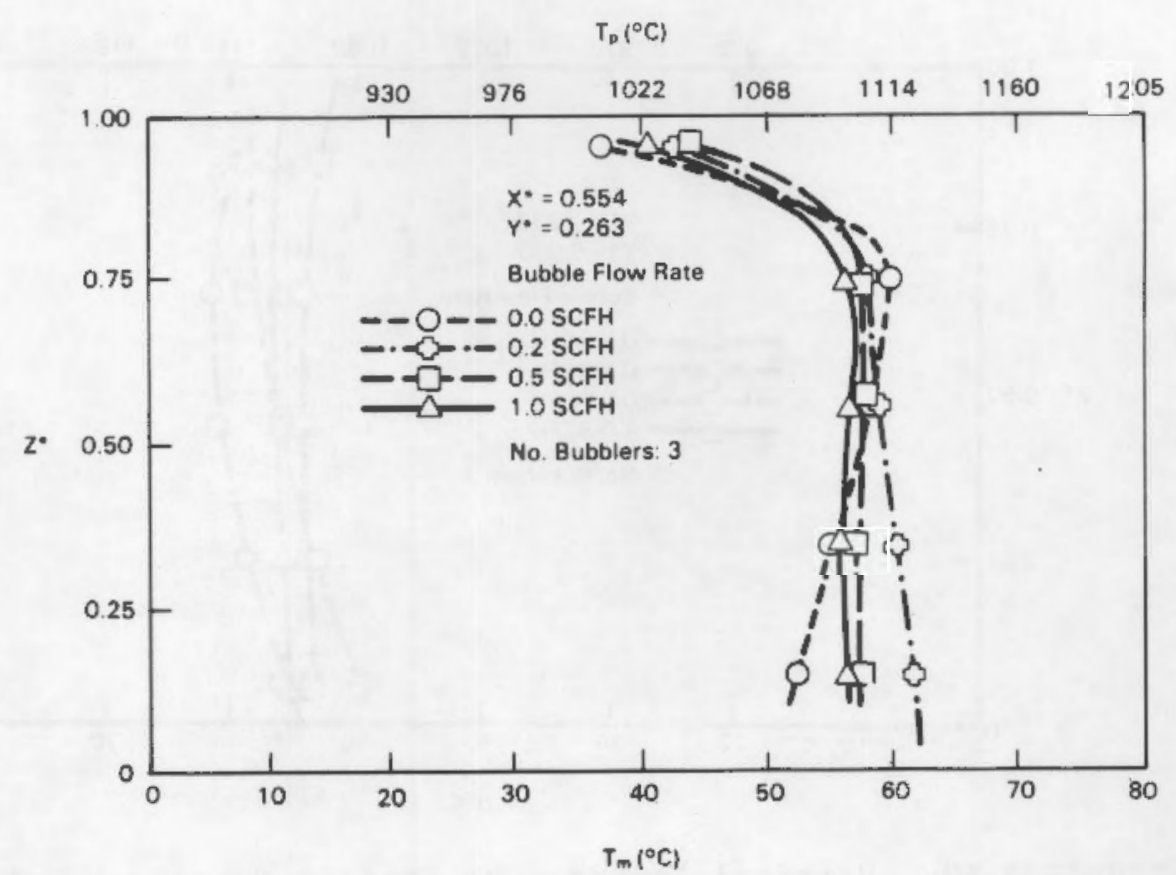

FIGURE 4.10. Vertical Temperature Profile Between Model Center and Back Wall 


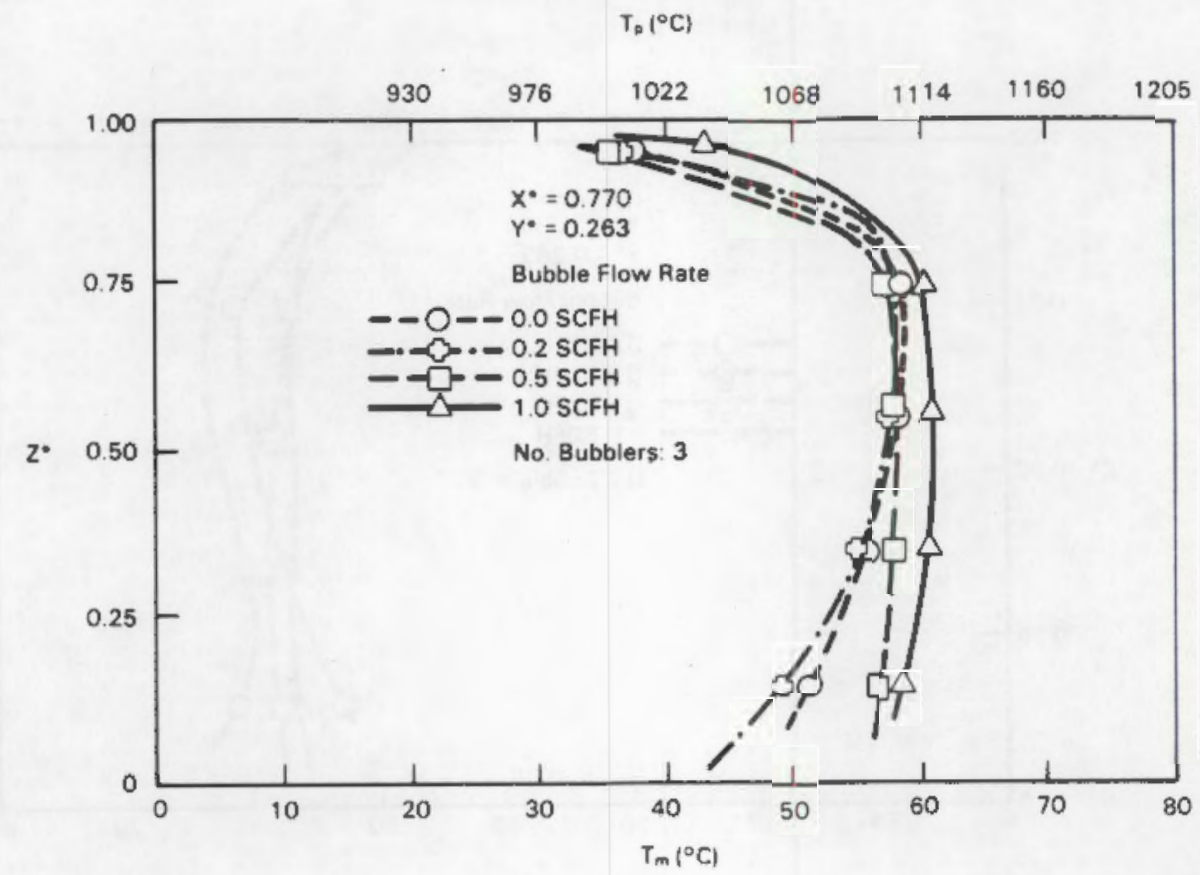

FIGURE 4.11. Vertical Temperature Profile Between Model Center and Back Wall

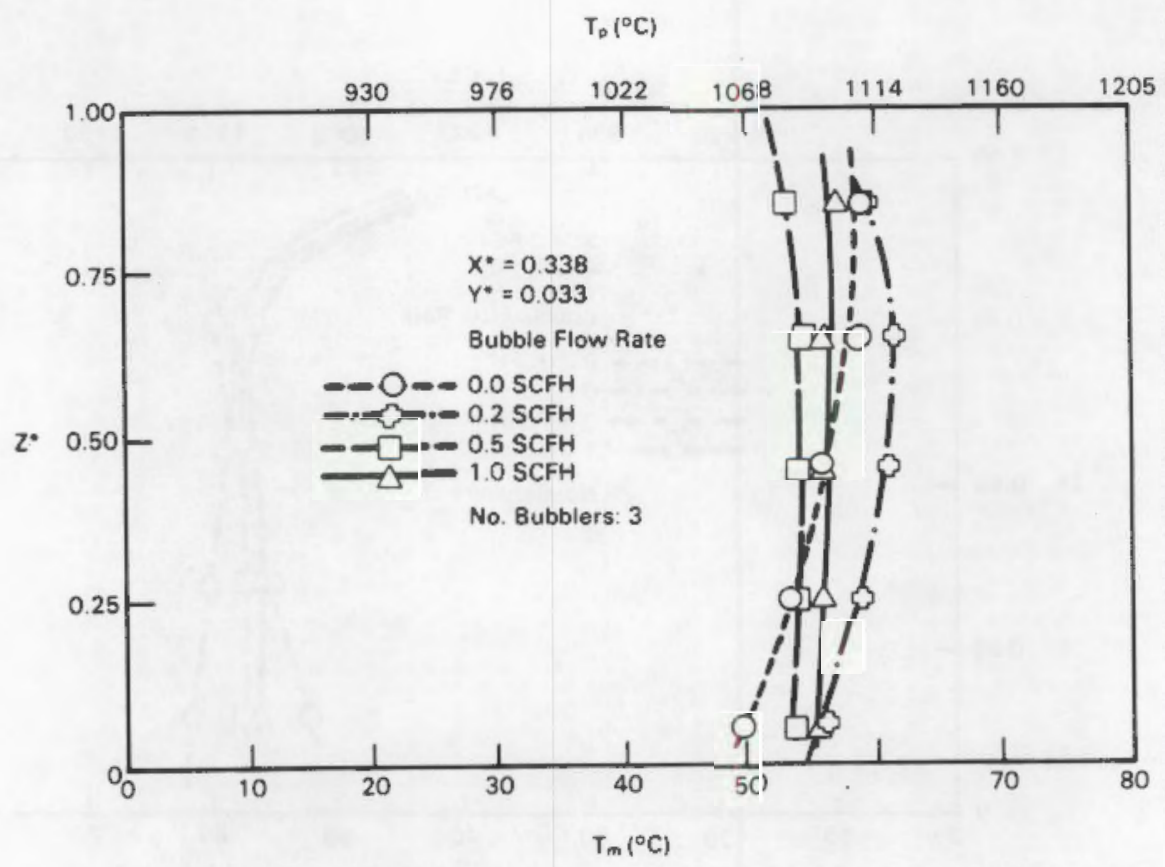

FIGURE 4.12. Vertical Temperature Profile Near Back Wall 


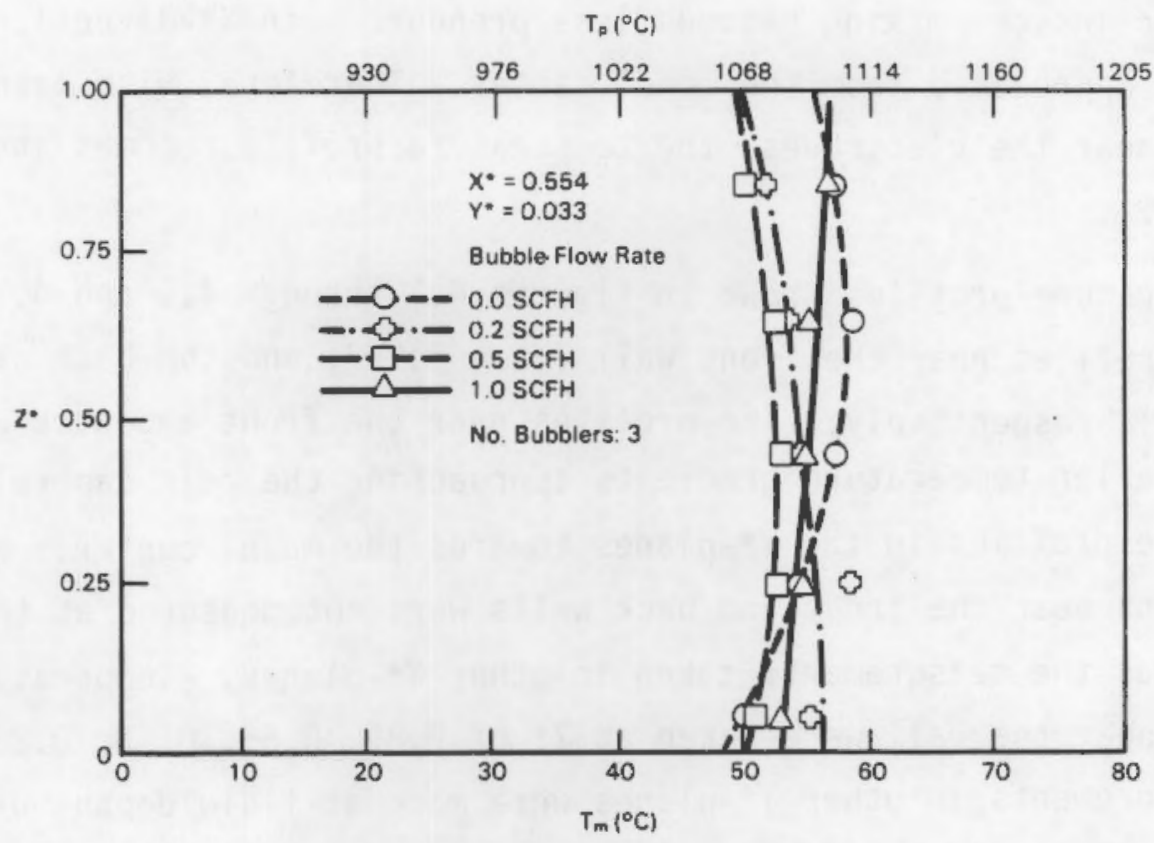

FIGURE 4.13. Vertical Temperature Profile Near Back Wall

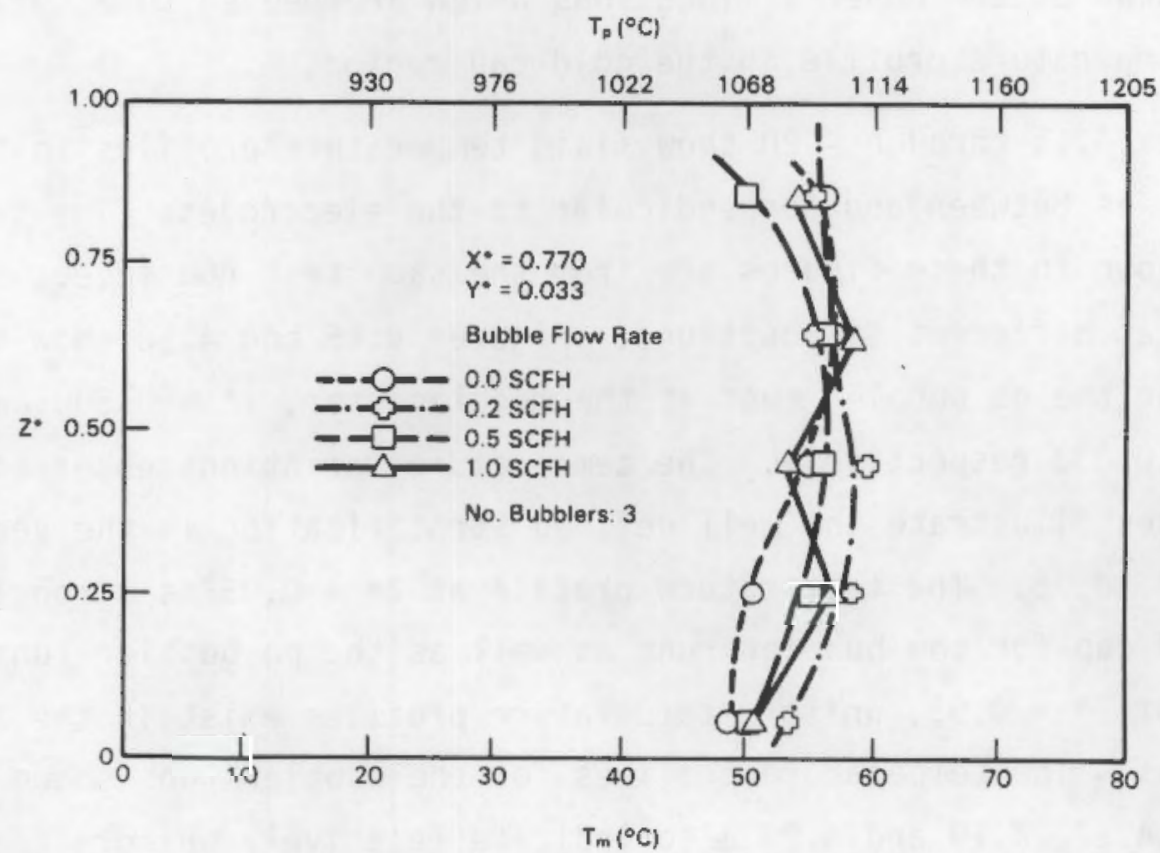

FIGURE 4.14. Vertical Temperature Profile Near Back Wall 
the bubbler induced mixing becomes less pronounced in $x^{*}$-direction as the electrodes are approached from the model center. Therefore, with less mixing occurring near the electrodes, the temperature profile becomes increasingly stratified.

Temperature profiles shown in Figures 4.3 through 4.5 and 4.12 through 4.14 are profiles near the front wall $\left(Y^{*}=0.967\right)$ and the back wall $\left(Y^{*}=0.33\right)$, respectively. The profiles near the front and back walls appear to have smaller temperature gradients approaching the cold cap relative to the temperature profiles in the $\gamma^{\star}$-planes towards the model center. However, measurements near the front and back walls were not measured at the same $Z^{*}$ locations as the measurements taken in other $\gamma^{\star}$-planes. Temperature measurements near the wall were taken at $Z^{*}$ of $0.85,0.65,0.45,0.25$ and 0.05 , while measurements in other $Y^{\star}$-planes were made at fluid depths of $Z^{*}=0.95$, $0.75,0.55,0.35,0.15$. The vertical temperature gradient decreases a small region from the cold cap, $Z^{*}=0.25$. Temperature measurements near the walls were not taken at the upper $z^{*}$ locations which are needed to accurately represent the temperature profile in the cold cap region.

Figures 4.15 through 4.20 show fluid temperature profiles in the $x^{\star}$ direction, which is between and perpendicular to the electrodes. The temperature profiles shown in these figures are from the same test run (i.e., bubbler flow rate), but at different $Z^{*}$ positions. Figures 4.15 and 4.18 show temperature profiles for the no bubbler runs at the model center, $\gamma^{*}=0.500$ and near the back, $Y^{*}=0.033$ respectively. The temperature variations observed at differ-

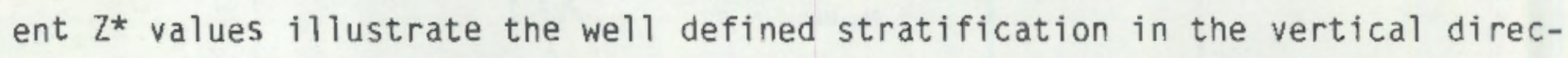
tion for $Z^{*}<0.75$. The temperature profile at $Z^{*}=0.95$ is strongly influenced by the cold cap for the bubbler runs as well as the no bubbler runs. With exception of $Z^{\star}=0.95$, uniform temperature profiles exist in the $X^{*}$ direction for all runs. The temperature profiles for the bubbler runs shown in Figures $4.16,4.17,4.19$ and 4.20 also indicate relatively uniform temperature profiles in the vertical direction. The greatest influence of the cold cap occurred in the region immediately beneath the cooled portion of top, for the no bubbler tests. In the bubbler runs however, the fluid is cooled such that 


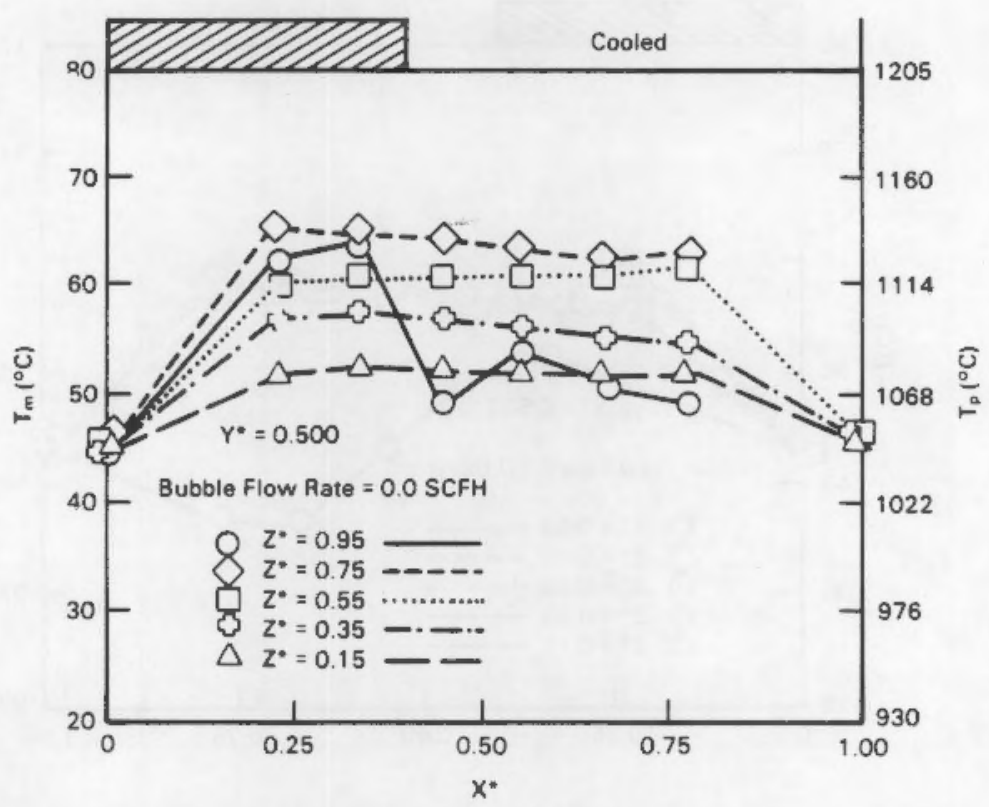

FIGURE 4.15. Horizontal Temperature Profile at Model Center

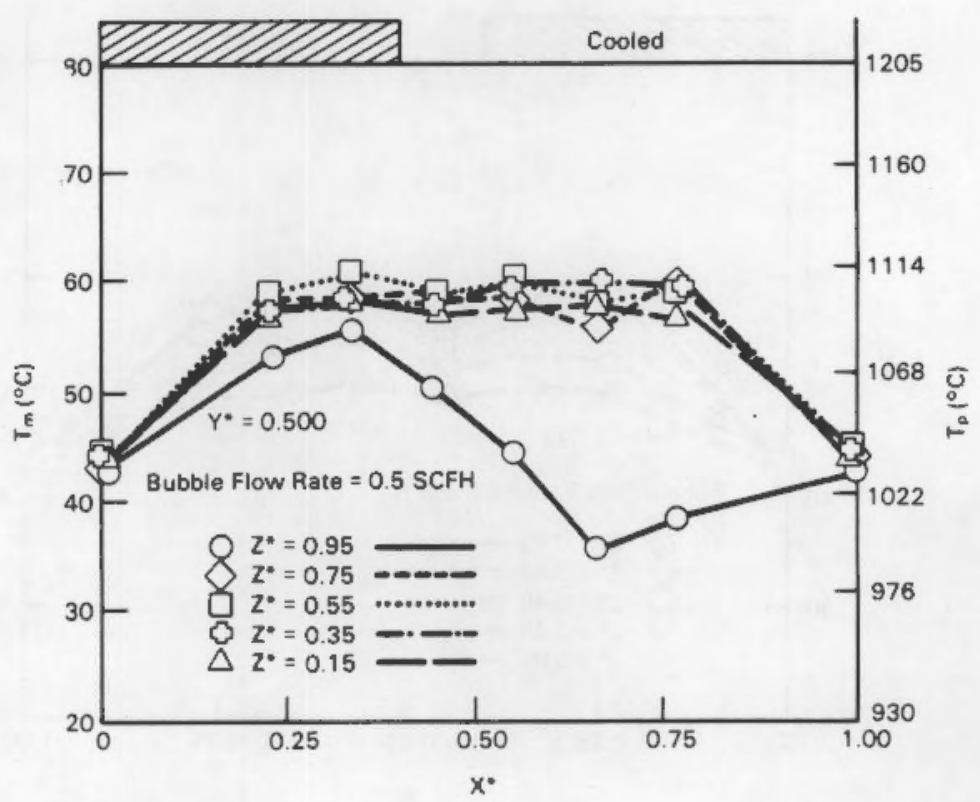

FIGURE 4.16. Horizontal Temperature Profile at Model Center 


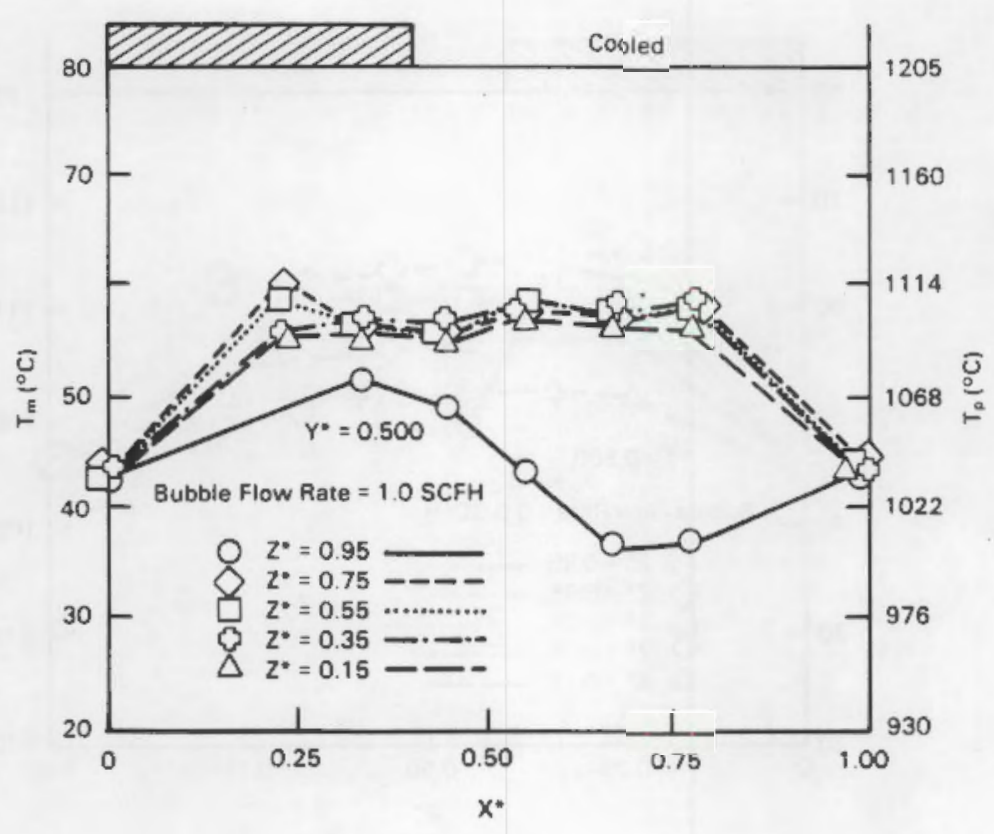

FIGURE 4.17. Horizontal Temperature Profile at Model Center

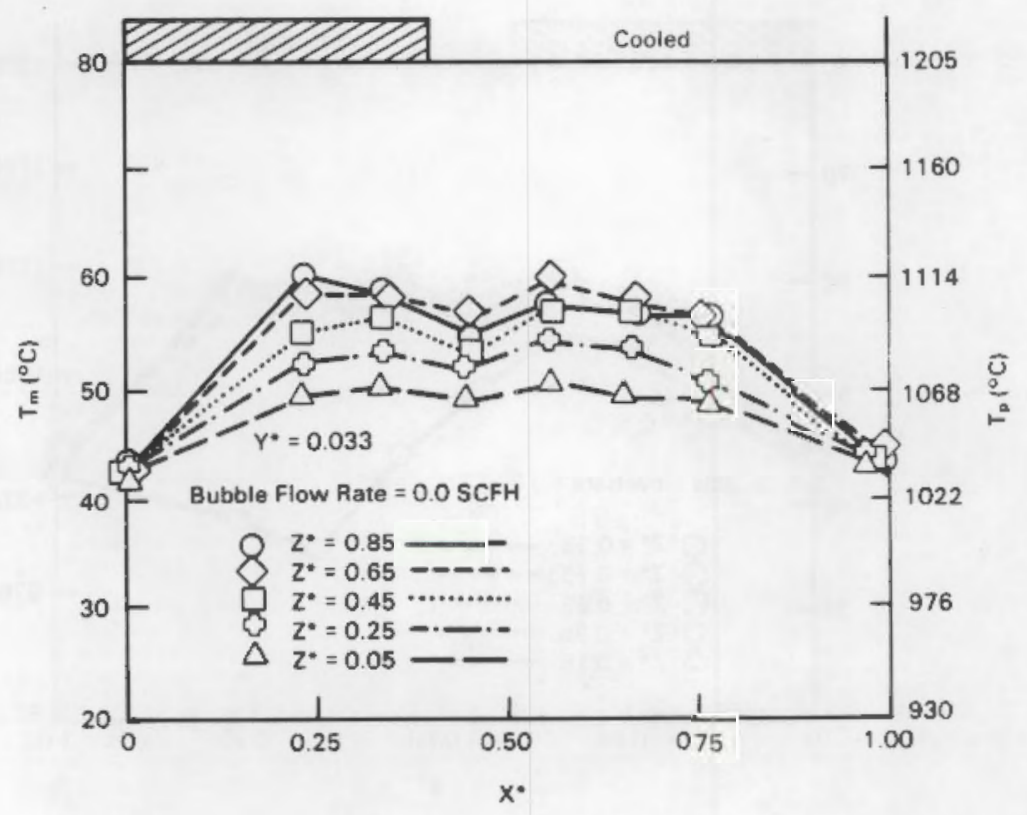

FIGURE 4.18. Horizontal Temperature Profile Near Back Wall 


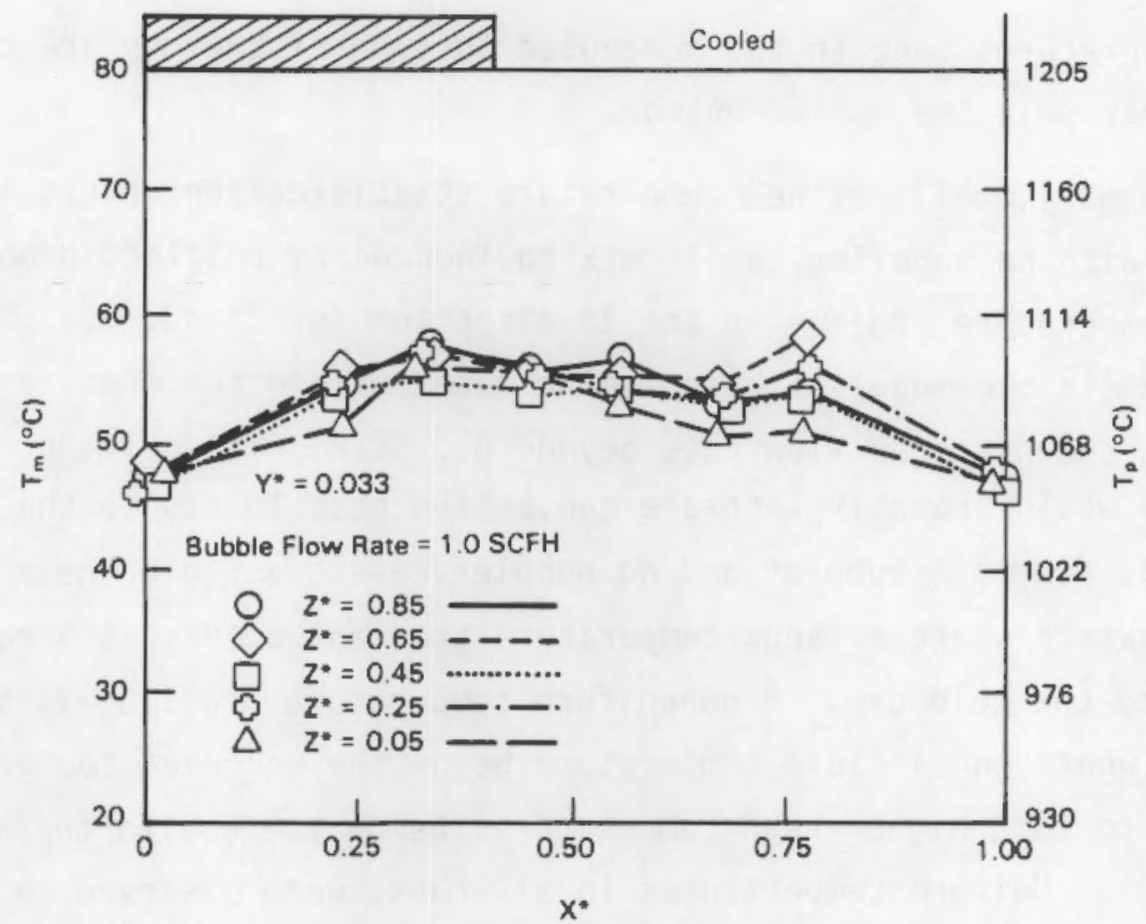

FIGIJRE 4.19. Horizontal Temperature Profile Near Back Wall

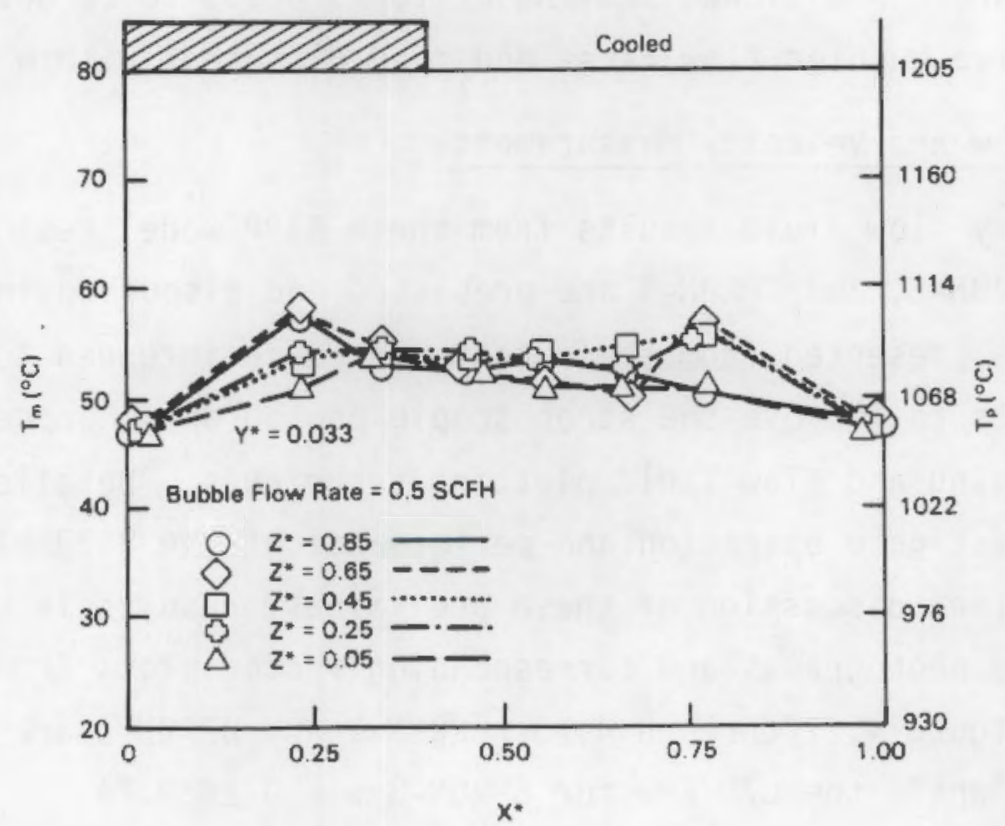

FIGURE 4.20. Horizontal Temperature Profile Near Back Wall 
fluid temperatures beneath the noncooled portion of the top are colder than temperatures near the melter bottom.

In summary, wel1 defined temperature stratification occurs in the vertical direction with no bubbling, while mixing induced by bubblers produces a more uniform temperature profile in the $Z^{\star}$ direction for $Z^{\star}<0.75$. Little benefit was gained (in the model) in terms of a more uniform temperature profile by increasing the nitrogen flow rate beyond $0.5 \mathrm{SCFH}$. In addition, the increased flow rates would probably increase convective heat losses to the model/melter boundaries. In both bubbler and no bubbler cases, a region near the cold cap $Z^{\star}>0.75$ exists where a large temperature gradient occurs as a result of heat transfer to the cold cap. A nonuniform temperature profile exists in the $x^{*}$ direction where model fluid temperature below the uncooled top area $\left(X^{*}<0.400\right)$ were $10^{\circ} \mathrm{C}$ to $15^{\circ} \mathrm{C}$ higher than temperatures below the cooled top area $\left(X^{*}>0.400\right)$. Uniform temperatures in all runs, were observed in the $X^{*}$, direction for $Z^{*}<0.75$. Based on the results of this subsection, use of bubblers in the melter should be considered as a viable method of obtaining a more uniform glass temperature. Additional scaling criteria needs to be developed to provide quantitative bubbler flow rates and tube diameters within the melter.

\subsubsection{BIPP Flow and Velocity Measurements}

Preliminary flow field results from these BIPP model test runs designated as BPRUN-1, BPRUN-2, and BPRUN-3 are presented and discussed in this subsection. The data presented from these test runs were intended to provide preliminary results to improve the stroboscopic photographic procedure and to develop digitizing and flow field plotting techniques. Detailed testing is planned to investigate operation and performance of the BIPP electrode configuration, therefore discussion of these preliminary results is brief. Stroboscopic velocity photographs and corresponding vector plots from these test runs are shown in Figure 4.21 through 4.23 BPRUN-1 and BPRUN-2 are tests at an $U / L$ EPR of 1.0:0.0 while the U/L EPR for BPRUN-3 was 0.26:0.74.

Two major conclusions regarding the 1:0 U/L EPR runs can be drawn from Figures 4.21 and 4.22. First, the vector plots indicate significantly larger 


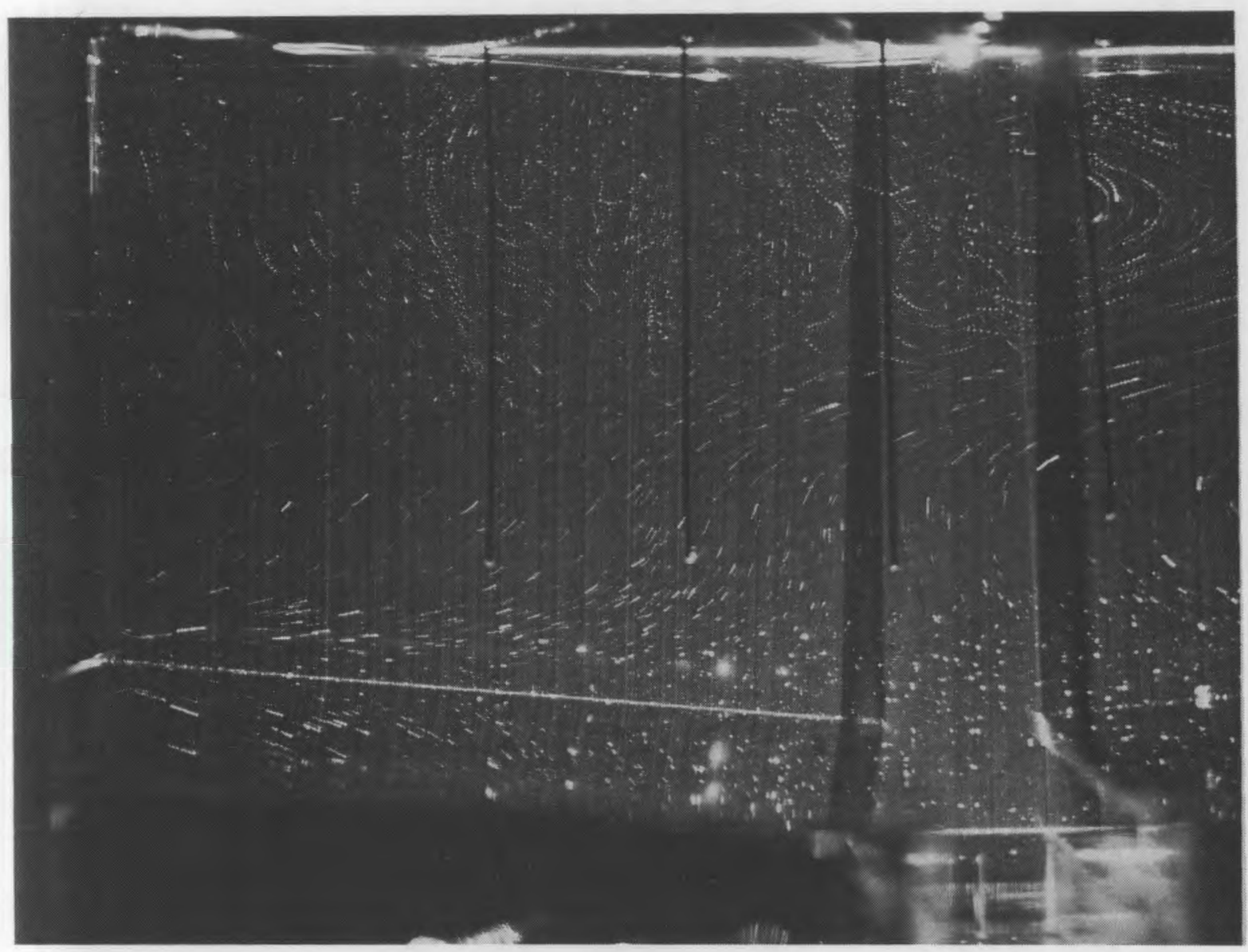

a)

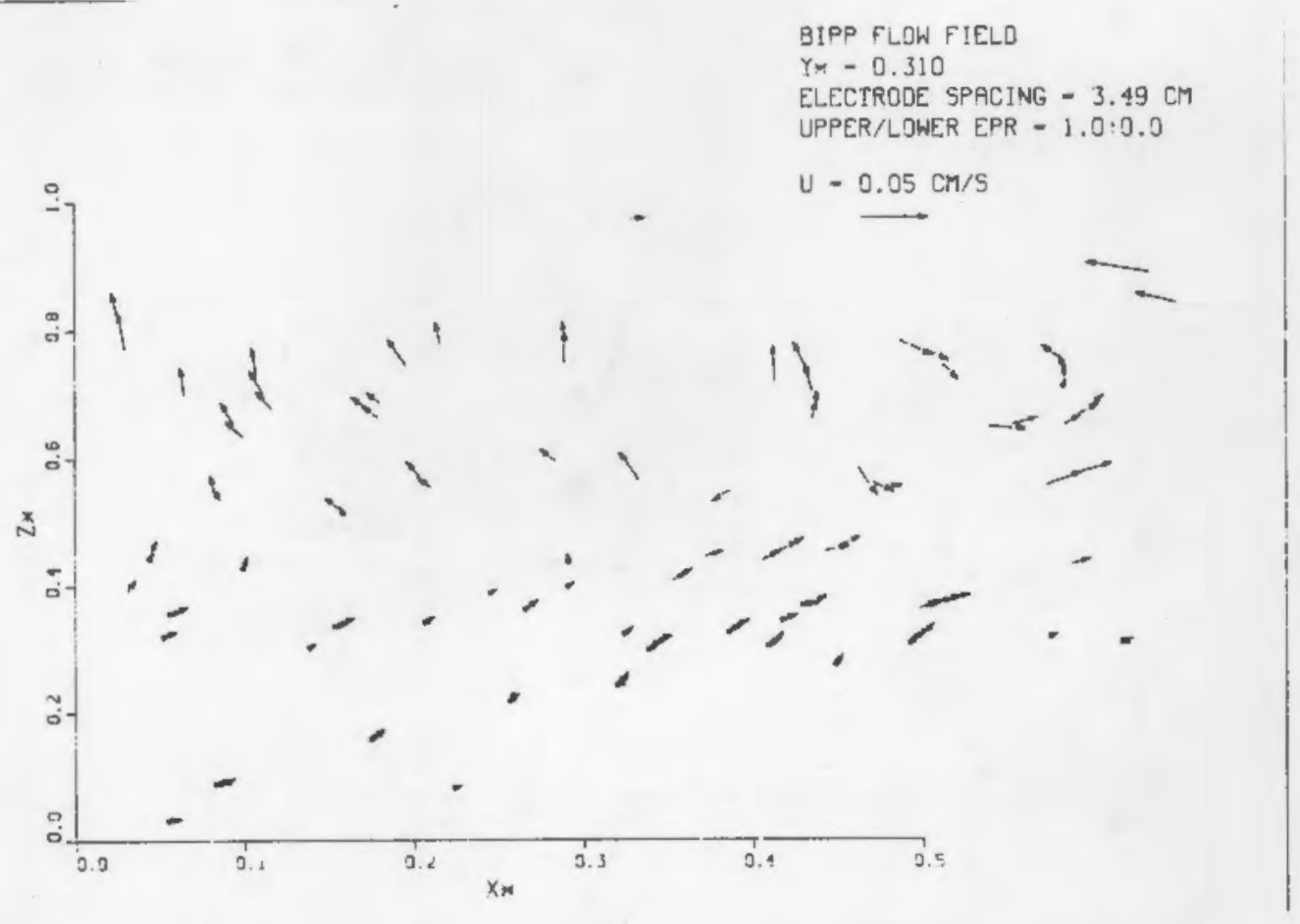

b)

FIGURE 4.21. BPRUN-1 Flow Field, U/R EPR $=1.0: 0.0, Y^{\star}=0.310$ 


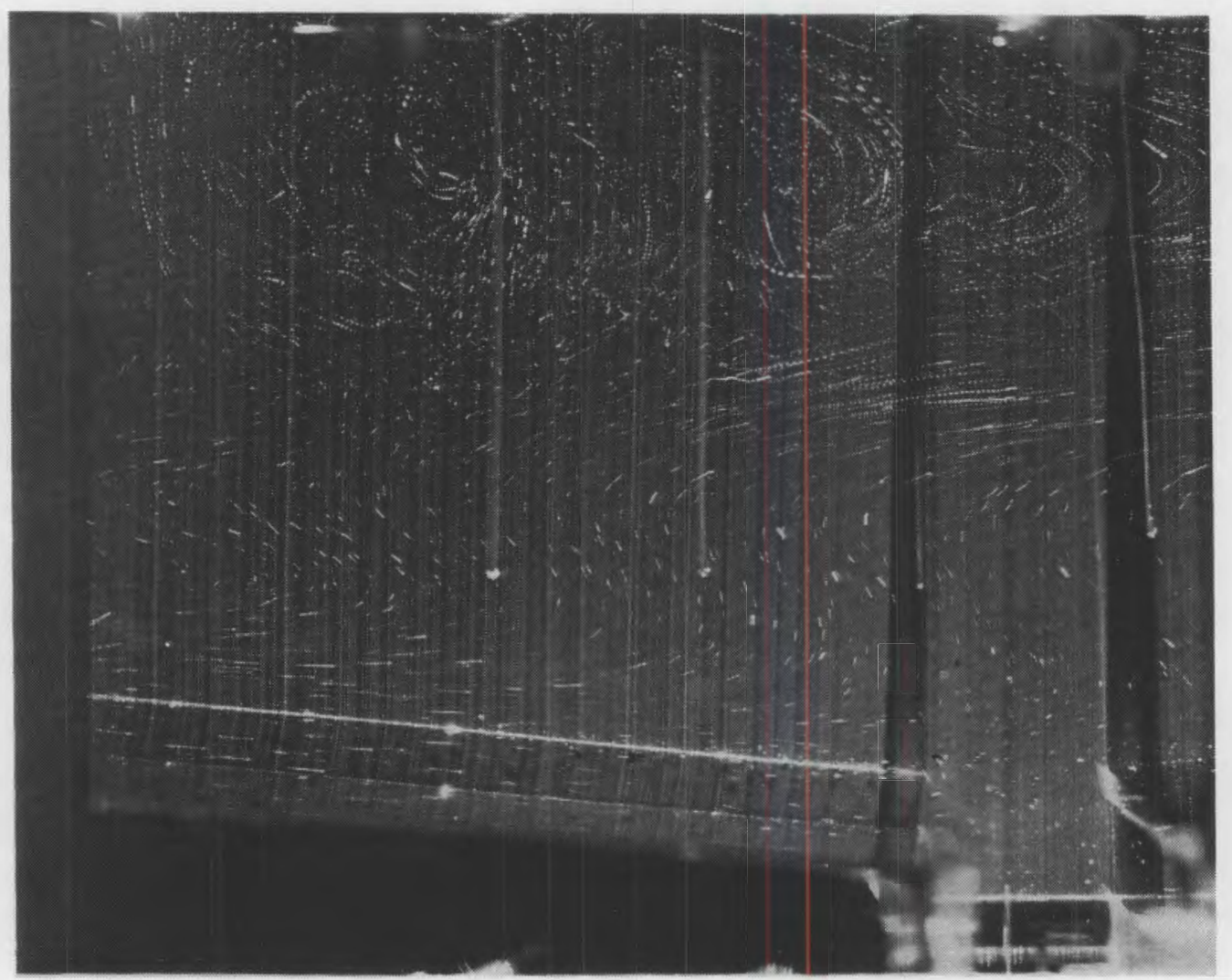

a)

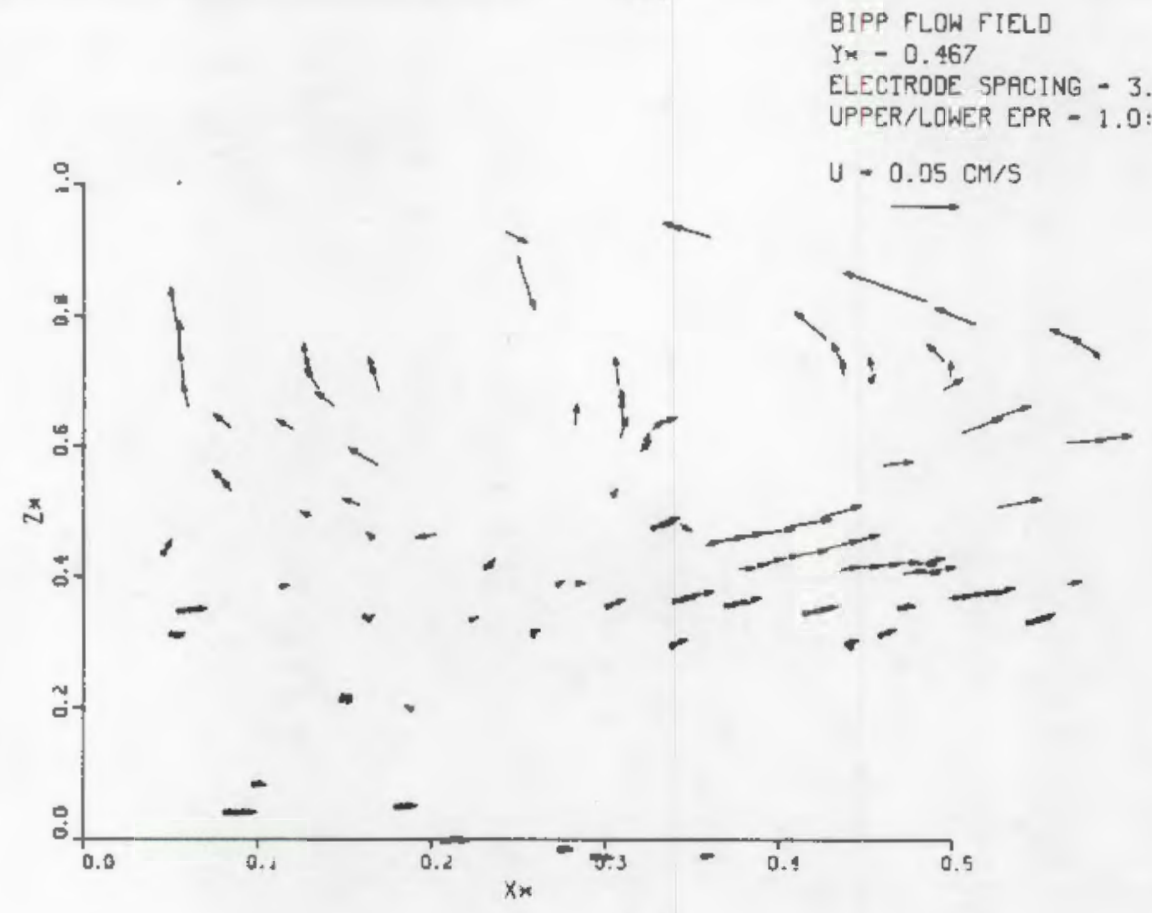

b)

FIGURE 4.22. BPRUN-2 Flow Field, U/R EPR $=1.0: 0, Y^{*}=0.467$ 


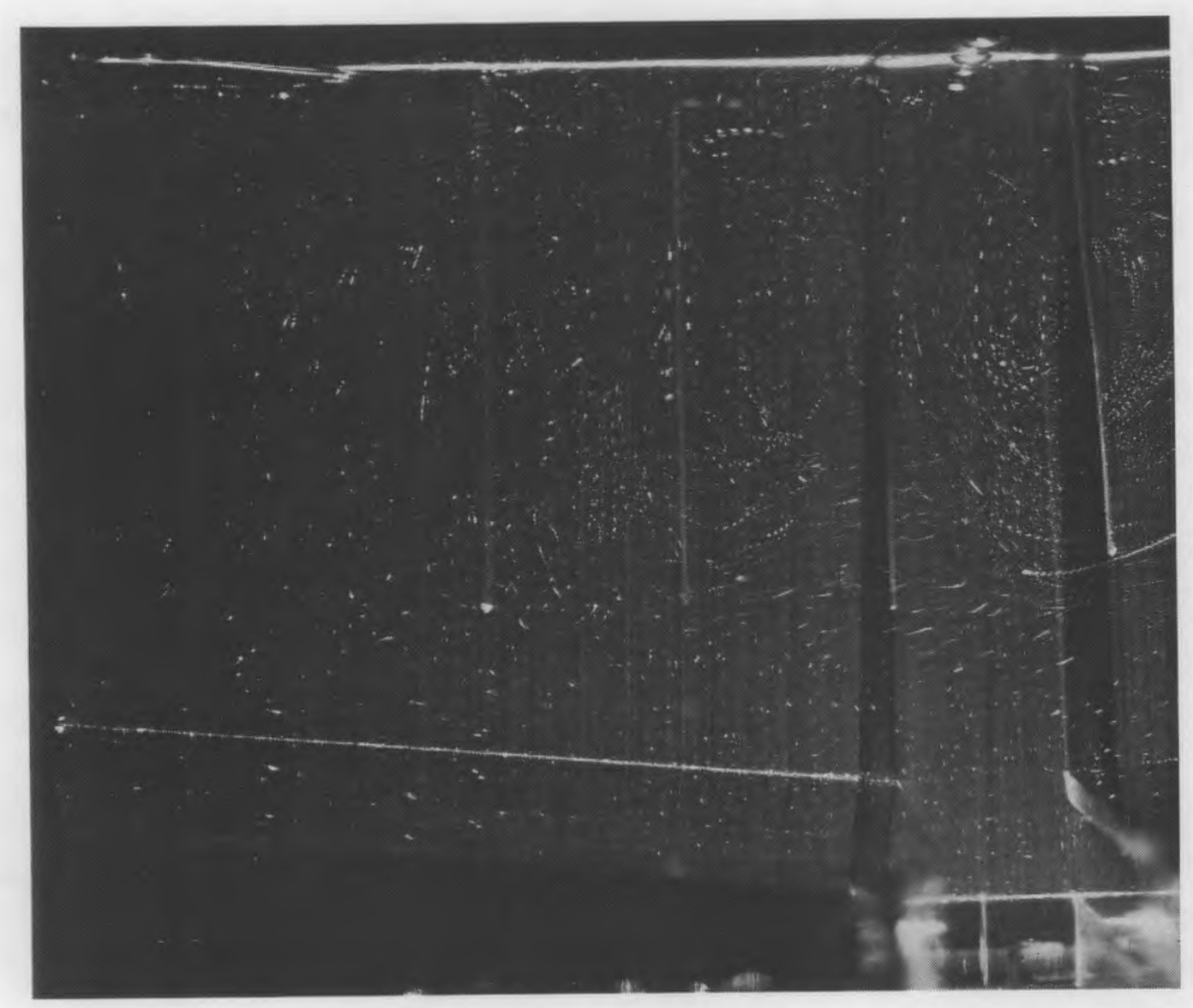

FIGURE 4.23. BPRUN-3 Flow Field, U/R EPR $=0.26: 74$ $Y *=0.423$

flow velocities in the region $Z^{*}>0.5$ relative to $Z^{\star}<0.5$. Secondly, two independent circulation cells, one in the upper fluid and one in the lower fluid are indicated by the vector plots. These observations suggest little interaction between the upper/warmer fluid and lower/cooler fluid which results in temperature stratification as discussed in subsection 2.1.1 The low fluid velocities in the lower region of the model as well as the large fluid temperature variation increase the possibility crystallization and/or particle settling. Thus, the electrode operating configuration of BPRUN-1 and BPRUN-2 is unsuitable for BIPP melter operation.

Results of BPRUN-3 indicate that U/L EPR of 0.26:0.74 is a more desirable electrode operating configuration than the configuration of BPRUN-1 and BPRUN-2. Figure 4.23 shows increased mixing which penetrates further into $Z^{*}$ 
fluid layers. Larger and more stable convective cells are observed developing near the model center. A vector plot is not provided for Figure 4.23 because of the difficulty in identifying the flow direction for this particular flow photograph.

The ability to independently supply power to upper and lower fluid regions provides additional control of fluid mixing which is not possible with single pair of plate electrodes. Increased mixing and minimal fluid temperature variations are desired to minimize particle settling and crystallization. Sufficient fluid mixing for successful BIPP melter operation is believed to be achievable for an appropriate electrode operating configuration. Additional BIPP modeling is scheduled to evaluate in greater detail various electrode operating configurations.

\subsubsection{PSCM Flow and Velocity Measurements}

The flow field results from PSCM model testing are presented and discussed in this subsection. Figures 4.24 and 4.26 through 4.30 are flow photographs that were taken in the vertical plane near the melter center while flow fields in vertical planes nearer the walls are shown in Figures 4.30 through 4.33 . Flow field photographs from the bubbler testing are shown in Figures $4.24 a$ through 4.24d. Figures $4.26,4.27$, and 4.28 are photographs taken at $0.2,0.5$, and 1.0 SCFH, respectively, using three bubblers. Results from testing with four bubblers are shown in Figure 4.29 .

Quantitative velocity measurements from photographs of bubbler induced mixing were generally not possible near the model center due to the presence of excess light scattering particles in this region. Velocity measurements which were obtained from some of the flow photographs are presented in vectoral flow field graphs. Test conditions for each photograph are provided below the respective figure and in Appendix $C$.

Principal features visible in the flow field photographs include reflections or shadows of the thermocouples inserted through the model top into the fluid, the overflow port in the lower center region of the model and thermocouples embedded in the Plexiglass (i) floor. Refraction scattering at the fluid/

(2) Rohm \& Hass Co. 

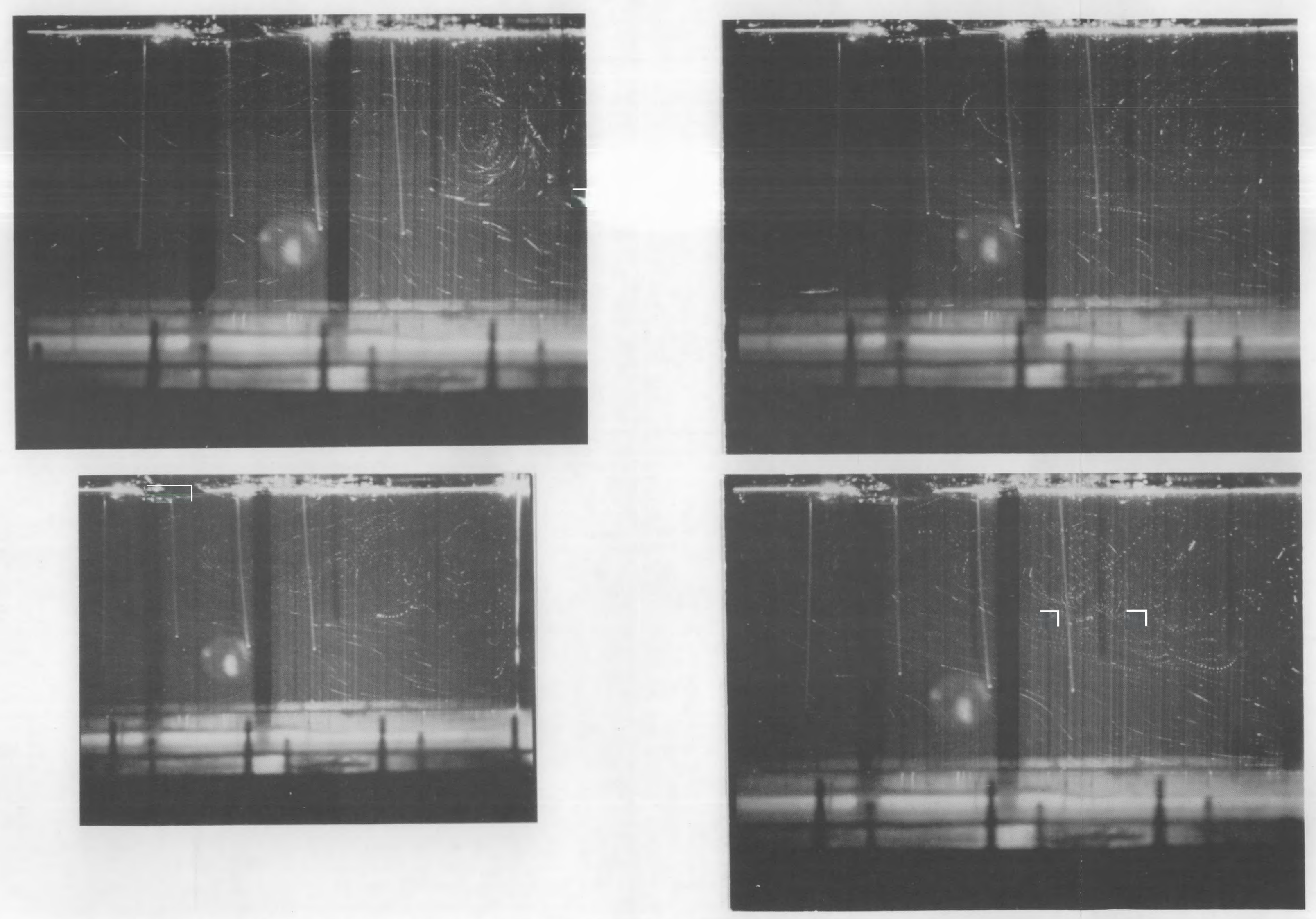

FIGURE 4.24. Bubbler Flow Rate $=0.0$ SCFH; Strobed Photographs, $t=1.0 \mathrm{sec}, \Delta t=5.0 \mathrm{sec}$, 


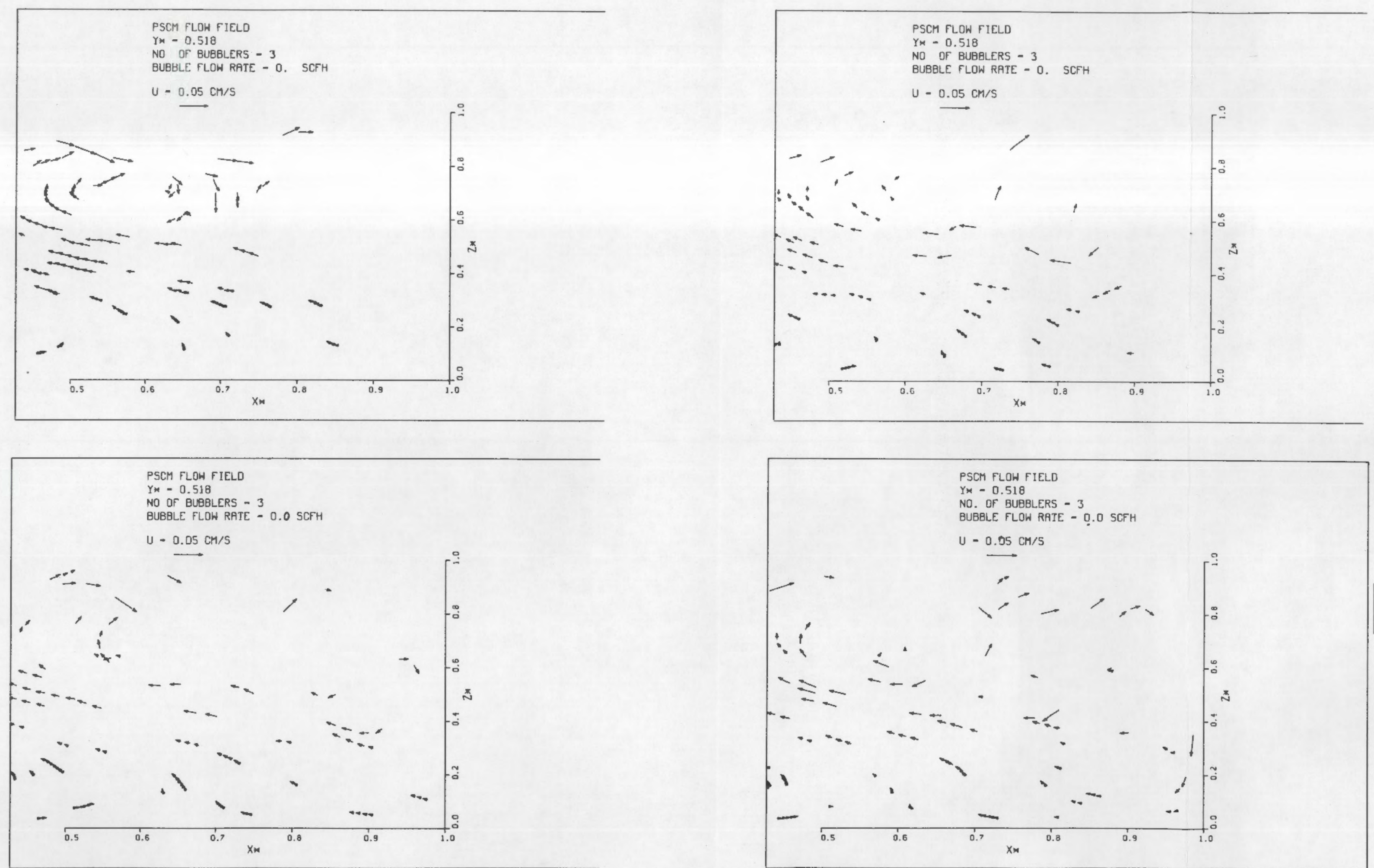

FIGURE 4.25. Vector Plots Bubbler Flow Rate $=0.0$ SCFH; $\gamma^{*}=0.518$ 



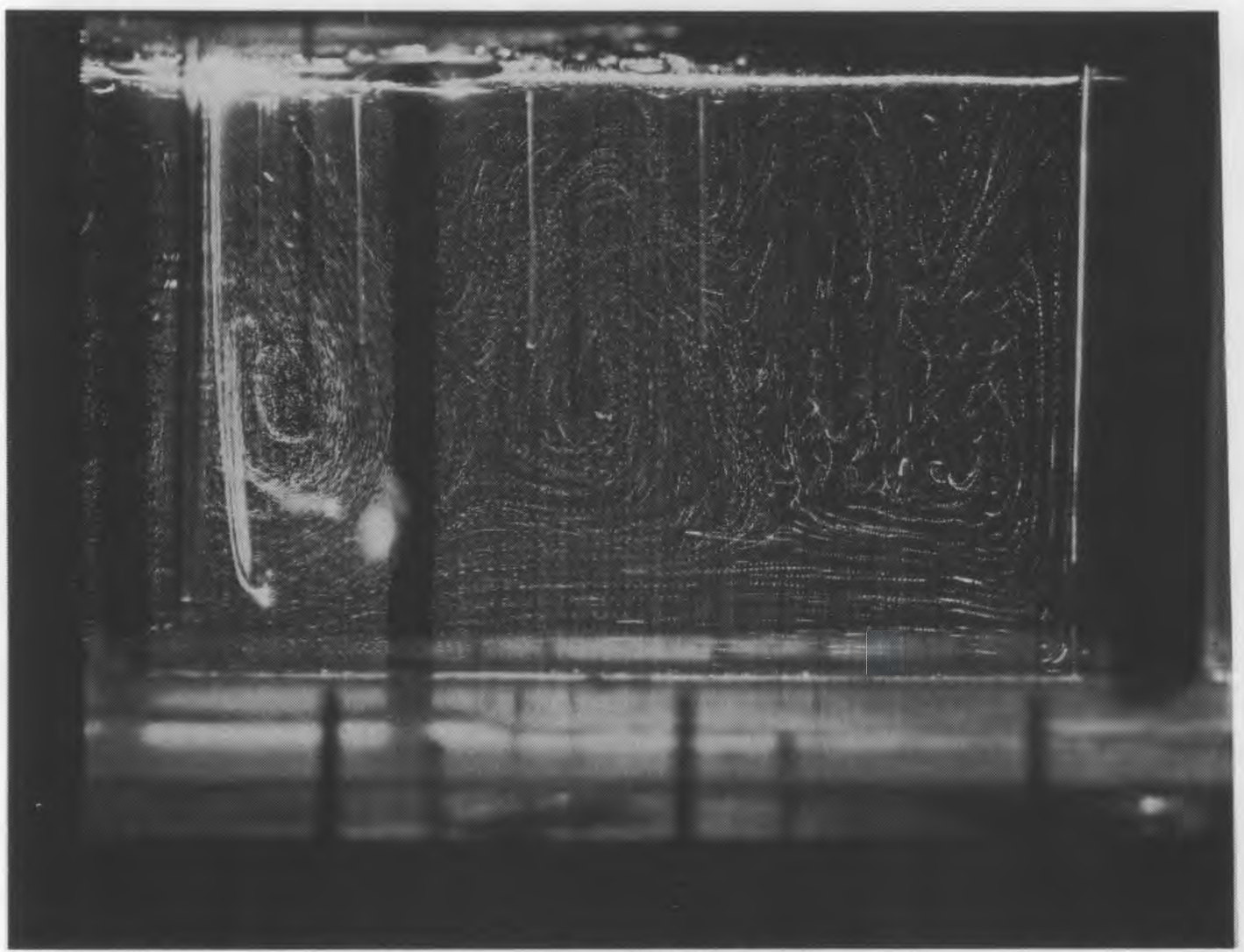

FIGURE 4.26. Bubbler Flow Rate $=0.2$ SCFH; Strobed Photograph, $t=1.0 \mathrm{sec}$, $\Delta t=5.0 \mathrm{sec} ; Y^{\star}=0.600 ;$ Three Bubblers

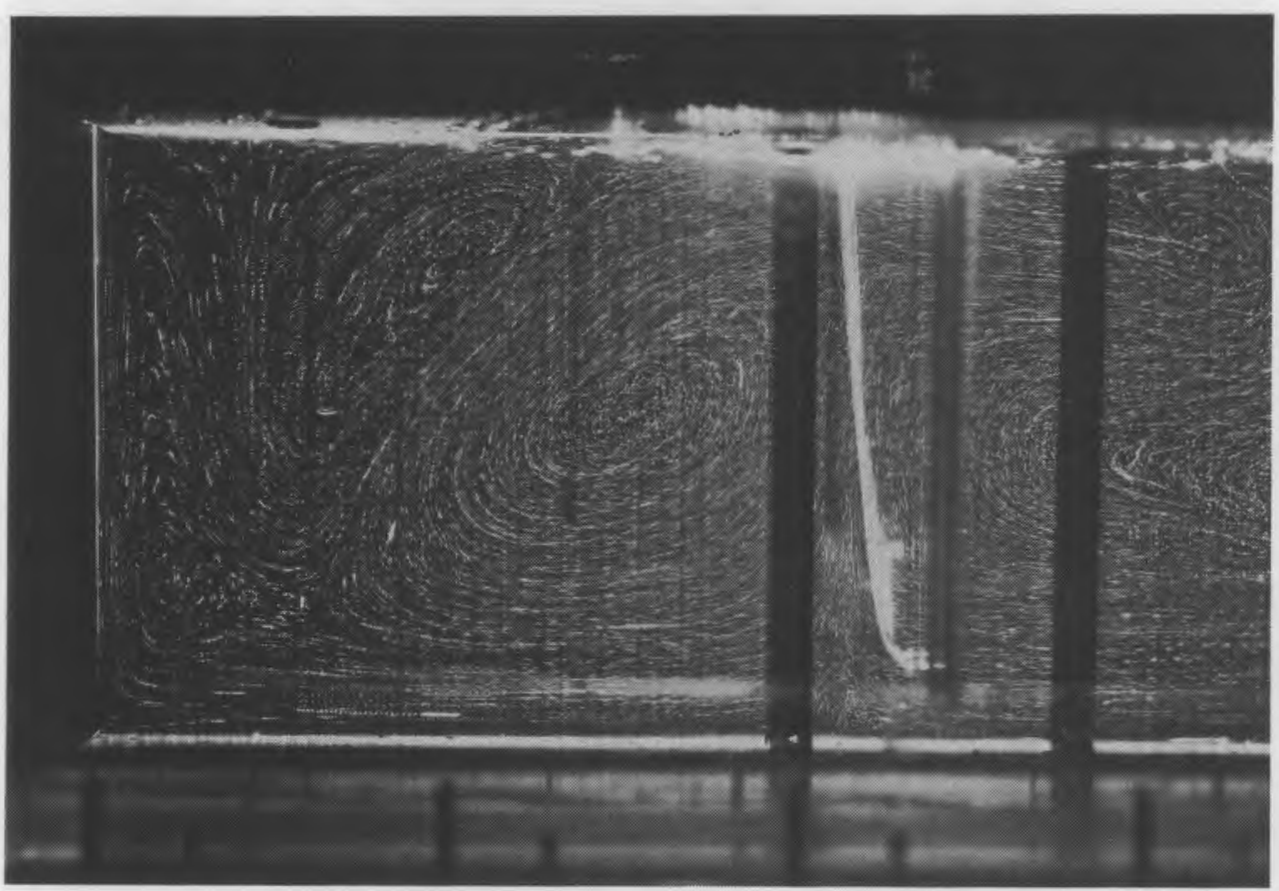

FIGURE 4.27. Bubble Flow Rate $=0.5$ SCFH; Strobe Photograph, $t=1.0 \mathrm{sec}$, $\Delta t=5.0 \mathrm{sec} ; Y^{*}=0.600 ;$ Three Bubblers 


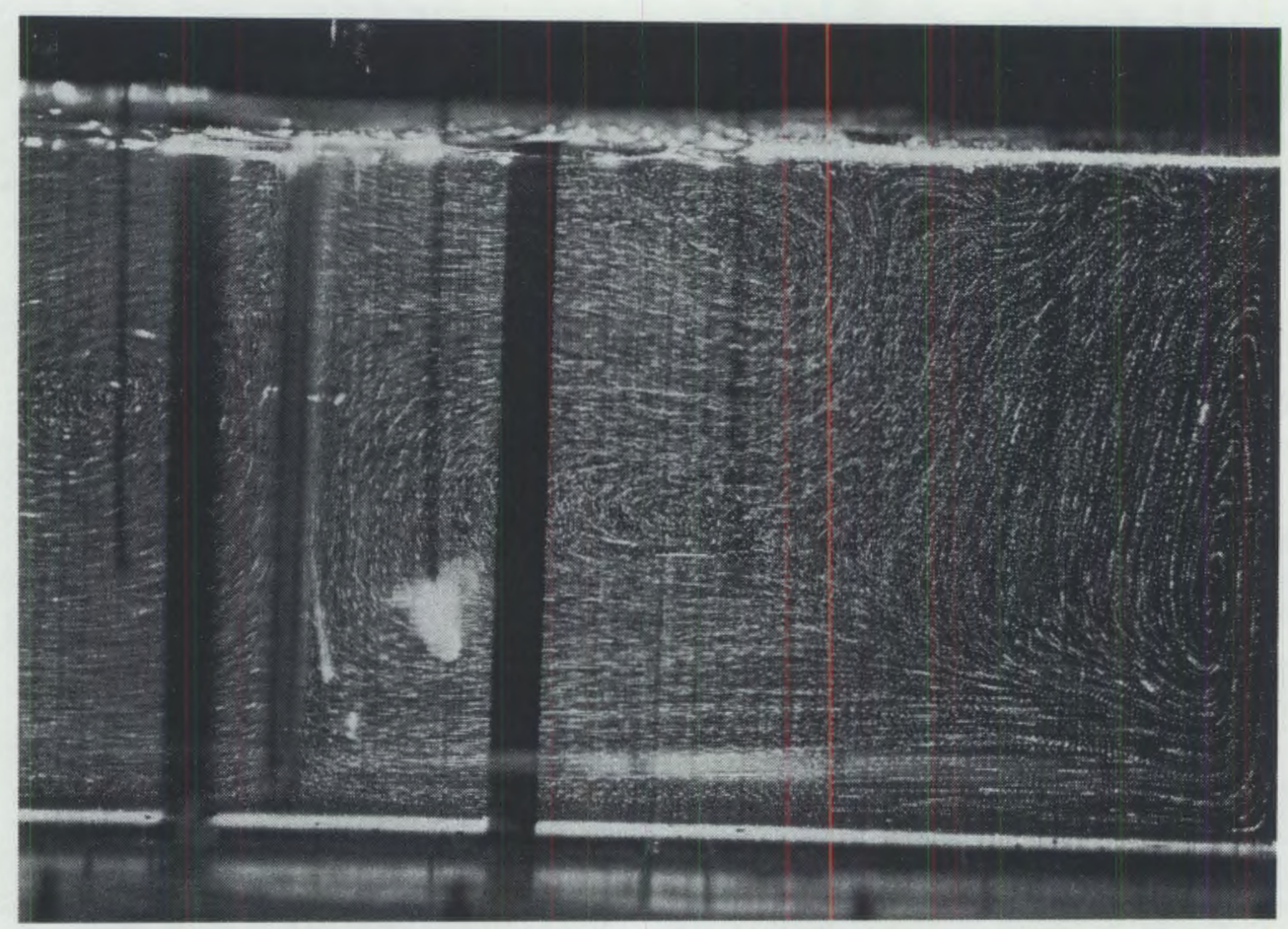

FIGURE 4.28. Bubbler Flow Rate 1.0 SCFH; Strobed Photograph, $t=1.0 \mathrm{sec}$, $\Delta t=5.0 \mathrm{sec} ; Y^{\star}=0.600 ;$ Three Bubblers

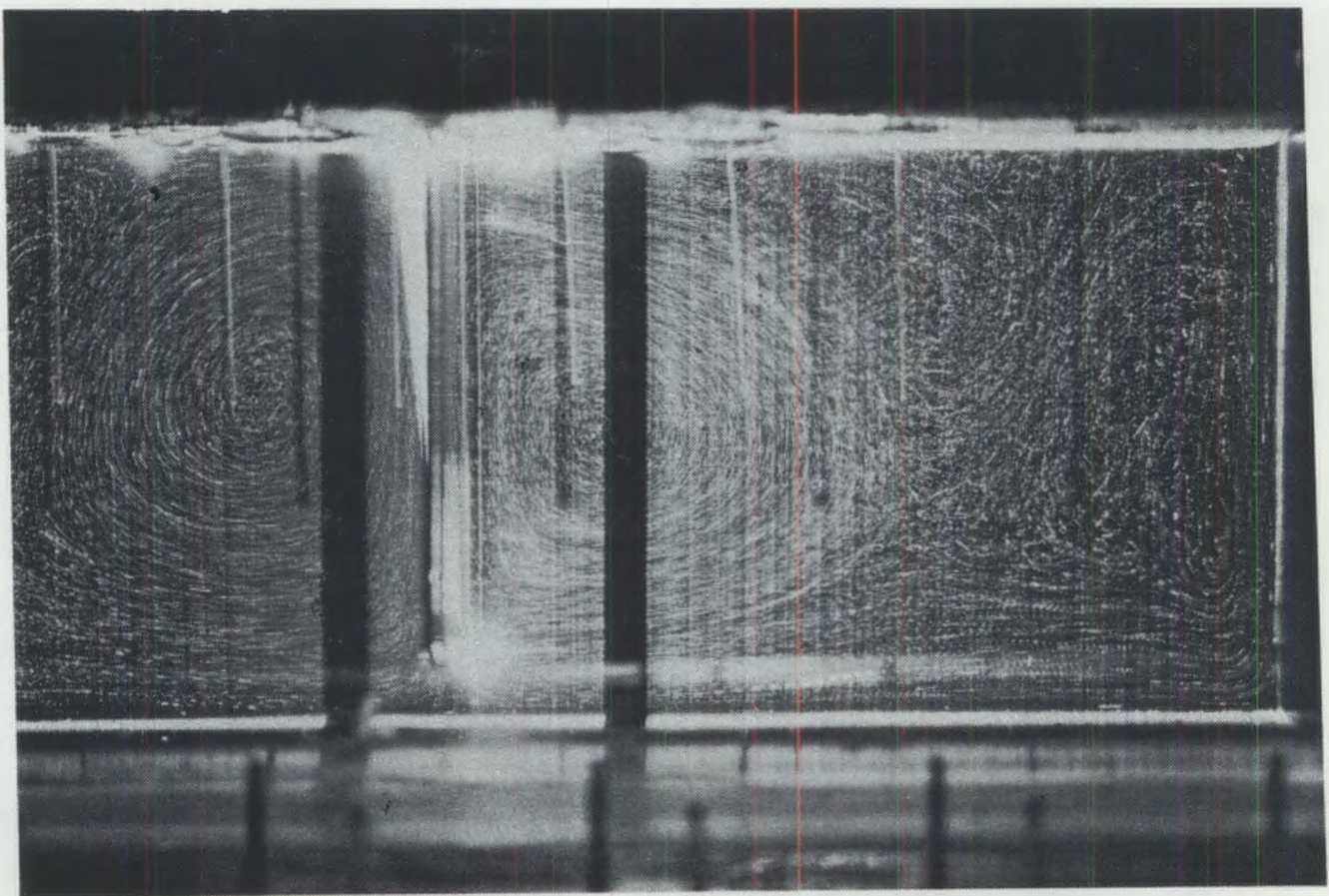

FIGURE 4.29. Bubbler Flow Rate 0.5 SCFH; Strobed Photograph, $t=1.0 \mathrm{sec}$, $\Delta t=5.0 \mathrm{sec} ; Y^{\star}=0.600 ;$ Four Bubblers 


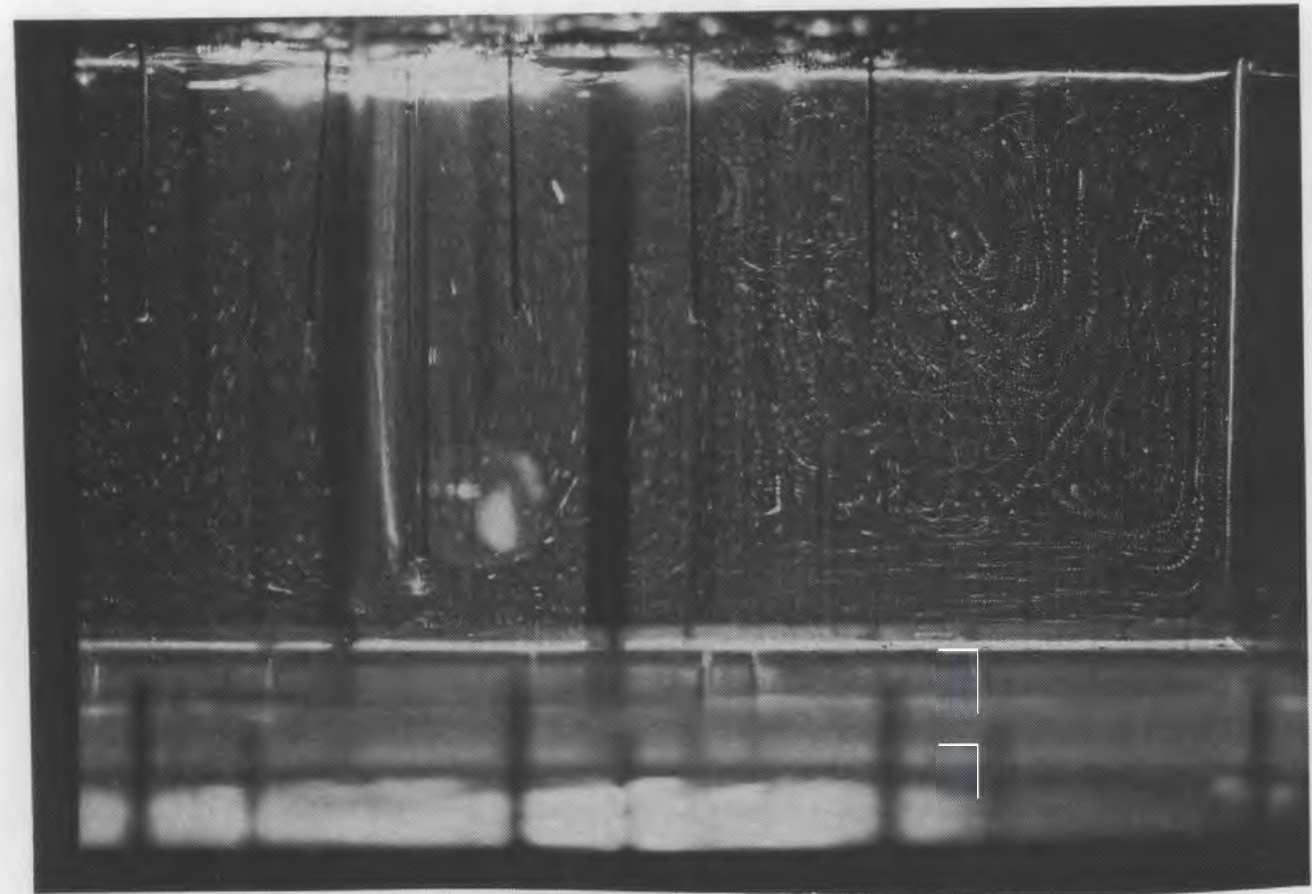

FIGURE 4.30. Bubbler Flow Rate $=0.2$ SCFH; Three Bubblers; $t=1.0 \mathrm{sec}$, $\Delta t=5.0 \mathrm{sec} ; Y^{\star}=0.276 ;$ Power $=190 \mathrm{~W} ; T_{\text {top }}=9.0^{\circ} \mathrm{C}$, $\mathrm{T}_{\text {walls }}=41.0^{\circ} \mathrm{C}, \mathrm{T}_{\text {ele }}=37.0^{\circ} \mathrm{C}$

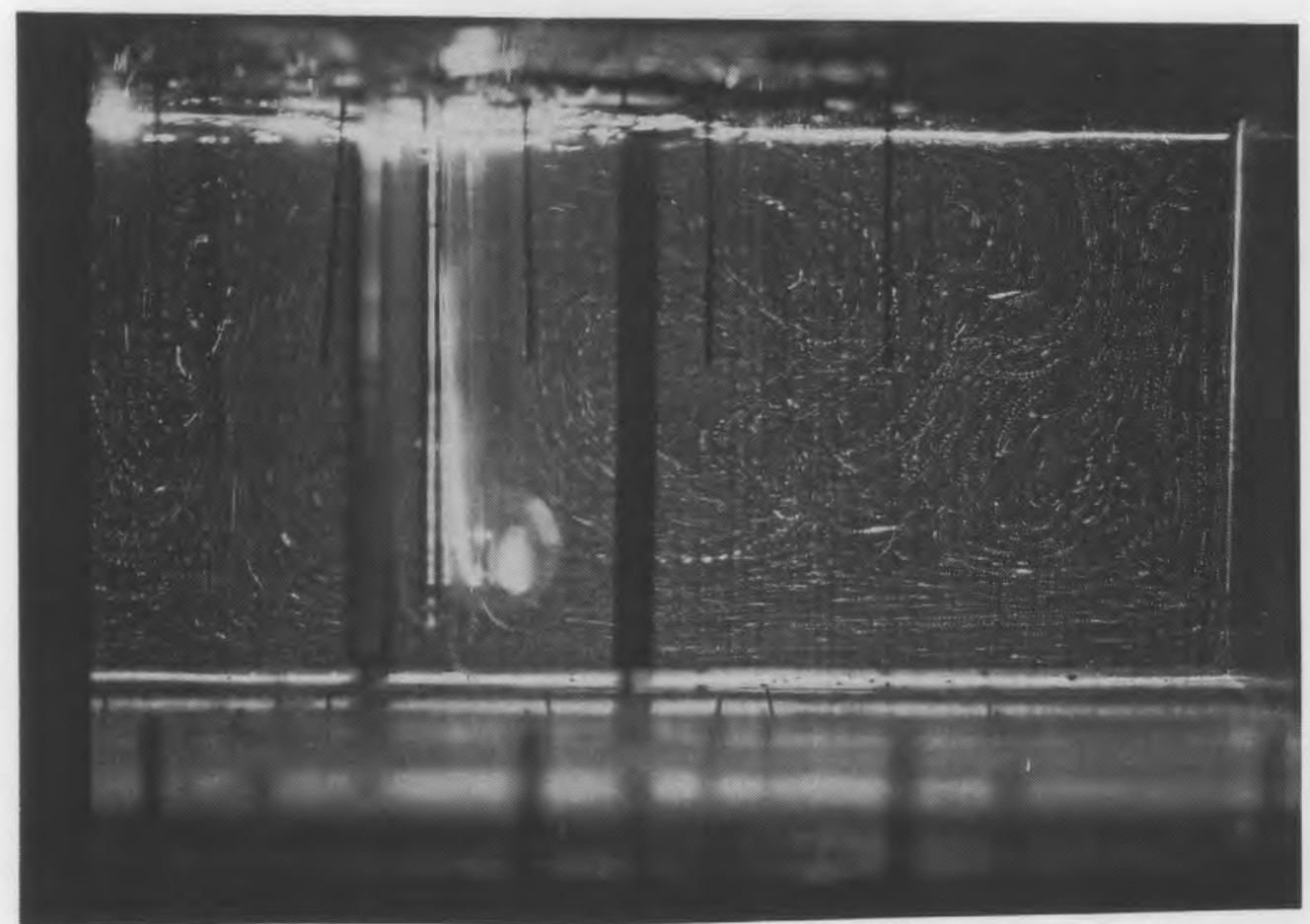

FIGURE 4.31. Bubbler Flow Rate $=0.2$ SCFH; Three Bubblers; $t=1.0 \mathrm{sec}$, $\Delta t=5.0 \mathrm{sec} ; Y^{\star}=0.171 ;$ Power $=195 \mathrm{~W}, T_{\text {top }}=9.0^{\circ} \mathrm{C}$, $\mathrm{T}_{\text {walls }}=41.0^{\circ} \mathrm{C}$, $\mathrm{T}_{\text {ele }}=37^{\circ} \mathrm{C}$ 


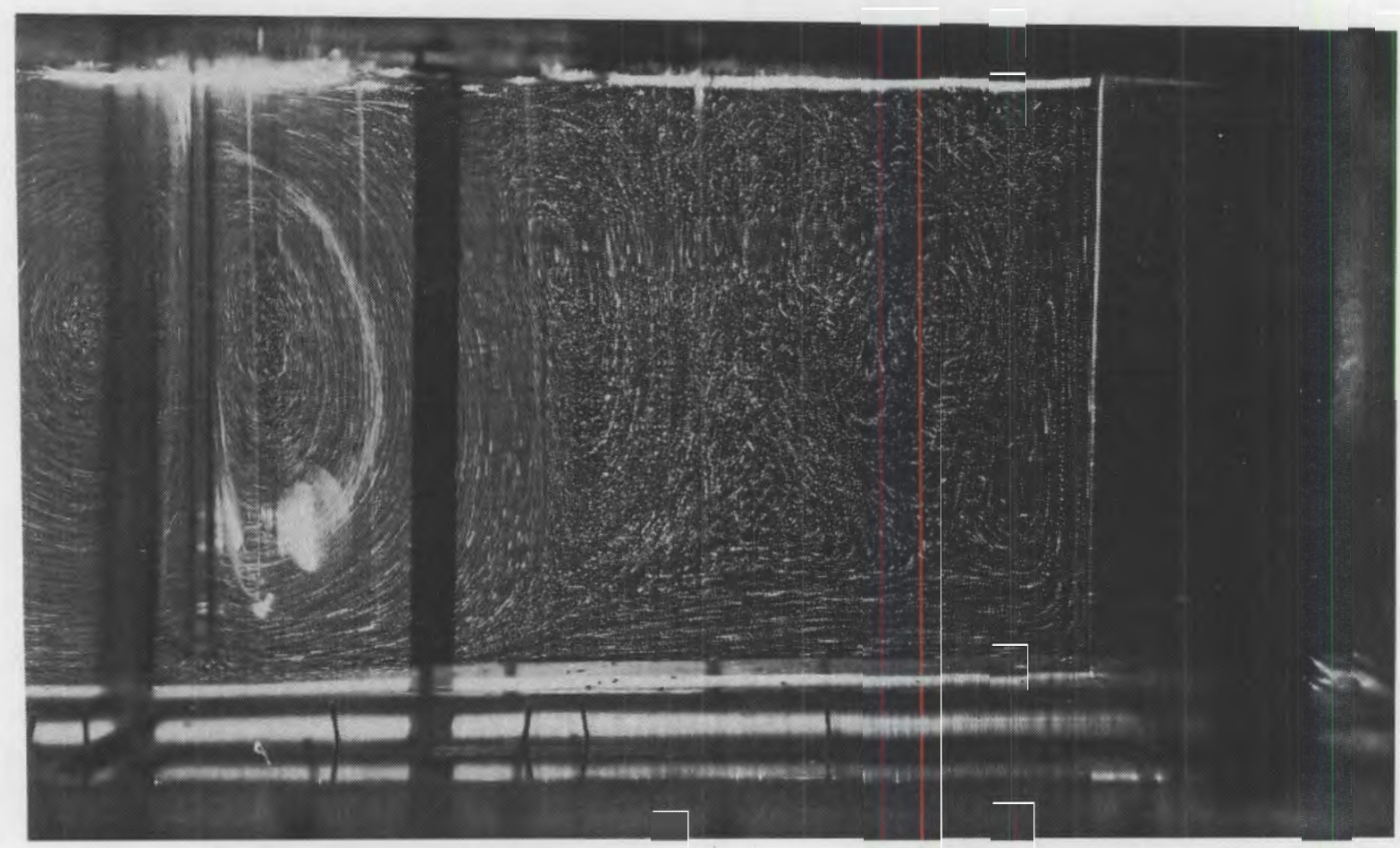

a)

PSCM FLOW FIELD

$Y \rightarrow-0.171$

NO. OF BUBBLERS - 4

BUBBLE FLOW RATE - $0.5 \mathrm{SCFH}$

$u=0.05 \mathrm{~cm} / \mathrm{s}$

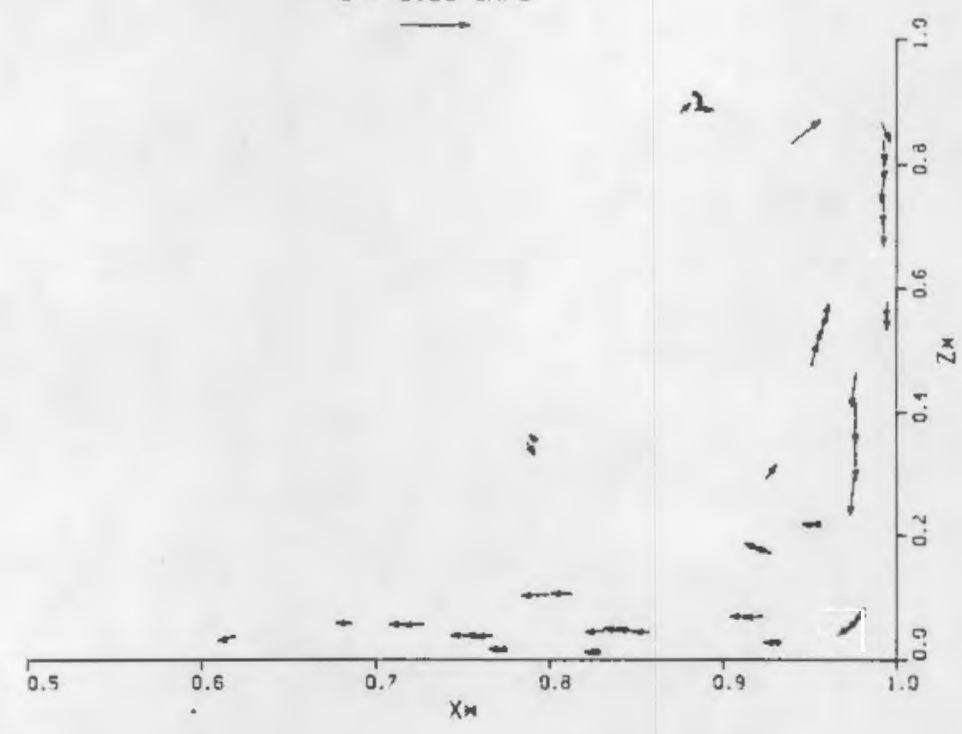

b)

FIGURE 4.32. Bubbler Flow Rate $=0.5 \mathrm{SCFH}$; Three Bubblers; $t=1.0 \mathrm{sec}$, $\Delta t=5.0 \mathrm{sec} ; Y^{\star}=0.171 ;$ Power $=171 \mathrm{~W}, T_{\text {top }}=8.0^{\circ} \mathrm{C}$, $\mathrm{T}_{\text {walls }}=46^{\circ} \mathrm{C}, \mathrm{T}_{\mathrm{elec}}=36.4^{\circ} \mathrm{C}$ 


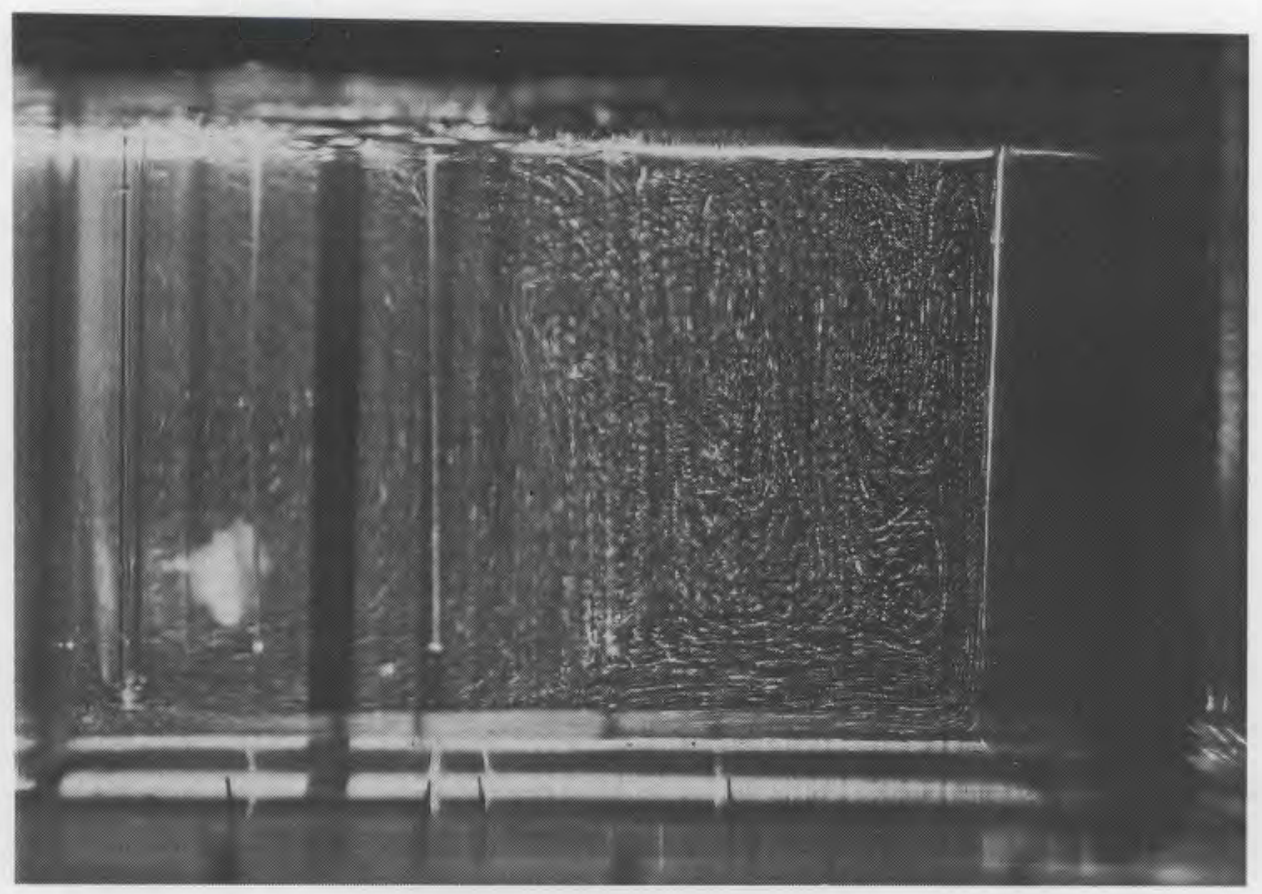

FIGURE 4.33. Bubbler Flow Rate $=1.0 \mathrm{SCFH}$; Three Bubblers; $t=1.0 \mathrm{sec}$, $\Delta t=5.0 \mathrm{sec} ; Y^{\star}=0.276 ;$ Power $=171 \mathrm{~W} ; \mathrm{T}_{\text {top }}=8.0^{\circ} \mathrm{C}$, $\mathrm{T}_{\text {walls }}=46^{\circ} \mathrm{C} ; \mathrm{T}_{\text {elec }}=38^{\circ} \mathrm{C}$

plexiglass interfaces produces horizontal light streaks at top and bottom model surfaces. Two shadows extending from top to bottom are located near the model center. The actual distance between the two shadows, which is two inches, serves as a reference distance in the light-sheet plane for photo enlargement and reduction to the desired size. Glass tubes (bubblers) appear in the bubbler photos as faint graph projections extending vertically between the reference shadows and behind the light sheet. The nitrogen gas flow in Figure 4.27 is clearly visible as a light streak exiting from the bubbler one-half inch above the model floor and extending to the fluid surface. Photographs with no bubbling in Figures 4.24 a through $4.24 d$, show a uniform flow moving downward along the electrode faces and then moving along the model bottom towards the center. The fluid approaching from both electrodes meets near the center where the warm fluid rises to the left of center.

The plate electrode study [1] which was performed with a $100 \%$ cooled top shows a symmetrical flow in the $Y^{*}$ plane about the model center. The flows in 
the $100 \%$ cooled top study move along the model bottom from both electrodes, meet at the model center, and then rise in the $Z^{*}$ direction towards the cold cap. However, the $60 \%$ offset cold cap used in the current investigation distorts the symmetry noted by Quigley and Kreid [1]. A large flow cell (eddy) rotating clockwise observed in the no bubbling photographs is bounded in the vertical direction by the cold cap and the model bottom and in the horizontal direction by the right electrode and $X^{\star}=0.18$. A smaller circulating cell rotating counter-clockwise is bounded in horizontal direction by the left electrode and $X^{\star}=0.18$ and also extends from the cold cap to the bottom in the vertical direction. A region of chaotic flow was observed inside the right eddy where the flow patterns were not discernible. The distortion of flow in the $60 \%$ offset cold cap study, relative to the $100 \%$ cold cap study [1] is also observed in the upwelling of warm fluid from the model bottom. The fluid upwelling in the $100 \%$ cooled top study occurred with fluid rising in only the $Y^{*}$ direction in the $60 \%$ offset cold cap study, fluid does not rise perpendicular to the model floor, but is inclined towards the left electrode $\left(X^{*}=0\right)$. The motion of the upwelling fluid towards the left electrode as the fluid rises appears to result from an increasing temperature gradient in the $x^{\star}$ direction. Near the top the flows separate and move toward the electrodes where the cooled flow again descends along the electrode faces.

The vectorially plotted flow field shown in Figures 25 a through $25 \mathrm{~d}$ correspond to the no bubbler tests of Figures $24 \mathrm{a}$ through $24 \mathrm{~d}$. The distorted flow direction previously described for the $60 \%$ offset cold cap is clearly shown in these figures. The vector plots are useful since relative velocity magnitudes can be determined in addition to flow direction. For example the low fluid velocities near the model bottom increase as the flow rises and then moves along the top towards the electrode. Average flow velocities were calculated for fluid near the floor since this region, $0.00 \leq Z^{\star} \leq 0.20$, was observed to have stable flow. Average velocities were $5.2 \times 10^{-3} \mathrm{~cm} / \mathrm{s}, 3.5 \times 10^{-3} \mathrm{~cm} / \mathrm{s}$, $4.2 \times 10^{-3} \mathrm{~cm} / \mathrm{s}$, and $4.2 \times 10^{-3} \mathrm{~cm} / \mathrm{s}$ for Figures $20 \mathrm{a}$ through $20 \mathrm{~d}$ respectively. The corresponding prototype velocities predicted from scaling are: $3.9 \times 10^{-3} \mathrm{~cm} / \mathrm{s}, 2.6 \times 10^{-3} \mathrm{~cm} / \mathrm{s}, 3.2 \times 10^{-3} \mathrm{~cm} / \mathrm{s}$, and $3.2 \times 10^{-3} \mathrm{~cm} / \mathrm{s}$. For comparison with the no-bubbler results, quantitative measurements from the 0.5 SCFH bubbler run are shown in Figure $4.32 \mathrm{~b}$ which correspond to the flow 
photograph, Figure 4.32a. An average velocity for flow along the rodel flow at $0.0<z^{\star} \leq 0.2$, was $1.9 \times 10^{-2} \mathrm{~cm} / \mathrm{s}$ corresponding to a glass velocity of $1.4 \mathrm{x}$ $10^{-2} \mathrm{~cm} / \mathrm{s}$. These preliminary quantitative results suggest that bubbie induced mixing increases fluid velocities near the boundaries as well as the fluid velocities at the melter center.

Because of the difficulties in obtaining quantitative velocity measurements in the higher velocity regions of the bubble photographs, these results are discussed qualitatively. The bubbler photographs, Figures 4.26 through 4.29 , show two principal counter rotating cells with higher model filuid velocities near the model center. Similar to the no bubble photographs, uniform flow is observed moviny downward along the electrode faces and along the nodel floor away from the electrodes and towards the center. The bubbler induced fluid flow is symmetric about the melter center. IJpelling of warm fluid occurs only in vertical, $Z^{*}$ direction as opposed to the inclined upwelling observed in the no bubbler photographs. Secondary eddies are located between an electrode and a primary circulating eddy and counter-rotate with respect to the adjacent primary eddy. At a nitrogen flow rate of 0.2 SCFH, secondary eddies were not well defined and occasionally appeared to breakdown into regions of instability. Secondary eddies are ruch more apparent in the 0.5 and 1.0 SCFH photographs. The primary eddies at the model center appear to penetrate further into the fluid in the $x^{*}$ direction with increasing bubble flow rate. The eddy size in the $x^{\star}$ direction for the primary eddies are 0.161 $\leq \Delta x^{\star}$ $\leq 0.214,0.250 \leq \Delta X^{*} \leq 0.286$ and an $\Delta x^{*}$ of approximately 0.321 for bubbler rate of $0.2,0.5$ and $1.0 \mathrm{SCFH}$ respectively.

The flow field in the no bubbling case is distorted in the $y^{*}$ plane due to use of a $60 \%$ offset cold cap. Relative sizes of the right and left counter rotating circulating cells and upwelling of warm fluid are affected by the cold cap location and size. Bubbling induced principal or primary eddies which are symmetrical about the model center, $x^{*}=0.500$. Secondary eddies as well as the principal eddies are responsible for fluid mixing which results in a more uniform temperature in both the vertical and horizontal directions. Bubbler induced mixing appear to promote increased fluid velocities in the lower velocity region alony the bottom. Therefore, particle settling could also be deterred in these regions. 


\subsection{PSCM POTENTIAL MEASUREMENTS}

Tabulated results of the electrical potential traverses are provided in Appendix D. Fluid potential measurements were made with respect to the negative electrode. Heasurements were nondimensionalized with respect to the voltage applied across the electrodes. Identical nondimensionalized linear profiles were observed in the $x^{*}$ direction independent of bubbler number or bubble flow rate. No variation in potential was detected at locations near the wal1. Only periodic measurements were made during 1.0 SCFH bubbling and the four bubbler testing. The periodic measurements were consistent with those provided in Appendix D. 


\subsection{CONCLUSIONS AND RECOMMENDATIONS}

Two glass melters, the PSCM and BIPP were tested during the 1984 glass melter modeling effort. A preliminary investigation of the upper to lower eiectrode power ratio was performed for the BIPP melter. Investigation of electrode spacing and additional electrode power ratio testing are intended as part of a future modeling effort. Effects of bubble flow rate, bubbler number, and cold cap size and location were investigated using the PSCM. Other parameters which will affect melter design, therefore requiring investigation include: bubbler size, bubbler location, conductive sludge formation, and electrode separation distances. All PSCM testing was performed with the simulated $60 \%$ offset cold cap. The influences of cold cap size and location were considered by comparing the $60 \%$ offset cold cap resuits with $100 \%$ simulated cold cap/plate electrode results performed by Quigley and Kreid [1].

\section{1 .1 Conclusions - BIPP Testing}

The following conclusions are based on the preliminary BIPP results presented in Section 4. A uniform temperature existed in the horizontal plane of the melter except near the boundaries in all test runs. Large temperature stratification of $150^{\circ} \mathrm{C}$ is predicted in the vertical plane of the melter for a U/L EPR of 1.0:0.0. The temperature variation predicted in the vertical meiter plane was reduced to $64.1^{\circ} \mathrm{C}$ for a $U / L$ EPR of $0.5: 0.5$. The cold cap provided only a slight influence on fluid temperatures at a measurement depth of $z^{*}=$ 0.81. No cold cap influence on temperature was observed at greater depths.

A large variation in fluid velocity between the upper and lower fluid regions existed for a U/L EPR of 1,0:0.0. Higher fluid velocities (approximately $0.02 \mathrm{~cm} / \mathrm{s}$ to $0.05 \mathrm{~cm} / \mathrm{s}$ ) were obtained for $Z^{\star}>0.5$, relative to the small flow velocities (less than $0.01 \mathrm{~cm} / \mathrm{s}$ ) for $Z^{\star}<0.4$. Larger overall velocities and greater penetration of mixing were obtained for BPRISN-3, U/L EPR of 0.26:0.74. Difficulty in asserting flow direction precluded presenting these data in vector plot form.

Preliminary conclusions from BIPP test results indicate that an upper to lower electrode power ratio of $1.0: 0.0$ is a poor operating configuration because large glass temperature variations and inadequate mixing exist. An 
upper to lower electrode power ratio of 0.26:0.74 is an improved operating configuration because larger and more developed convection celis occur in the inodel. Supplying joule heating using two independently fired electrode pairs, provides the ability to vary the power density ratio of the upper and lower fluid regions, which is not possible with a single electrode pair.

\section{1 .2 Conclusions - PSCM Testing}

Well defined temperature stratification was observed in both the $60 \%$ offset cold cap and $100 \%$ cold cap studies with no bubbling. However, in the 60\% offset cold cap study a temperature gradient also existed in the $x^{*}$ direction as well as in the $Z^{*}$ (vertical) direction. Uniform temperatures were observed in the $x^{\star}$ direction in $100 \%$ cold cap study. While the flow field was symetric about $x^{\star}=0.500$ in the $100 \%$ cold cap study, a distorted or nonsyminetrical f10w field about $x^{\star}=0.500$ occurred during the $60 \%$ offset testing. Testing with the $60 \%$ centered cold cap was not performed, but based on the above results, one might expect a symmetric flow field about $x^{\star}=0.500$ and temperature gradient (nonuniform temperatures) in the $X^{*}$ direction for $Z^{\star}>0.500$.

Use of bubblers enhanced fluid mixing which resulted in a more uniform temperature throughout the PSCM model. A inore uniform temperature provides less regions in the melter conducive to crystallization. As indicated in subsection 4.0 , melter to model scaling of bubble flow rates was not performed. Bubble flow rate scaling can and should be performed to provide some indication of tube size and flow rate within the melter. Temperature traverses indicate that sufficient mixing occurs to obtain uniform modeling fluid/glass temperatures using three bubblers. Improvement in mixing was not observed using four bubblers in the model which suggests no benefit is gained using a four bubbler system in place of a three bubbler system. Stratification was apparent for a nitrogen flow rate of 0.2 SCFH while a nitrogen flow rates of 0.5 SCFH provided sufficient mixing to obtain uniform temperatures (excluding the region near the cold cap) in the melter model. No additional benefit was gained, in the model (in terms of mixing) increasing the nitrogen flow rate from $0.5 \mathrm{SCFH}$ to 1.0 SCFH. Higher fluid velocities were bubbler induced in the laninar flow region near the melter bottom. Preliminary results indicated that fluid 
velocities for a bubbling flow rate of 0.5 SCFH near the floor were over four times larger than fluid velocities during model operation without bubblers. Increased fluid velocity can possibly deter particle setting.

Bubbling rate and bubbler numbers had no observable effect on the potential field. Nondimensionalizing the potential measurements with respect to the applied electrode voltage provides the identical linear potential profile for ail runs. Comparison of potential results with the results of Quigley and Kreid, also suggest that cold cap orientation also produces no observable change in the potential field.

\subsection{RECOMMENDATIONS}

The following actions and investigations are recomended based on the prelininary evaluation of these resuits and comparison with the previous physical modeling study [1].

- Bubbler installation for the PSCM should be considered to improve overall fluid mixing.

- Preliminary BIPP model results indicated that the two independently fired electrodes, had a definite influence on fluid mixing. Results were insufficient to propose a best electrode operating configuration. However, results indicate that:

- a U/L EPR of 1.0:0.0 is an undesirable electrode operating configuration which should be avoided to deter particle setting and crystallization.

- a U/L EPR of 0.26:0.74 provides better overall mixing and may be a suitable operating configuration.

- upper to lower electrode crossfiring is a possible complication that should be investigated in greater detail. 
- Thermophysical properties such as themal conductivity, $k$, and specific heat, $c_{p}$, of proposed glasses should be measured in addition to the currentiy measured glass viscosity and electrical conductivity. These property measurements are required to assess the validity of both the numerical and physical models.

- Melter system operating data such as actual operating power, boundary temperatures, fluid temperatures, and heat losses should be provided when available for model verification.

- Scaling criteria can and should be developed to relate model/melter bubble mixing effects.

- Instrumentation to measure cold cap heat losses should be implemented in future physical modeling studies. This information would provide a data base for comparison to empirical correlations which may be suitable for estimating the actual melter cold cap heat losses.

- Time varying flow phenonena should be investigated to determine overa11 eddy variation and examine periodices that may exist. Because of the unstable nature of the glass flow, "flow movies" would assist in evaluating flow mixing. This would also provide a data base for prototype operation and numerical modeling. 


\section{REFERENCES}

1. Quigley, M. S. and D. K. Kreid. "Physical Modeling for Joule Heated Ceramic Glass Melters for High Leve1 Waste Immobilization," PNL-2809/UC-70, prepared for the U.S. Department of Energy by Battelle, Pacific Northwest Laboratories, Richland, Washington, 1979.

2. Stanek, J. Electric Melting of Glass, Elsevier Scientific Publishing Company, New York, New York, 1977.

3. Bird, B. R., W. E. Stewart and E. N. Lightfoot. Transport Phenomena, John Wiley and Sons, Inc., New York, New York, 1960.

4. White, F. M. Viscous Fluid Flow, McGraw Hill Publishing Co., New York, New York, 1974.

5. Schlichting, Dr. Hermann. Boundary-Layer Theory, McGraw-Hill Publishing Co., New York, New York, 1968.

6. Schenck, H. Jr., Theories of Engineering Experimentations. McGraw-Hill Book Company, New York, New York, 1961.

7. Taylor, R. E., and H. Groot, Thermophysical Properties of Glycerine/ Lithium Chloride Solutions, TPRL 395, Thermophysical Properties Research Laboratory, Purdue Iniversity, Indiana, July 1984.

8. Taylor, R. E., H. Groot and R. L. Shoemaker, Thermophysical Properties of Glass, TPRL 191A Thermophysical Properties Research Laboratory, Purdue University, Indiana, August 1979.

9. Ross, W. A., et al., Annual Report on the Characterization of High-Level Waste Giasses. PNL-2625, Pacific Northwest Laboratories, RichTand, Washington, June 1978.

10. Mendel, J. E., Annual Report on the Characterization of High-Level Waste Glasses. BWNL-2252, Battelle, Pacific Northwest Laboratories, Richland, Washington, June 1977.

11. Chick, L. A., et al., West Valley High-Level Nuclear Waste Glass Development: A Statistically Designed Mixture Study. PNL-4997, Pacific Northwest Laboratories, Richland, Washington, October 1984.

12. Holman, J. P. Heat Transfer, McGraw Hill Publishing Co. New York, New York, 1981.

13. ASHRAE Handbook, 1977 Fundamentals, American Society of Heating, Refrigeration, and Air-Conditioning Engineers, New York, New York, 1978. 
. 
APPENDIX A

NOMENCLATURE 


$$
\begin{aligned}
& \mathrm{A}=\text { area } \\
& c_{p}=\text { specific neat } \\
& \text { D = fluid depth } \\
& B r=\text { Brinkman number }=\frac{\mu(U / L)^{2}}{k \Delta T / L^{2}} \\
& E c=\text { Eckert number }=\frac{v^{2}}{C_{p} \Delta T} \\
& E P R=\text { Electrode power ratio } \\
& \mathrm{Ga}=\mathrm{Galileo} \text { number }=\frac{\mathrm{g} \mathrm{L}^{3}}{v^{2}} \\
& \mathrm{Gr}=\text { Grashof number }=\frac{g B \Delta \mathrm{TL}^{3}}{\nu^{2}} \\
& \mathrm{H}=\text { volumetric neat generation rate } \\
& K=\text { thermal conductivity } \\
& \mathrm{L} \quad=\mathrm{a} \text { length or dimension } \\
& \mathrm{Nu}=\text { Nusselt number }=\frac{\mathrm{hL}}{\mathrm{K}} \\
& \mathrm{p} \quad=\text { pressure or power } \\
& \text { Pe }=\text { Peclet number }=\operatorname{RePr}=\frac{U L}{\alpha} \\
& \text { Pr }=\text { Prandtl number }=\frac{\nu}{\alpha}=\frac{\mu C_{p}}{R} \\
& Q=\text { Heat transfer rate } \\
& \text { Ra }=\text { Raleigh number }=\mathrm{GrPr}=\frac{\mathrm{gB \Delta T \textrm {TL } ^ { 3 }}}{\nu \mathrm{a}} \\
& \text { Re }=\text { Reynolds number }=\frac{U L}{v}
\end{aligned}
$$




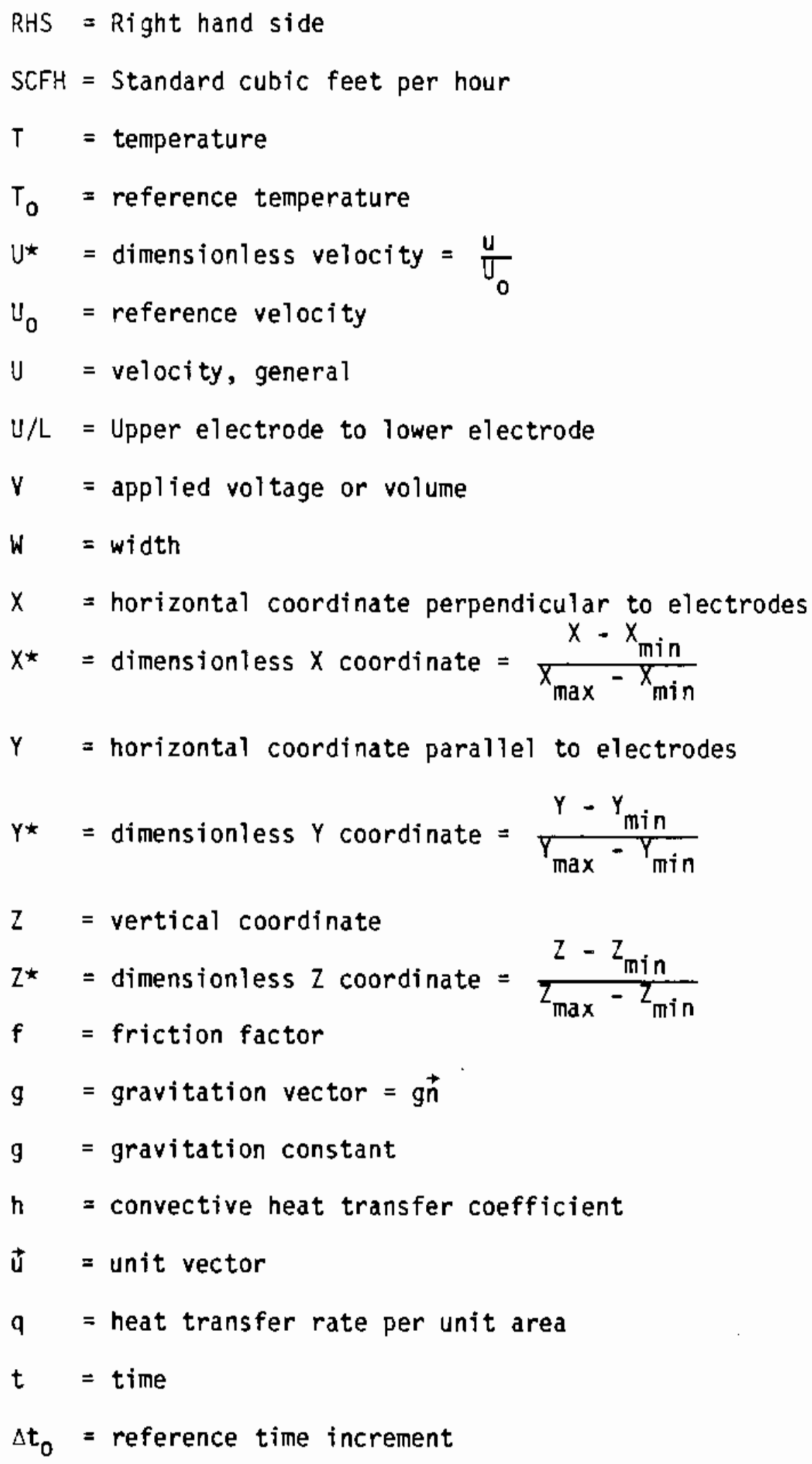




\section{Greek Symbols}

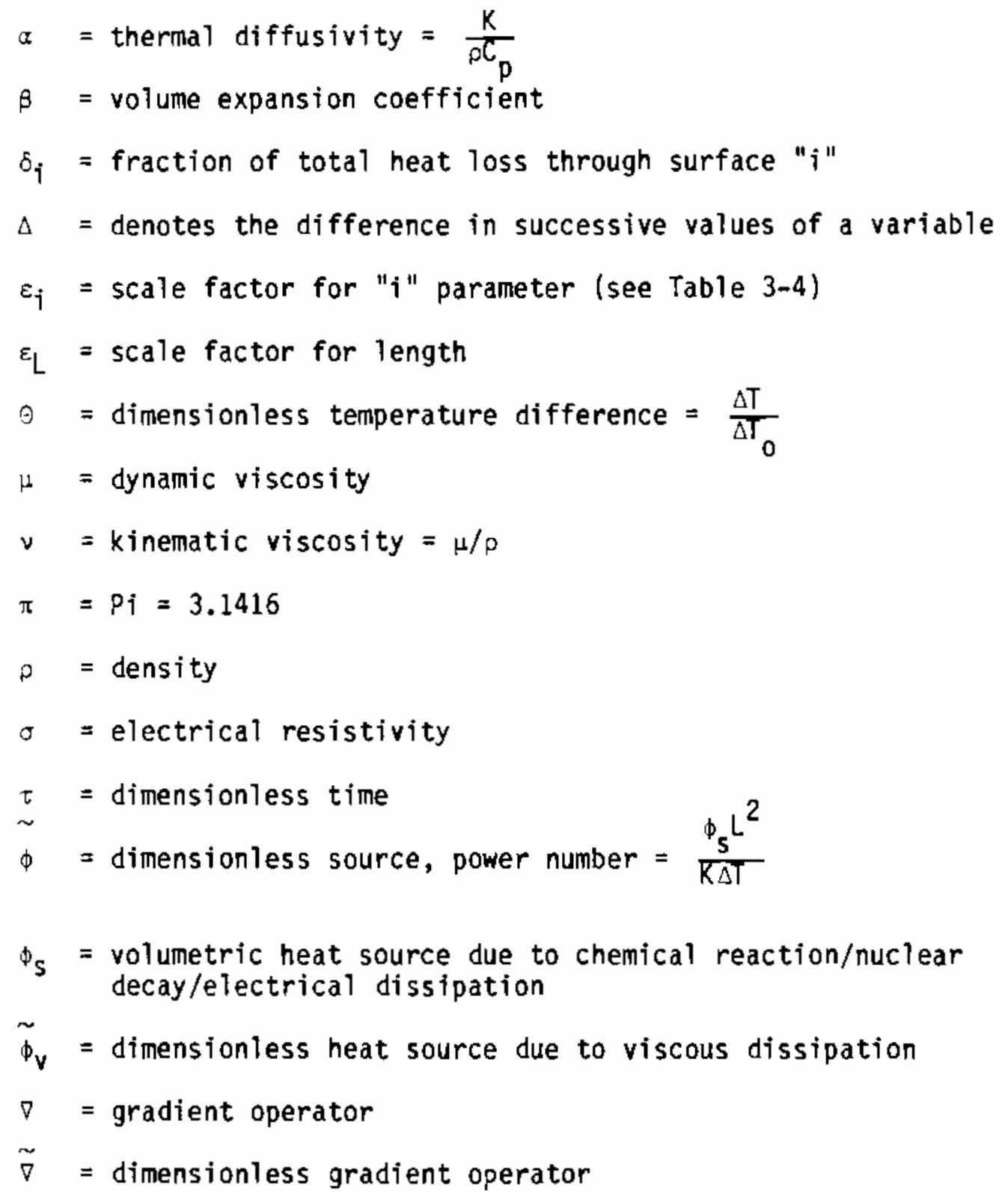

\section{Subscripts}

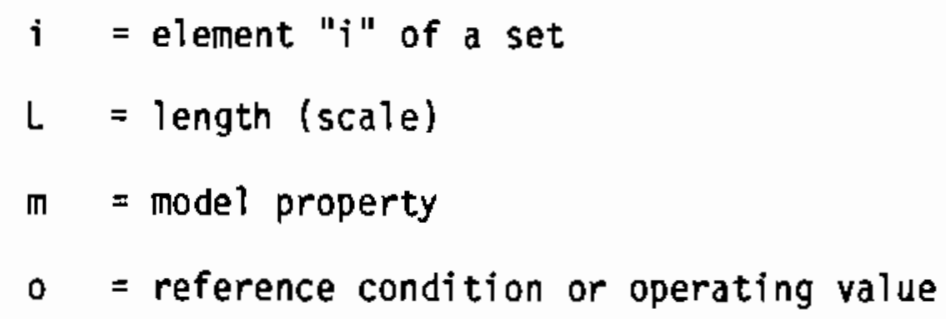




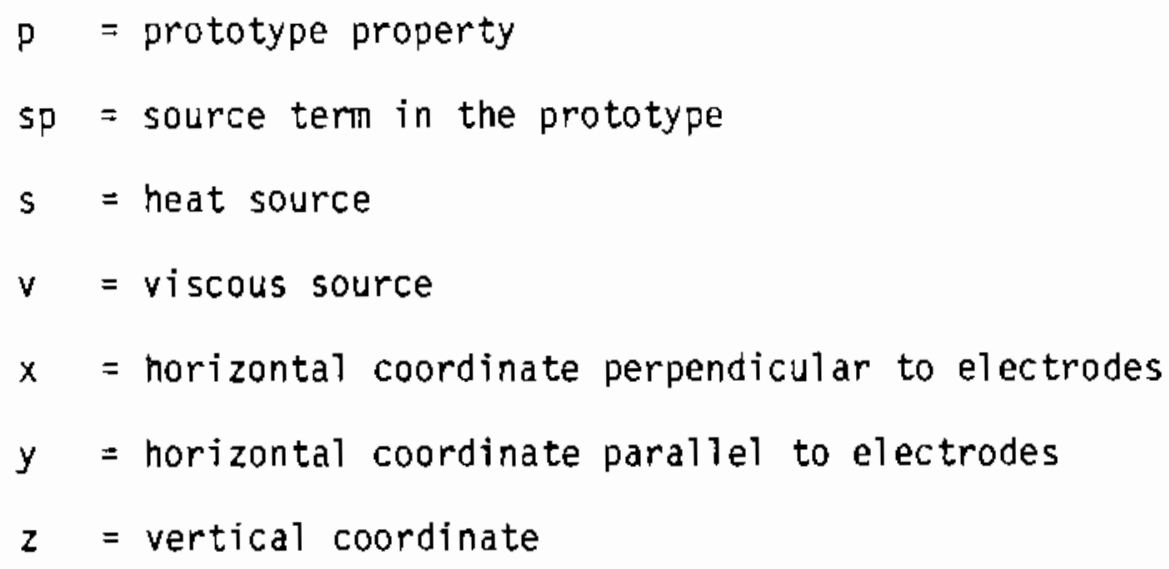


APPENDIX $B$

MODEL FLUID TEMPERATURE DATA 
BIPP MODEL FLUID TEMPERATIJRE DATA

TABLE B.1-1. Temperature Field lleasurements

$y^{*}=0.500 ;$ Fluid Temperature $\left({ }^{\circ} \mathrm{C}\right)$

$\begin{array}{llr}\text { Electrodes } & T=40^{\circ} \mathrm{C} & \text { U/L EPR: } \\ \text { Walls } & \mathrm{T}=45^{\circ} \mathrm{C} & \text { Upper } 100 \% \\ \text { Top } & \mathrm{T}=8.5^{\circ} \mathrm{C} & \text { Lower } 0 \%\end{array}$

\section{Electrode Characteristics}

Upper Electrode: Lower Electrode: Voltage 119 VAC Voltage 21. VAC Current 2.23 A Current $<0.15 \mathrm{~A}$

Power 264. U Power -- W

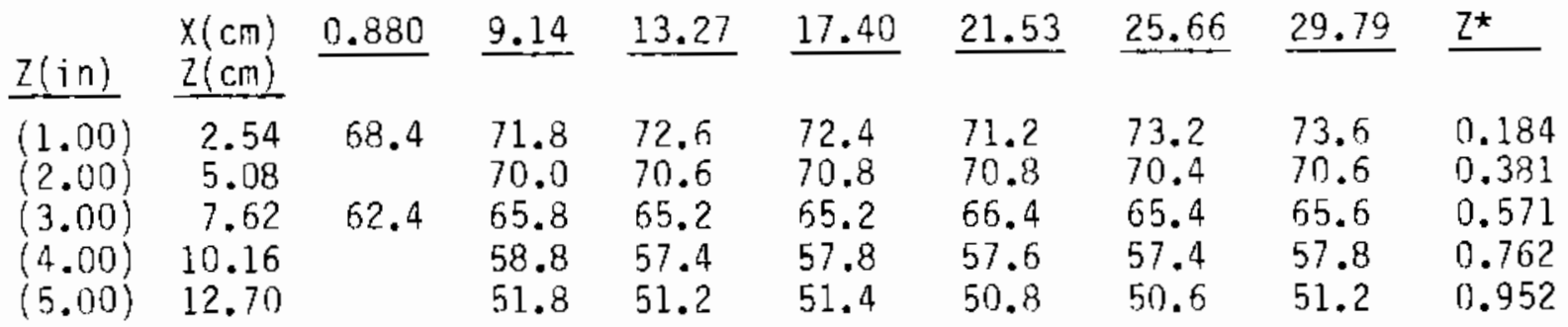

\begin{tabular}{|c|c|c|c|c|c|c|c|c|}
\hline \multirow{2}{*}{$x^{\star}=$} & & 0.023 & 0.240 & 0.348 & 0.457 & 0.565 & 0.674 & 0.782 \\
\hline & $x(i n)$ & $(0.188)$ & $(3.60)$ & $(5.22)$ & $(6.85)$ & $(8.43)$ & $(10.10)$ & $(11.73)$ \\
\hline
\end{tabular}


TABLE B.1-2. Temperature Field Measurements $\gamma^{*}=0.500 ;$ Fluid Temperature $\left({ }^{\circ} \mathrm{C}\right)$

$\begin{array}{lll}\text { Electrodes } & T=38^{\circ} \mathrm{C} & \text { Power Skew: } \\ \text { Walls } & \mathrm{T}=45^{\circ} \mathrm{C} & \text { Upper } 50 \% \\ \text { Top } & T=86^{\circ} \mathrm{C} & \text { Lower } 50 \%\end{array}$

\section{Electrode Characteristics}

$\begin{array}{ll}\text { Upper Electrode } & \text { Lower Electrode } \\ \text { Voltage } 79.5 \mathrm{VAC} & \text { Voltage } 87 \text { VAC, } \\ \text { Current } 1.19 \mathrm{~A} & \text { Current } 1.03 \mathrm{~A} \\ \text { Power } 94.6 \mathrm{~W} & \text { Power } 89.6 \mathrm{~W}\end{array}$

\begin{tabular}{|c|c|c|c|c|c|c|c|c|c|}
\hline (in) & $\begin{array}{l}X(\mathrm{~cm}) \\
Z(\mathrm{~cm})\end{array}$ & 0.880 & 9.14 & 13.27 & 17.40 & 21.53 & 25.66 & 29.76 & 38.05 \\
\hline $\begin{array}{l}(1.00) \\
(2.00) \\
(3.00) \\
(4.00) \\
(5.00)\end{array}$ & $\begin{array}{r}2.54 \\
5.08 \\
7.62 \\
10.16 \\
12.70\end{array}$ & $\begin{array}{l}58.4 \\
57.2 \\
57.4\end{array}$ & $\begin{array}{l}62.4 \\
62.0 \\
61.2 \\
59.0 \\
56.0\end{array}$ & $\begin{array}{l}63.6 \\
62.8 \\
61.6 \\
58.6 \\
54.4\end{array}$ & $\begin{array}{l}63.6 \\
60.6 \\
61.6 \\
58.6 \\
54.4\end{array}$ & $\begin{array}{l}63.2 \\
63.2 \\
61.0 \\
58.4 \\
54.0\end{array}$ & $\begin{array}{l}54.4 \\
62.6 \\
60.8 \\
59.0 \\
54.2\end{array}$ & $\begin{array}{l}64.8 \\
62.6 \\
61.8 \\
59.4 \\
54.4\end{array}$ & $\begin{array}{l}60.0 \\
60.4 \\
56.6\end{array}$ \\
\hline$x^{\star}=$ & & 0.023 & 0.240 & 0.348 & 0.457 & 0.565 & 0.674 & 0.782 & 0.999 \\
\hline & $x(i n)$ & $(0.188)$ & $(3.60)$ & $(5.22)$ & $(6.85)$ & $(8.48)$ & $(10.10)$ & (11.72) & $(14.93)$ \\
\hline
\end{tabular}


TABLE 8.2-1. Temperature Field Measurements Bubbler Flow Rate 0.0 SCFH; $Y \star=0.500$ Fluid Temperatures $\left({ }^{\circ} \mathrm{C}\right)$

$$
\begin{array}{ll}
\text { Electrodes } & T=39^{\circ} \mathrm{C} \\
\text { Walls } & T=46^{\circ} \mathrm{C} \\
\text { Top } & T=19^{\circ} \mathrm{C} \\
\text { Electrode } & \text { Power }=132 \mathrm{~W}
\end{array}
$$

\begin{tabular}{|c|c|c|c|c|c|c|c|c|}
\hline & $x(\mathrm{~cm})$ & 8.095 & 11.91 & 15.72 & 19.53 & 23.34 & 27.15 & $Z^{\star}$ \\
\hline $\begin{array}{r}12.07 \\
9.53 \\
6.99 \\
4.85 \\
1.91 \\
-0.08\end{array}$ & $\begin{array}{l}(4.75) \\
(3.75) \\
(2.75) \\
(1.75) \\
(0.75) \\
(-0.031)\end{array}$ & $\begin{array}{l}61.6 \\
64.4 \\
59.8 \\
56.6 \\
51.6\end{array}$ & $\begin{array}{l}63.8 \\
64.6 \\
60.6 \\
57.1 \\
52.5 \\
40\end{array}$ & $\begin{array}{l}48.8 \\
63.6 \\
60.3 \\
56.5 \\
52.4\end{array}$ & $\begin{array}{l}53.5 \\
63.0 \\
60.4 \\
55.6 \\
51.8 \\
42\end{array}$ & $\begin{array}{l}50.6 \\
62.0 \\
60.6 \\
54.7 \\
51.2\end{array}$ & $\begin{array}{l}49.4 \\
62.1 \\
60.7 \\
54.5 \\
51.3 \\
40\end{array}$ & $\begin{array}{l}0.950 \\
0.750 \\
0.550 \\
0.350 \\
0.150\end{array}$ \\
\hline
\end{tabular}

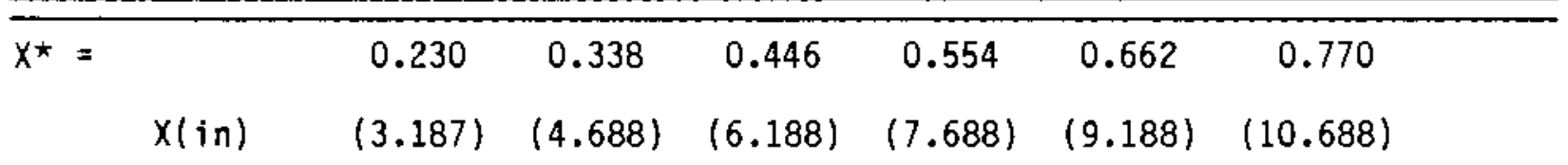


TABLE B.2-2. Temperature Field Measurements Bubbler Flow Rate 0.2 SCFH; $\gamma^{*}=0.500$ Fluid Temperatures $\left({ }^{\circ} \mathrm{C}\right)$

Electrodes $\mathrm{T}=37^{\circ} \mathrm{C}$

Walls $T=43^{\circ} \mathrm{C}$

Top $\quad T=8.5^{\circ} \mathrm{C}$

Electrode Power $=187 \mathrm{~W}$

\begin{tabular}{|c|c|c|c|c|c|c|c|c|}
\hline \multirow{2}{*}{$\mathrm{Z}(\mathrm{cm})$} & \multirow{2}{*}{$\begin{array}{l}X(\mathrm{~cm}) \\
Z(\mathrm{in})\end{array}$} & \multirow[t]{2}{*}{8.095} & \multirow[t]{2}{*}{11.91} & \multirow[t]{2}{*}{15.72} & \multirow[t]{2}{*}{19.53} & \multirow[t]{2}{*}{23.34} & \multirow[t]{2}{*}{27.15} & \multirow[t]{2}{*}{$Z^{\star}$} \\
\hline & & & & & & & & \\
\hline $\begin{array}{r}12.07 \\
9.53 \\
6.99 \\
4.45 \\
1.91 \\
-0.079\end{array}$ & $\begin{array}{l}(4.75) \\
(3.75) \\
(2.75) \\
(1.75) \\
(0.75) \\
(-0.031)\end{array}$ & $\begin{array}{l}59.6 \\
62.4 \\
62.5 \\
60.7 \\
57.9\end{array}$ & $\begin{array}{c}59.3 \\
63.0 \\
57.5 \\
58.8 \\
58.6 \\
39\end{array}$ & $\begin{array}{l}48.2 \\
57.9 \\
59.6 \\
59.5 \\
56.8\end{array}$ & $\begin{array}{c}45.3 \\
59.9 \\
61.2 \\
60.4 \\
59.2 \\
44\end{array}$ & $\begin{array}{l}45.8 \\
59.9 \\
61.5 \\
60.9 \\
58.9\end{array}$ & $\begin{array}{c}41.7 \\
57.9 \\
60.8 \\
60.3 \\
57.9 \\
42\end{array}$ & $\begin{array}{l}0.950 \\
0.750 \\
0.550 \\
0.350 \\
0.150\end{array}$ \\
\hline
\end{tabular}

\begin{tabular}{|c|c|c|c|c|c|c|c|}
\hline$x^{\star}=$ & & 0.230 & 0.338 & 0.446 & 0.556 & 0.662 & 0.770 \\
\hline & $x(i n)$ & $(3.187)$ & $(4.688)$ & $(6.188)$ & $(7.688)$ & $(9.188)$ & $(10.688)$ \\
\hline
\end{tabular}

TABLE B.2-3. Temperature Field Measurements Bubbler Flow Rate 0.5 SCFH; $\gamma^{*}=0.500$ Fluid Temperatures $\left({ }^{\circ} \mathrm{C}\right)$

Electrodes $\mathrm{T}=36^{\circ} \mathrm{C}$

Walls $T=43^{\circ} \mathrm{C}$

Top $\quad T=8.5^{\circ} \mathrm{C}$

Electrode Power $=164 \mathrm{~W}$

\begin{tabular}{|c|c|c|c|c|c|c|c|c|}
\hline & $x(\mathrm{~cm})$ & 8.095 & 11.91 & 15.72 & 19.53 & 23.34 & 27.15 & $Z^{\star}$ \\
\hline $\begin{array}{r}12.07 \\
9.53 \\
6.99 \\
4.45 \\
1.95 \\
-0.079\end{array}$ & $\begin{array}{l}(4.75) \\
(3.75) \\
(2.75) \\
(1.75) \\
(0.75) \\
(-0.031)\end{array}$ & $\begin{array}{l}55.2 \\
60.3 \\
58.9 \\
56.7 \\
55.5\end{array}$ & $\begin{array}{c}51.3 \\
56.5 \\
56.1 \\
57.1 \\
56.5 \\
39\end{array}$ & $\begin{array}{l}49.0 \\
55.4 \\
55.7 \\
56.7 \\
55.3\end{array}$ & $\begin{array}{c}43.6 \\
57.6 \\
58.6 \\
58.0 \\
57.3 \\
44\end{array}$ & $\begin{array}{l}36.8 \\
56.5 \\
56.9 \\
57.5 \\
56.6\end{array}$ & $\begin{array}{c}36.9 \\
58.5 \\
58.4 \\
58.9 \\
55.9 \\
40\end{array}$ & $\begin{array}{l}0.95 \\
0.750 \\
0.550 \\
0.350 \\
0.150\end{array}$ \\
\hline
\end{tabular}

\begin{tabular}{|c|c|c|c|c|c|c|c|}
\hline$x^{\star}=$ & & 0.230 & 0.338 & 0.446 & 0.556 & 0.662 & 0.770 \\
\hline & $x($ in $)$ & $(3.187)$ & $(4.688)$ & $(6.188)$ & $(7.688)$ & $(9.188)$ & $(10.688)$ \\
\hline
\end{tabular}


TABLE B.2-4. Temperature Field Measurements Bubbler Flow Rate 1.0 SCFH; $Y^{\star}=0.500$ Fluid Temperatures $\left({ }^{\circ} \mathrm{C}\right)$

$\begin{array}{ll}\text { Electrodes } & T=37^{\circ} \mathrm{C} \\ \text { Walls } & T=45^{\circ} \mathrm{C} \\ \text { Top } & T=9.0^{\circ} \mathrm{C}\end{array}$

Electrode Power $=171 \mathrm{~W}$

\begin{tabular}{|c|c|c|c|c|c|c|c|c|}
\hline \multirow[b]{2}{*}{$Z(\mathrm{~cm})$} & \multirow{2}{*}{$\begin{array}{l}X(\mathrm{~cm}) \\
Z(i \mathrm{n})\end{array}$} & \multirow[t]{2}{*}{8.095} & \multirow[t]{2}{*}{11.91} & \multirow[t]{2}{*}{15.72} & \multirow[t]{2}{*}{19.53} & \multirow[t]{2}{*}{23.34} & \multirow[t]{2}{*}{27.15} & \multirow[t]{2}{*}{$Z^{*}$} \\
\hline & & & & & & & & \\
\hline $\begin{array}{c}12.07 \\
9.53 \\
6.99 \\
4.45 \\
1.95 \\
-0.079\end{array}$ & $\begin{array}{c}(4.75) \\
(3.75) \\
(2.75) \\
(1.75) \\
(0.75) \\
(-0.031)\end{array}$ & $\begin{array}{l}53.1 \\
58.1 \\
58.4 \\
58.3 \\
58.1\end{array}$ & $\begin{array}{c}55.6 \\
59.1 \\
60.8 \\
59.5 \\
58.8 \\
40\end{array}$ & $\begin{array}{l}50.6 \\
58.6 \\
58.8 \\
58.5 \\
58.2\end{array}$ & $\begin{array}{c}44.4 \\
58.3 \\
60.3 \\
60.0 \\
57.5 \\
45\end{array}$ & $\begin{array}{l}35.4 \\
55.4 \\
58.1 \\
60.1 \\
57.8\end{array}$ & $\begin{array}{c}38.8 \\
60.1 \\
59.7 \\
59.2 \\
57.3 \\
42\end{array}$ & $\begin{array}{l}0.950 \\
0.750 \\
0.550 \\
0.350 \\
0.150\end{array}$ \\
\hline$X^{\star}=$ & & 0.230 & 0.338 & 0.446 & 0.554 & 0.662 & 0.770 & \\
\hline & $x(i n)$ & $(3.187)$ & $(4.688)$ & $(6.188)$ & $(7.688)$ & $(9.188)$ & $(10.688)$ & \\
\hline
\end{tabular}


.

$-$ 


\section{APPENDIX C}

BIPP BOUNDARY CONOITIONS - FOR STROBOSCOPIC PHOTOGRAPHS 
APPENDIX C

BIPP BOUNDARY CONDITIONS - FOR STROBOSCOPIC PHOTOGRAPHS

TABLE C.1. BPRUN-1 Boundary Conditions

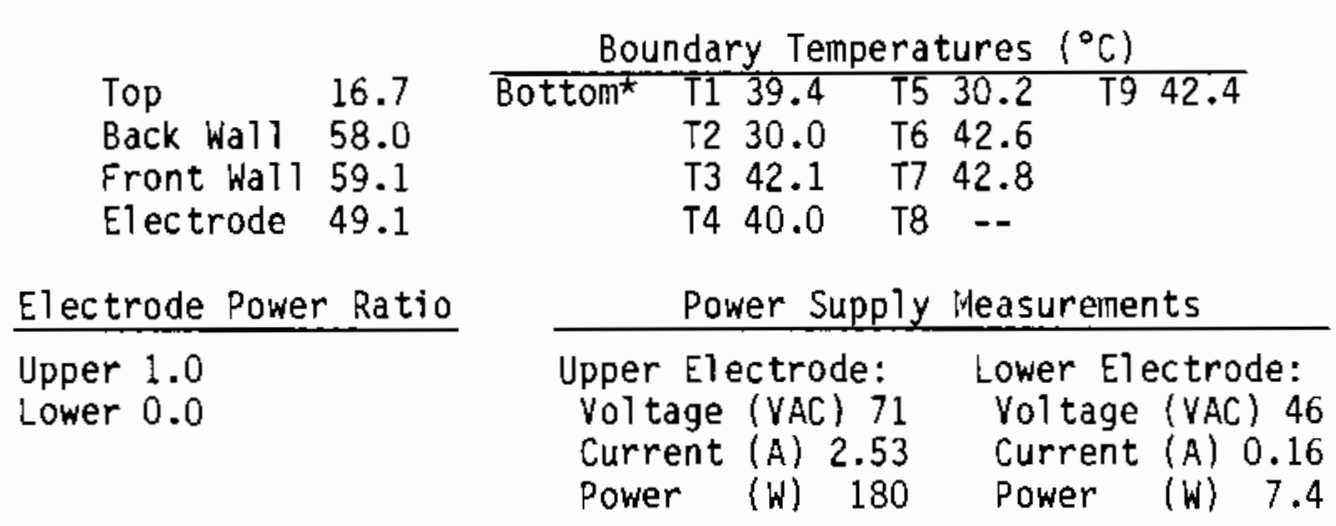

* Bottom temperatures, $T 1$ through $T 8$ are at locations shown in Figure C.1.

TABLE C.2. BPRUN-2 Boundary Conditions

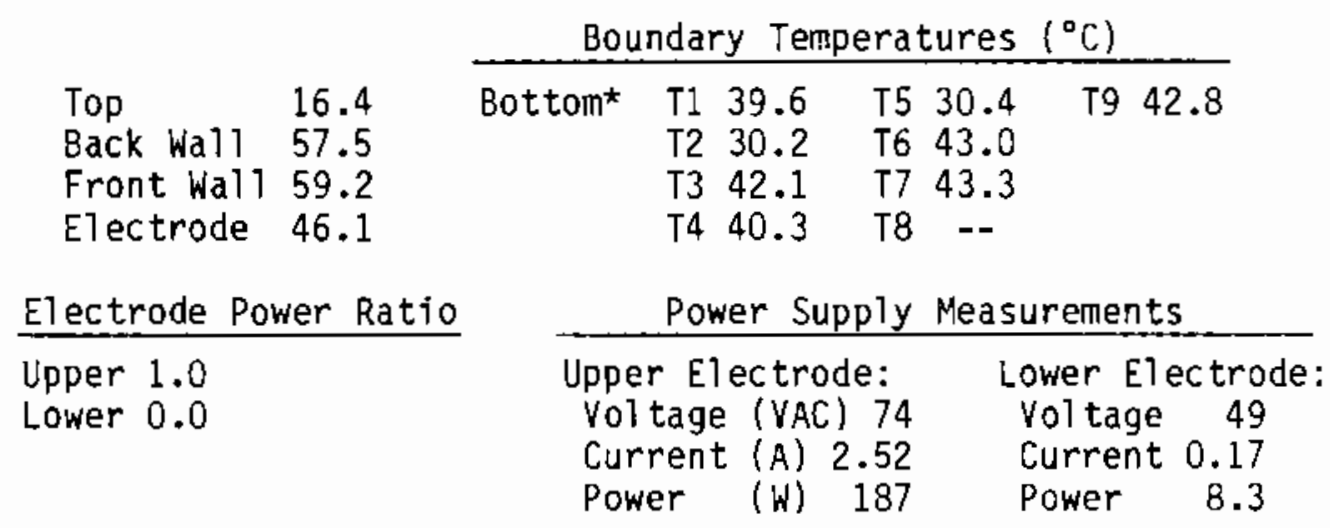

* Bottom temperatures, $\mathrm{Tl}$ through $\mathrm{T} 8$ are at locations shown in Figure C.1. 
TABLE C.3. BPRUN-3 Boundary Conditions

\begin{tabular}{|c|c|c|c|c|}
\hline \multirow{3}{*}{$\begin{array}{ll}\text { Top } & 10.3 \\
\text { Back wall } & 48.4 \\
\text { Front wall } & 50.0 \\
\text { Electrode } & 46.0 \\
& \\
\text { ectrode Power Ratio }\end{array}$} & \multicolumn{4}{|c|}{ Boundary Temperatures $\left({ }^{\circ} \mathrm{C}\right)$} \\
\hline & \multirow[t]{2}{*}{ Bottom } & $\begin{array}{ll}\text { T1 } & 46.7 \\
\text { T2 } & 36.0 \\
\text { T3 } & 49.6 \\
\text { T4 } & 48.0\end{array}$ & $\begin{array}{cc}\text { T5 } & 36.7 \\
\text { T6 } & 50.0 \\
\text { T7 } & 50.2 \\
\text { T8 } & --\end{array}$ & T9 50.0 \\
\hline & & \multicolumn{3}{|c|}{ Power Supply Measurements } \\
\hline $\begin{array}{l}\text { eer } 0.26 \\
\text { ver } 0.74\end{array}$ & $\begin{array}{l}\text { Upper } \\
\text { Volt } \\
\text { Curr } \\
\text { Powe }\end{array}$ & $\begin{array}{l}\text { Electrode } \\
\text { age (VAC) } \\
\text { ent (A) } 0 \text {. } \\
r \quad \text { (W) }\end{array}$ & $\begin{array}{l}\text { Lower } \\
\text { Volt } \\
\text { Curr } \\
\text { Powe }\end{array}$ & $\begin{array}{l}\text { Electrode: } \\
\text { ge (VAC) } 82 \\
\text { int }\end{array}$ \\
\hline
\end{tabular}

* Bottom temperatures, T1 through T8 are at locations shown in Figure C.1. 


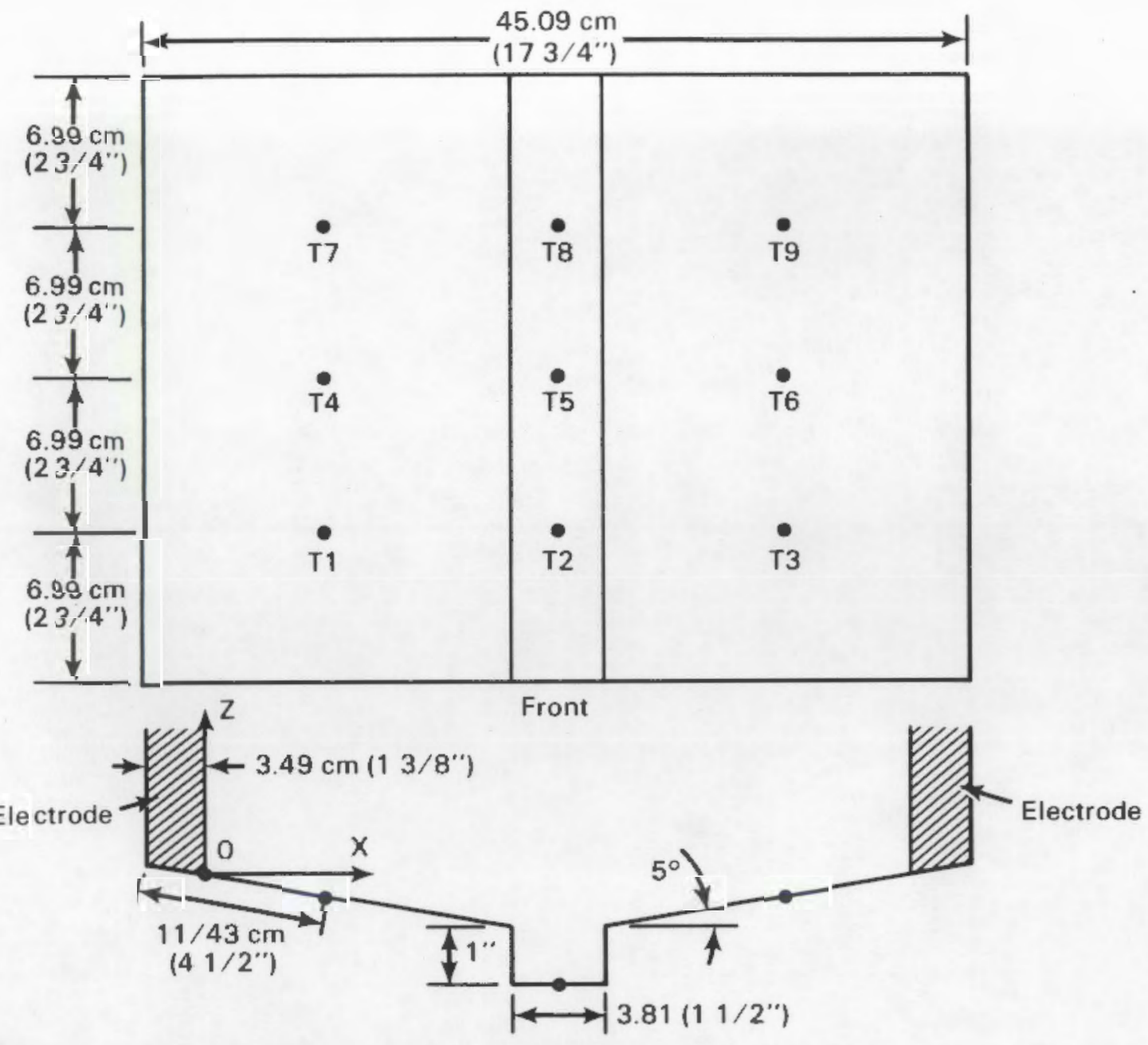

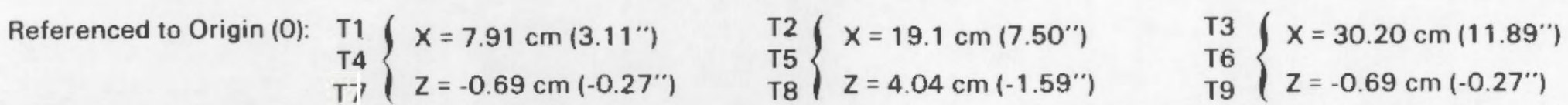

FIGURE C.1. Temperature masurement Locations on Model Bottom 
APPENDIX D

PSCM MODEL DATA FLUID ELECTRICAL POTENTIAL 


\section{APPENDIX D}

\section{MODEL FLUID ELECTRICAL POTENTIAL DATA}

TABLE D-1. Potential Field Measurements Bubbler Flow Rate 0.0 SCFH; $Y^{\star}=0.500$ Fluid Potential Traverses (Vac)

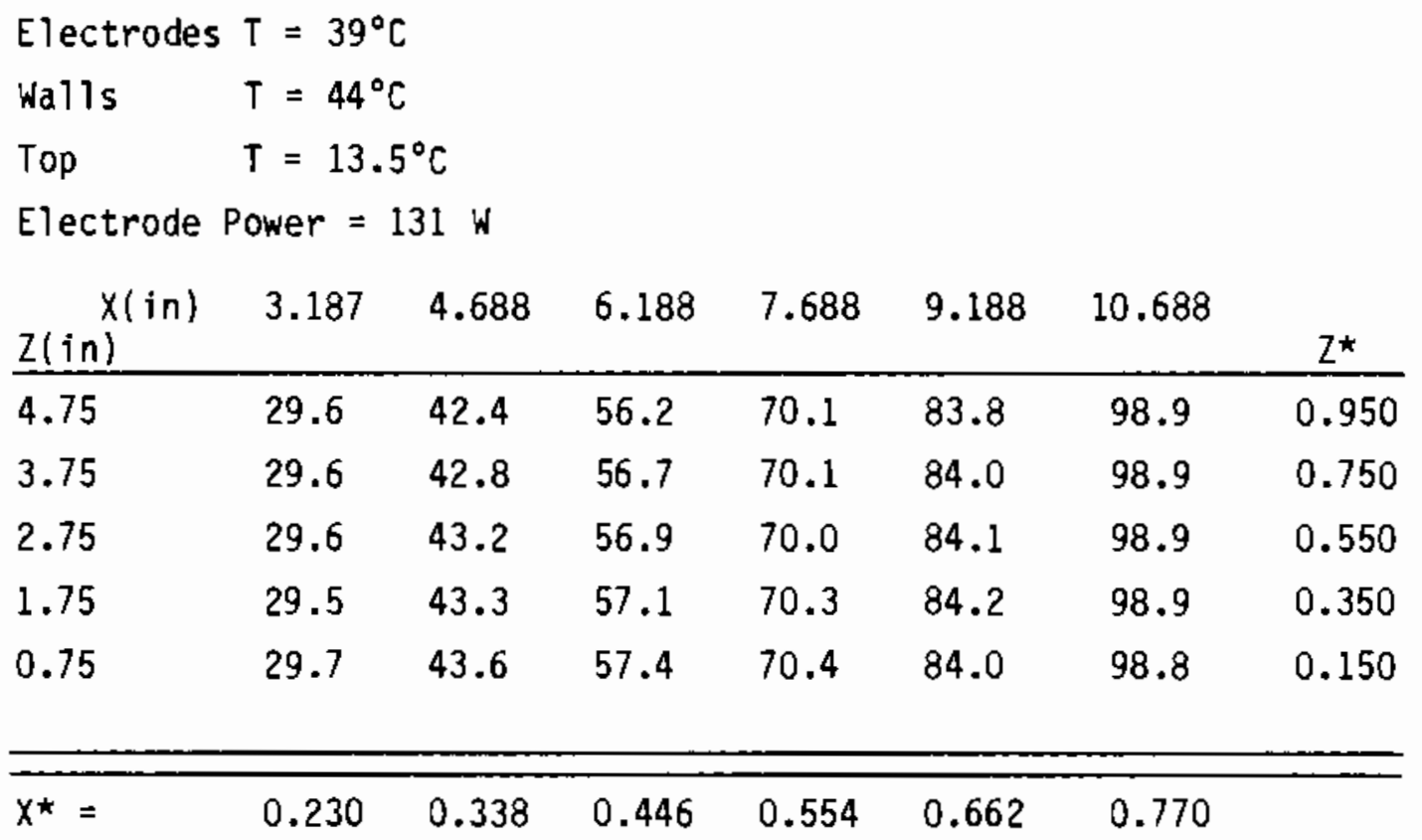


TABLE D-2. Potential Field Measurements Bubbler Flow Rate 0.2 SCFH; $Y^{\star}=0.500$ Fluid Potential Traverses (Vac)

Electrodes $\mathrm{T}=37^{\circ} \mathrm{C}$

Wails $\quad T=43^{\circ} \mathrm{C}$

Top $\quad T=9.5^{\circ} \mathrm{C}$

Electrode Power $=189 \mathrm{~W}$

\begin{tabular}{llllllll}
$\begin{array}{c}X(i n) \\
Z(i n)\end{array}$ & 3.187 & 4.688 & 6.188 & 7.688 & 9.188 & 10.688 & $Z^{\star}$ \\
\hline 4.75 & 30.2 & 43.3 & 58.4 & 74.8 & 89.6 & 103.7 & 0.950 \\
3.75 & 30.2 & 43.3 & 58.8 & 74.4 & 89.7 & 104.9 & 0.750 \\
2.75 & 31.1 & 44.7 & 58.8 & 74.3 & 89.8 & 103.4 & 0.550 \\
1.75 & 31.7 & 45.2 & 59.4 & 74.4 & 88.7 & 103.6 & 0.350 \\
0.75 & 30.8 & 45.6 & 59.6 & 75.2 & 89.6 & 103.8 & 0.150
\end{tabular}

\begin{tabular}{lllllll}
\hline$x^{\star}=$ & 0.230 & 0.338 & 0.446 & 0.554 & 0.662 & 0.770
\end{tabular}

TABLE D-3. Potential Field Measurements Bubbler Flow Rate 0.5 SCFH; $Y^{\star}=0.500$ Fluid Potential Traverses (Vac)

Electrodes $\mathrm{T}=36^{\circ} \mathrm{C}$

walls $T=34^{\circ} \mathrm{C}$

Top $\quad T=8.8^{\circ} \mathrm{C}$

Electrode Power $=168 \mathrm{~W}$

\begin{tabular}{llllllll}
$\begin{array}{l}X(i n) \\
Z(i n)\end{array}$ & 3.187 & 4.688 & 6.188 & 7.688 & 9.188 & 10.688 & $Z^{\star}$ \\
\hline 4.75 & 30.1 & 44.2 & 59.0 & 74.9 & 90.3 & 105.2 & 0.950 \\
3.75 & 30.7 & 45.2 & 59.1 & 74.7 & 90.2 & 105.8 & 0.750 \\
2.75 & 31.8 & 45.6 & 59.3 & 74.8 & 89.3 & 105.6 & 0.550 \\
1.75 & 31.8 & 45.8 & 59.7 & 74.6 & 90.1 & 105.5 & 0.350 \\
0.75 & 32.3 & 46.0 & 59.9 & 74.8 & 89.9 & 105.5 & 0.150 \\
\hline$X^{*}=$ & 0.230 & 0.338 & 0.446 & 0.554 & 0.662 & 0.770 &
\end{tabular}




\section{APPENDIX E}

UNCERTAINTY ANALYSIS 


\section{UNCERTAINTY ANALYSIS}

The accuracy of the modeling results were determined using kline and McCTintock's uncertainty method as described in Schenck [6]. A function, R, and its deviation, $r$, can be written in terms of two measurable variables as given in Equation E.1.

$$
R_{c}+r_{1}=\left(X+x_{1}\right)\left(y+Y_{1}\right)
$$

If $R$ is continuous and differentiable, and $X$ and $Y$ are independent variables it has been shown $(6)$ that $R$ lies between an uncertainty interval, $W_{r}$, with a $95 \%$ confidence level. The general equation for calculating the uncertainty interval, $W_{r}$ using three independent variables is given by Equation E.2.

$$
w_{r}^{2}=\left(\frac{\partial R}{\partial X_{m}}\right)^{2} w_{x}^{2}+\left(\frac{\partial R}{\partial Y_{m}}\right)^{2} w_{y}^{2}+\left(\frac{\partial R}{\partial Z_{m}}\right)^{2} w_{z}^{2}
$$

Using the Kline and Mcclintock uncertainty method, Ouigley and Kreid [1] derived uncertainty relationships for strobographic velocity measurements, cooling jacket flows, and power supply readings. These same relationships are used in a modified fashion to account for analog to digital conversion error. Cooling Jacket Flow

The relationship used to determine the cooling jacket flow, $\dot{0}$ was:

$$
\dot{0}=\frac{C V K_{a d}}{k}
$$

where: $C=$ flowmeter frequency to voltage conversion

$$
k=\text { flowneter constant }
$$




$$
\begin{aligned}
& V=\text { analog voltage recorded } \\
& \mathrm{K}_{\mathrm{ad}}=\text { analog to digital conversion ratio }
\end{aligned}
$$

$$
W_{Q}^{2}=\left(\frac{-C V k a d}{k^{2}}\right) w_{k}^{2}+\left(\frac{V k a d}{k}\right)^{2} w_{C}^{2}+\left(\frac{C k_{a d}}{k}\right)^{2} w_{V}^{2}+\left(\frac{C V}{k}\right)^{2} w_{a d}^{2}
$$

$$
\text { Nominal Values: } \begin{aligned}
& K=4953 . \pm 25 \text { counts } / 1 \text { iter } \\
& K_{a d}=1.000 \pm .0003 \\
& C=405 \pm 2.0 \mathrm{~Hz} / \mathrm{V} \\
& V=1 \pm .001 \mathrm{~V}_{\mathrm{ac}} \\
& Q_{r}=4.922 / \mathrm{m} \\
& Q_{r}=\frac{405 \times 1 \times 1}{4953} \times 60=4.92 \mathrm{\ell} / \mathrm{m} \\
& W_{Q}^{*}=0.035 \ell / \mathrm{m} \\
&\left(W_{Q}^{*} / Q_{r}^{*}\right) \times 100=0.71 \%
\end{aligned}
$$

Power Supply Readings

The uncertainties in the power supply voltage, current, and power measurements are evaluated below.

$\underline{\text { Vol tage }}$

The power supply voltage, $V_{r}$, was determined from:

$$
V_{r}=V \times T R_{v} \times T D \times K_{a d}
$$

where: $V=$ power transducer analog, voltage output

$T D=$ power transducer conversion ratio

$T R_{V}=$ sensing transformer ratio

$\mathrm{K}_{\mathrm{ad}}=$ analog to digital conversion ratio

$$
\begin{aligned}
w_{v_{r}}^{2}= & \left(T R_{v} \times T D \times x_{a d}\right)^{2} W_{v}^{2}+\left(V \times T D \times K_{a d}\right)^{2} w_{T R}^{2}+\left(V \times T R_{v} \times K_{a d}\right)^{2} W_{T D}^{2} \\
& +\left(V \times T R_{v} \times T D\right)^{2} W_{K a d}^{2}
\end{aligned}
$$




$$
\text { Nominal values: } \begin{aligned}
V_{r} & =105 \mathrm{VAC} \\
\mathrm{TR}_{\mathrm{V}} & =1.80 \pm 0.036 \\
\mathrm{TD} & =24.0 \pm 0.24 \\
\mathrm{~K}_{\mathrm{ad}} & =1.00 \pm 0.0003 \\
V & =2.41 \pm 0.1 \mathrm{VDC}
\end{aligned}
$$

$W v_{r}=4.91 \mathrm{VAC}$

$\left(H v_{r} / V_{r}\right) \times 100 \%=4.67 \%$

\section{Current}

The relationship to calculate the power supply current Ir was:

$$
I_{r}=V \times T R_{I} \times T D \times K_{a d}
$$

where: $\quad V=$ Power transducer analog voltage output

$$
\mathrm{TD}=\text { Power transducer conversion rates }
$$

$T R_{I}=$ Sensing transformer ratio

$x_{\text {ad }}=$ Analog to digital conversion ratio

$$
\begin{aligned}
W_{I_{r}}^{2}= & \left(T R_{I} \times T D \times k_{a d}\right)^{2} W_{v}^{2}+\left(V \times T O \times K_{a d}\right)^{2} H_{T R}^{2}+\left(V \times T R_{I} \times k_{a d}\right)^{2} W_{T D}^{2} \\
& +\left(V \times T R_{I} \times T D\right)^{2} W_{K_{a d}}^{2}
\end{aligned}
$$

Nominal values: $\quad V=1 \pm 0.05$ VDC

$$
\begin{aligned}
\mathrm{TR}_{\mathrm{I}} & =2 \pm .06 \\
\mathrm{TD} & =1 \pm 0.01 \\
\mathrm{~K}_{\mathrm{ad}} & =1.0 \pm 0.0003 \\
\mathrm{I}_{\mathrm{R}} & =2 \mathrm{~A}
\end{aligned}
$$

$$
\begin{aligned}
& W_{I_{r}}=0.118 \mathrm{~A} \\
& \left(W_{I_{r}} / I_{r}\right) \times 100 \%=5.92 \%
\end{aligned}
$$


Power supply power, $P_{r}$, was determined from the following relationship,

$$
\begin{aligned}
& P=V \times T R_{y} \times T R_{I} \times T D \times K_{a d} \\
& \text { Nominal values: } P_{r}=274 \mathrm{~W} \\
& T R_{v}=1.8 \pm 0.036 \\
& T R_{I}=120 \pm 0.060 \\
& \mathrm{TD}=120 \pm 1.2 \\
& \mathrm{~K}_{\mathrm{ad}}=1.0 \pm 0.0003 \\
& w_{P}^{2}=\left(T R_{v} \times T R_{I} \times T D \times K_{a d}\right)^{2} w_{v}^{2}+\left(V \times T R_{I} \times T D \times k_{a d}\right)^{2} W_{T R_{v}}^{2} \\
& +\left(V \times T R_{v} \times T D \times K_{a d}\right)^{2} W_{T R}^{2}+\left(V \times T R_{v} \times T R_{I} \times K_{a d}\right)^{2} W_{T D}^{2} \\
& +\left(V \times T R_{V} \times T R_{I} \times T D\right)^{2} W_{K_{a d}}^{2} \\
& W_{p}=13.05 \mathrm{~W} \\
& \left(W_{p_{r}} / P_{r}\right) \times 100 \%=4.8 \%
\end{aligned}
$$

\section{Stroboscopic Velocity Measurements}

The procedure and equipment used to obtain the stroboscopic velocity photographs were the same used during the physical modeling effort described in [1]. However, during the present modeling effort, velocity measurements were obtained from the photographs using a digitizing technique. This allowed improvement in local resolution in velocity measurements and a faster method of obtaining velocities. The uncertainty procedure used to evaluate the stroboscopic velocity measurements is taken directly from Quigley and Kreid [1]. Nominal values differ as a result of the differing measurement techniques and lower velocities obtained. 
The velocity $u$ of a light-scattering particle suspended in the modeling fluid was calculated from the relationship

$$
u=\frac{l}{M_{p}^{M} c^{\Delta t}}
$$

where $l=$ length of the image string on the photograph

$M_{C}=$ camera magnification

$M_{p}=$ photograph enlargement

$\Delta \mathrm{t}=$ total exposure time.

$$
w_{u}^{2}=\left(\frac{\partial u}{\partial l}\right)^{2} w_{l}^{2}+\left(\frac{\partial u}{\partial M_{p}}\right)^{2} w_{M}^{2}+\left(\frac{\partial u}{\partial M_{c}}\right)^{2} w_{M}^{2}+\left(\frac{\partial u}{\partial \Delta t}\right) w_{\Delta t}^{2}
$$

The photograph enlargement was known to within $\pm 0.1 \%$ and the magnification of the camera could be determined consistently to $+0.8 \%$. The exposure time was assumed to be at least as accurate as 1 part in 60 or $\pm 0.017 \mathrm{sec}$. The image string length was measured to within \pm 0.125 m. Nominal values for this study were:

$$
\begin{aligned}
& U=0.30 \mathrm{~mm} / \mathrm{sec} \\
& \ell=6.0 \mathrm{~mm} \quad \pm 0.125 \\
& M_{p}=4 \quad \pm 0.004 \\
& M_{c}=0.5 \quad \pm 0.004 \\
& \Delta \mathrm{t}=30.0 \mathrm{sec} \pm 0.017 \\
& w_{u}^{2}=\left(\frac{1}{M_{p} M_{c} \Delta t}\right)^{2} w_{\ell}^{2}+\left(\frac{-\ell}{M_{p}{ }^{2} M_{c} \Delta t}\right)^{2} w_{M}^{2}+\left(\frac{-l}{M_{p} M_{c}{ }^{2} \Delta t}\right)^{2} w_{M_{c}}^{2} \\
& +\left(\frac{-l}{M_{p} M c^{\Delta} t^{2}}\right)^{2} w_{\Delta t}^{2} \\
& =\left(\frac{1}{4.0 \times 0.5 \times 5}\right)^{2}(0.125)^{2}+\left(\frac{-3.0}{16.0 \times 0.5 \times 5}\right)^{2}(0.004)^{2} \\
& +\left(\frac{-3.0}{4.0 \times 0.25 \times 5}\right)^{2}(0.004)^{2}+\left(\frac{-3.0}{4.0 \times 0.5 \times 25}\right)^{2}(0.017)^{2}
\end{aligned}
$$




$$
\begin{aligned}
& =1.563\left(10^{-4}\right)+9.000\left(10^{-8}\right)+5.760\left(10^{-6}\right)+1.040\left(10^{-6}\right) \\
& =1.632\left(10^{-4}\right) \\
W_{u} & = \pm 0.013 \mathrm{~mm} / \mathrm{sec} \\
W u / u & = \pm 4.26 \% .
\end{aligned}
$$

The uncertainty in the absolute location of images in the photographs was determined from repeated measurements as $\pm 1.59 \mathrm{~mm}$. 


\section{APPENDIX F}

PSCM MODEL HEAT LOSS ANALYSIS 
- Uncooled portion of the model top

- Model bottom

Heat losses form "noncooled" surface (model bottom and uncooled portion of the top) were assumed to be small. These assumptions were based on the heat loss estimates determined in this Appendix.

\section{F.1 Maximum Heat Loss from Uncooled Portion of Model Top}

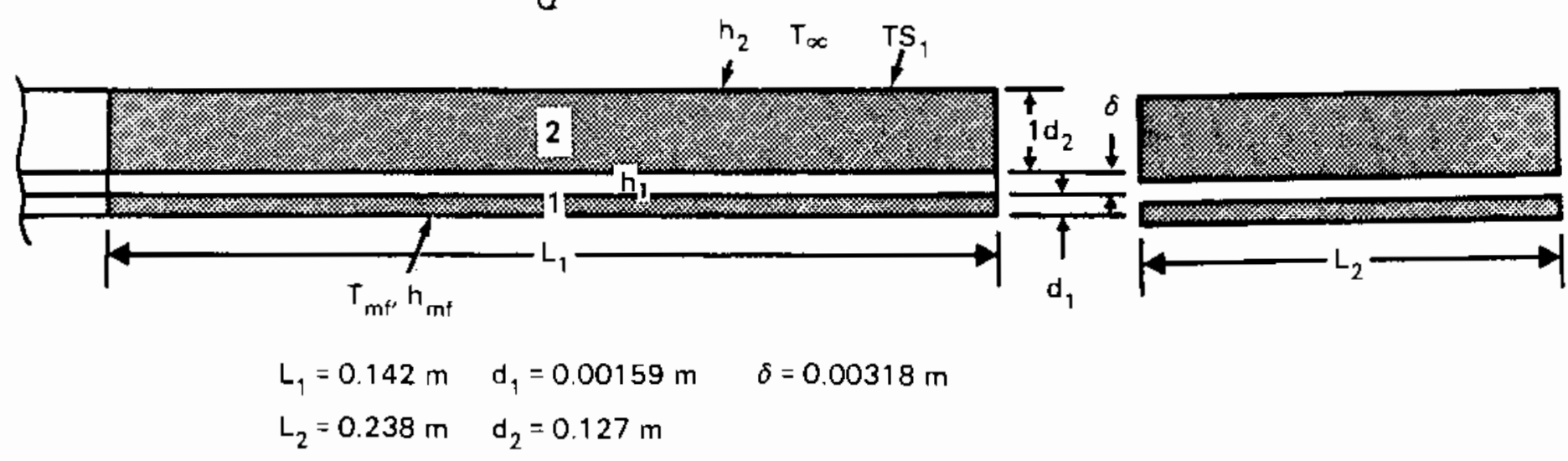

FIGURE F.1. Uncooled Portion of Model Top

Heat transfer through the uncooled portion of the top shown in Figure F.1 is given by Equation F.1. The regions, one and two are sheets of plexiglass on either side of an air gap.

$$
Q=U A\left(T_{m f}-T_{\infty}\right)
$$

where $T_{m f}=$ Modeling fluid bulk temperature

$T_{\infty}=$ Environmental temperature

$A=$ Surface area from which heat is lost (into the plane for Figure F.1)

$U$ - Overall heat transfer coefficient 
The overall heat transfer coefficient, $U$, is given by Equation F.2.

$$
U=\left[\frac{1}{\hbar_{m f}}+\frac{d_{1}}{R_{1}}+\frac{1}{\hbar_{1}}+\frac{d_{2}}{R_{2}}+\frac{1}{\hbar_{2}}\right]^{-1}
$$

where $d_{1}$ and $d_{2}=$ characteristic lengths as defined in Figure F.1

$k_{1}$ and $k_{2}=$ thermal conductivity of plexiglass, $k_{p l x}$

$d_{1}=1.59 \times 10^{-3} \mathrm{~m}$

$\mathrm{d}_{2}=1.27 \times 10^{-2} \mathrm{~m}$

$\mathrm{K}_{1}=\mathrm{K}_{2}=0.187 \mathrm{~W} / \mathrm{m}^{\circ} \mathrm{C}$

Therefore the 2nd and 4 th RHS terms of Equation F.2, are:

$$
\begin{aligned}
& \frac{d_{1}}{K_{1}}=8.50 \times 10^{-3}\left(\mathrm{~m}^{2}\right)(\mathrm{c}) / \mathrm{w} \\
& \frac{d_{2}}{\mathrm{~K}_{2}}=6.79 \times 10^{-2}\left(\mathrm{~m}^{2}\right)(\mathrm{c}) / \mathrm{w}
\end{aligned}
$$

$h_{1}$ was determined using a correlation, Equation F.3, proposed by Holman [12] for convection in an enclosed space.

$$
n_{1}=\frac{k_{\text {gap }}}{\delta}
$$

valid for $\mathrm{Gr}_{\delta} \mathrm{Pr}<1700$

where $K_{\text {gap }}$ is the thermal conductivity of the air in the gap

$\delta$ is the gap characteristic length shown in Figure F.1.

$h_{2}$ was determined by assuming the upper surface of body two in Figure $F .1$ to be a heated horizontal plate facing upward. The natural convection correlation which was obtained from Reference [13] is shown in Equations F.4a and F.4b

$$
\mathrm{Nu}=0.56(\mathrm{Ra})^{1 / 4}
$$




$$
\begin{gathered}
h_{2}=\frac{N u K_{f 1}}{L_{c}} \\
L_{c}=\left(L_{1}+L_{2}\right) / 2
\end{gathered}
$$

$$
\text { valid for: } 10^{4} \leqslant \mathrm{Ra} \leqslant 10^{8}
$$

Equation $F .4$ is a reasonable approximation for predicting $n_{\text {mf }}$ during PSCM testing without bubbles [12]. However as indicated in Section 4, flow velocity magnitudes were not obtained near the top during bubbler testing. Due to the modeling fluid flow complexities, heat generation, within the fluid, and velocity uncertainty during bubble testing, it was assumed, $\mathrm{n}_{\mathrm{hf}} \gg 1$. Therefore, the first term in Equation F.2 can be neglected, and the equation values to Equation F.5.

$$
\mathrm{U}=\left[\frac{\mathrm{d}_{1}}{\mathrm{k}_{1}}+\frac{1}{\mathrm{~h}_{1}}+\frac{\mathrm{d}_{2}}{\mathrm{k}_{2}}+\frac{1}{\mathrm{~h}_{2}}\right]^{-1}
$$

The actual heat loss from the uncooled portion of the top will be less than the neat loss calculated from Equation F.5

The convective heat transfer coefficient, $h_{1}$ was calculated using the air gap temperatures and properties shown in Table F.1.

TABLE F.1. Air Gap Properties (maximum heat loss estimate)

$$
\begin{aligned}
& T_{\text {mf }}=T_{1 \text { gap }}=60^{\circ} \mathrm{C} \quad \rho_{\text {gap }}=1.131 \mathrm{Kg} / \mathrm{m}^{3} \\
& T_{\infty}=T_{2 \text { gap }}=20^{\circ} \mathrm{C} \quad C_{\text {pgap }}=1.0066 \times 10^{3} \mathrm{~J} / \mathrm{kg}^{\circ} \mathrm{C} \text {. } \\
& T_{f}=40^{\circ} \mathrm{C} \\
& \mathrm{B}_{\text {gap }}=0.00319(\mathrm{~K})^{-1} \\
& H_{\text {gap }}=2.007 \times 10^{-5} \mathrm{~kg} / \mathrm{m}-\mathrm{s} \\
& \delta=0.00318 \mathrm{~m} \\
& g=9.81 \mathrm{~m} / \mathrm{s}^{2} \\
& v_{\text {gap }}=1.70 \times 10^{-5} \mathrm{~m}^{2} / \mathrm{s} \\
& \mathrm{K}_{\text {gap }}=0.0272 \mathrm{~W} / \mathrm{m}^{\circ} \mathrm{C} \\
& G r_{\delta}=\frac{\rho_{\text {gap }}{ }^{B_{\text {gap }}}\left(T_{1 \text { gap }}-T_{2 g a p}\right) \delta^{3}}{v_{\text {gap }}^{2}} \\
& \operatorname{pr}=\frac{\mu_{\text {gap }} C_{\text {pgap }}}{K_{\text {gap }}} \\
& \mathrm{G} r_{\delta}=157 \\
& \mathrm{Pr}=0.744
\end{aligned}
$$




$$
\mathrm{Gr}_{8} \mathrm{Pr}=117
$$

Therefore, Gro $\mathrm{Pr}<1700$ satisfies the criteria required to use Equation F.3. Applying Equation F.3 and solving for $h_{1}$ gives

$$
h_{1}=8.55 w / m^{20} \mathrm{C}
$$

The convective heat transfer coefficient, $h_{2}$ was determined using nominal temperatures and air properties given in Table F.2.

TABLE F.2. Temperature and Property Values Used to Determine $h_{2}$

$$
\begin{aligned}
& \mathrm{T}_{51}=40^{\circ} \mathrm{C} \quad \rho_{\mathrm{a}}=1.167 \mathrm{~kg} / \mathrm{m}^{2} \\
& \mathrm{~T}_{\infty}=20^{\circ} \mathrm{C} \quad \mathrm{C}_{\mathrm{pa}}=1.0059 \times 10^{3} \mathrm{~J} / \mathrm{Kg} \cdot{ }^{\circ} \mathrm{C} \\
& \mathrm{T}_{f}=30^{\circ} \mathrm{C} \quad \mathrm{\mu}_{\mathrm{a}}=1.99 \times 10^{-5} \mathrm{Kg} / \mathrm{m}^{*} \mathrm{~s} \\
& B_{a}=0.0033(\mathrm{~K})^{-1} \quad v_{a}=1.60 \times 10^{-5} \mathrm{~m}^{2} / \mathrm{s} \\
& g=9.81 \quad k_{a}=0.0265 \mathrm{~W} / \mathrm{m}^{\circ}{ }^{\circ} \mathrm{C} \\
& L_{c}=1 / 2\left(L_{1}+L_{2}\right)=0.190 m \\
& G r=\frac{\rho_{a} g \beta_{a}\left(T_{s l}-T_{\infty}\right) L_{c}^{3}}{v_{a}^{2}} \quad \operatorname{Pr}=\frac{\mu_{a} c_{p a}}{K_{a}} \\
& \mathrm{Gr}=2.02 \times 10^{7} \\
& \mathrm{Pr}=0.755 \\
& \mathrm{Ra}=\mathrm{GrPr}=1.53 \times 10^{7}
\end{aligned}
$$

Since $10^{4}<$ Ra $<10^{8}$ is satisfied, Equation $F .4$ can be used to estimate $h_{2}$. The Nusselt number, Nu, was first determined from Equation F.4a:

$$
\begin{aligned}
& \mathrm{Nu}=0.56\left(1.53 \times 10^{7}\right)^{1 / 4} \\
& \mathrm{Nu}=35.0
\end{aligned}
$$

Using Equation F.4b, $h_{2}=4.88 \mathrm{~W} / \mathrm{m}^{2}{ }^{\circ} \mathrm{C}$ was calculated. Substituting the values for $h_{1}, h_{2}, k_{1} / d_{1}$, and $k_{2} / d_{2}$ into Equation $F .5$ and solving for the overall heat transfer coefficient resulted in: 


$$
U=\left[8.50 \times 10^{-2}+\frac{1}{8.55}+0.679+\frac{1}{4.88}\right]^{-1}
$$

or

$$
U=0.919 \mathrm{~W} / \mathrm{m}^{2} \cdot{ }^{\circ} \mathrm{C}
$$

Finally, the maximum neat loss was determined from Equation F.1 and using the following nominal values.

$$
\text { Nominal Values: } \begin{aligned}
U & =0.919 \mathrm{~W} / \mathrm{m}^{2} \cdot{ }^{\circ} \mathrm{C} \\
A & =3.39 \times 10^{-2} \mathrm{~m}^{2} \\
T_{m f} & =60^{\circ} \mathrm{C} . \\
T_{\infty}=20^{\circ} \mathrm{C} \quad & Q=U A\left(T_{m f}-T_{\infty}\right) \\
Q & =1.24 \mathrm{~W}
\end{aligned}
$$

The large temperature differentials, property values and assumption, $n_{m f} \gg 1$ were chosen to provide a predicted heat loss larger than the actual heat loss, such that an upper bound or maximum heat loss was predicted. Therefore, at a nominal PSCi operating power of $175 \mathrm{~W}$, the maximum fractional heat dissipated from the noncooled portion of the top is $0.71 \%$.

The PSCM model bottom is a sheet of plexiglass exposed to the heated modeling fluid on its upper surface and to ambient air on its power surface as

\section{F.2 Maximum Heat Loss from PSCM Model Bottom}

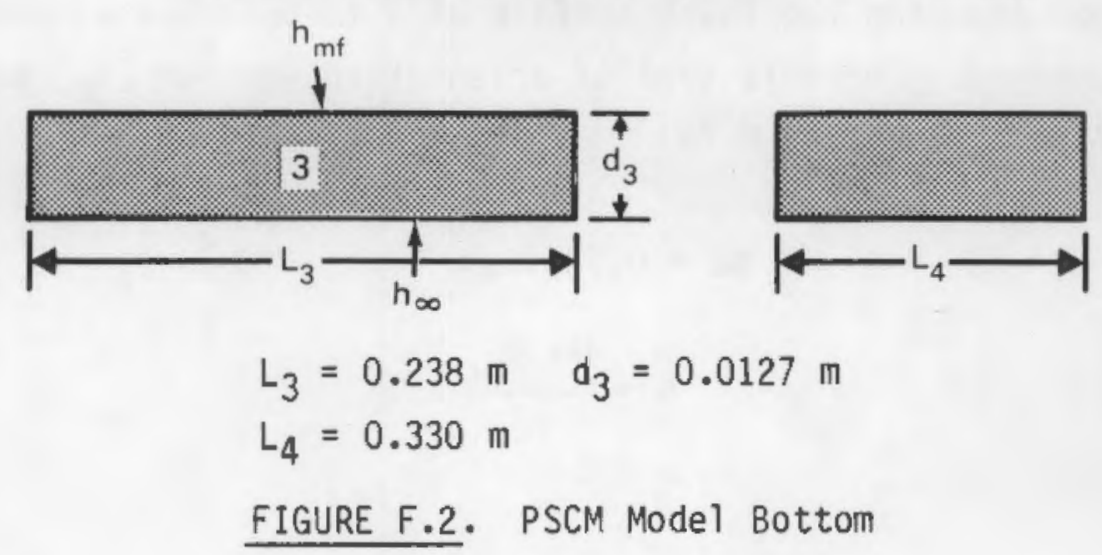


shown in Figure F.2. Equation F.1 was again used to estimate the maximum heat transferred from the modeling fluid through the plexiglass bottom. The overall heat transfer coefficient is determined from Equation F.6.

$$
U=\left[\frac{1}{h m f_{b}}+\frac{d_{3}}{K_{3}}+\frac{1}{h_{4}}\right]^{-1}
$$

where $h_{m f b}$ is the heat transfer coefficient of the modeling fluid at the upper surface of the model bottom

$d_{3}$ is the characteristic length for the RHS 2nd term of F.6

$\mathrm{K}_{3}$ is the thermal conductivity of plexiglass

$\mathrm{h}_{4}$ is the convective heat transfer coefficient at lower surface of the model bottom.

Due to the flow complexities mentioned in subsection F.1, $h_{m_{b}} \gg 1$ was assumed. The result of this assumption is a conservative predicted heat loss through the model bottom larger than the actual heat loss.

$$
\begin{aligned}
& K_{3}=K_{p l x}=0.187 \mathrm{~W} / \mathrm{m} \cdot{ }^{\circ} \mathrm{C} \\
& d_{3}=0.0127 \mathrm{~m}
\end{aligned}
$$

Therefore the 2nd RHS term of Equation F.6 is

$$
\frac{d_{3}}{R_{3}}=0.0679 \mathrm{~m}^{2} \cdot{ }^{0} \mathrm{C} / \mathrm{W} \text {. }
$$

$h_{3}$ was determined assuming the lower surface of 3 to be a heated horizontal plate facing downward. For this type of orientation, Holman [12] suggests the relationship given by Equation F.7a

$$
\begin{gathered}
\mathrm{Nu}=0.58(\mathrm{Ra})^{1 / 5} \\
h=\frac{\mathrm{Nu} \mathrm{K} \mathrm{Ka}_{\mathrm{f}}}{\mathrm{L}_{\mathrm{c}}}
\end{gathered}
$$




$$
L_{c}=\left(L_{3}+L_{4}\right) / 2
$$

Valid for: $10^{5} \leqslant \mathrm{Ra} \leqslant 10^{11}$

As discussed in subsection F.1, a larger than actual temperature differential was used to determine the maximum or upper bound heat loss from the bottom. Temperature and property values used to determine $h_{1}$ are given in Table F.3.

TABLE F.3. Temperature and Property Values Used to Determine $h_{3}$

$$
\begin{aligned}
& T_{m f}=60^{\circ} \mathrm{C} \\
& \rho_{a_{3}}=1.131 \mathrm{~kg} / \mathrm{m}^{3} \\
& T_{\infty}=20^{\circ} \mathrm{C} \\
& T_{f}=40^{\circ} \mathrm{C} \\
& \beta_{\mathrm{a} 3}=0.00319{ }^{\circ} \mathrm{K}^{-1} \\
& \mathrm{~g}=9.81 \mathrm{~m} / \mathrm{s}^{2} \\
& L_{c}=1 / 2\left(L_{3}+L_{4}\right)=0.284 \mathrm{~m} \\
& c_{p_{a 3}}^{a_{3}}=1.0066 \times 10^{3} \mathrm{~J} / \mathrm{kg}^{\circ} \mathrm{C} \\
& { }_{\mathrm{H}_{3}}=2.007 \times 10^{-5} \mathrm{~kg} / \mathrm{r} \cdot \mathrm{s} \\
& v_{a_{3}}=1.70 \times 10^{-5} \mathrm{~m}^{2} / \mathrm{s} \\
& \mathrm{k}_{\mathrm{a}_{3}}=0.0272 \mathrm{~W} / \mathrm{m} \cdot{ }^{\circ} \mathrm{C} \\
& G r=\frac{\rho_{a 3} g_{a 3}\left(T_{m f}-T_{\infty}\right) L_{c}^{3}}{v a_{3}^{2}} \\
& \mathrm{Gr}=1.12 \times 10^{8} \\
& \mathrm{Pr}=\frac{{ }_{\mathrm{a} 3} \mathrm{C}_{\mathrm{pa} 3}}{\mathrm{~K}_{\mathrm{a} 3}} \\
& \mathrm{Pr}=0.743 \\
& \mathrm{Ra}=\mathrm{GrPr}=8.33 \times 10^{7}
\end{aligned}
$$

The criteria, $10^{5}<$ Ra< $10^{11}$ is satisfied nence, Equation F.7 can be applied to determine $n_{3}$. Substituting the Raleigh number, Ra, which was determined from the properties in Table F.3, into Equation F.7, the Nusselt number, Nu, and subsequently $h_{3}$ were calculated as 22.1 and $2.12 \mathrm{w} / \mathrm{m}^{2}{ }^{\circ} \mathrm{C}$, respectively.

The overall heat transfer coefficient, $U$, was solved from Equation $F .6$ using the known values of $h_{m f}, h_{3}$, and $k_{3} / d_{3}$

$$
\begin{gathered}
U=\left[0+0.0679+\frac{1}{2.12}\right]^{-1} \\
U=1.85 \mathrm{~W} / \mathrm{m}^{2} \cdot{ }^{\circ} \mathrm{C}
\end{gathered}
$$


$\underline{\text { DISTRIBUTION }}$

No. of

Copies

OFFSITE

30 DDE Technical Information Center

5 Geologic Repository Division

DOE Office of Civilian

Radioactive Waste Management

Forrestal Building

Washington, DC 20585

ATTN: J. W. Bennet, RW-20

C. R. Cooley, RW-4

M. W. Frei

B. C. Rusche, RW-1

R. Stein, RW-23

2 DOE Office of Defense Waste \& GTN

Byproducts Management

Washington, DC 20545

ATTN: D. B. LeClaire, DP-12

R. D. Walton, Jr., DP-123

7 DOE Office of Terminal Waste

Disposal \& Remedial Action GTN

Washington, DC 20545

ATTN: J. E. Baublitz, NE-24

J. A. Coleman, NE-25

D. J. MCGoff, NE-23

J. A. Turi, NE-25

W. R. Voigt, NE-20

H. F. Walter, NE-25

J. B. Zorn, NE-25

11. J. Bell

Division of Nuclear Materials Safety \& Safeguards

Mail Station 881-SS

Nuclear Regulatory Commission

Washington, DC 20555

A. T. Clark

Division of Fuel Material Safety

Nuclear Regulatory Commission

Washington, DC 20555
No of

Copies

W. J. Dircks

Office of the Executive

Director for Operations

Mail Station 6209

Nuclear Regulatory Commission

Washington, DC 20555

2 Environmental Protection Agency

Office of Radiation Programs

401 M Street, S.W.

Washington, DC 20460

ATTN: D. Egan

G. L. Sjoblom

2 DOE Alburquerque Operations

Office

P.0. Box 5400

Alburquerque, NM 87185

ATTN: R. Y. Lowrey

J. McGough

W. H. Hannum

DOE West Valley Operations

Office

P.0. Box 191

West Valley, NY 14171

2 DOE Idaho Operations Office

550 Second Street

Idaho Falls, ID 83401

ATTN: J. D. Hamric

J. B. Whitsett

L. Lanni

DOE San Francisco Operations

1333 Broadway

San Francisco, CA 94612

W. E. Pasko

DOE Oak Ridge Operations Office

P.0. Box E

Oak Ridge, TN 37830 
No. of

Copies

7 E. I. du Pont de Nemours Company

Savannah River Laboratory

Aiken, SC 29801

ATTN: M. D. Boersma

J. L. 'Crandall

E. J. Hennelly

L. L. Kilpatrick/

L. M. Lee

S. Mirshak

R. 14. Wallace

D. C. Witt

J. F. Ortaldo

E. A. Jennrich

EGóg Idaho

P.0. Box 1625

Idaho Fal1s, ID 83415

K. V. Gilbert/P. G. Hagen

Rockwell International

Rocky Flats Plant

P.0. Box 464

Golden, C0 80401

G. W. Meyers

Atomics International Division

Rockwell International

8900 DeSoto Avenue

Canoga Park, CA 91304

T. H. Pigford

Department of Nuclear Engineering

University of California

Berkeley, CA 94720

M. E. Spaeth

Science Applications, Inc. 2769 South Highland

Las Vegas, NV 89109

J. F. Strah1

Weston

2301 Research Boulevard

Third Floor

Rockville, MD 20850
No. of

Copies

R. Williams

Electric Power Research

Institute

3412 Hillview Avenue

P.0. Box 10412

Palo Alto, CA 94304

5 West Valley Nuclear Services Company

P.0. Box 191

West Valley, NY 14171

ATTN: C. C. Chapman

J. L. Knabenschuh

J. E. Krauss

J. M. Pope

S. M. Barnes

J. W. Bartlett

The Analytic Sciences

Corporation

6 Jacob Way

Reading, MA 01867

W. A. Freeby/J. L. Jardine

Bechtel National, Inc.

P.0. Box 3965

San Francisco, CA 94119

Librarian

Westinghouse Electric

Corporation

Technical Library

P.0. Box 40039

Albuquerque, NN: 87196

L. L. Hench

Department of Materials Science \& Engineering

University of Florida

Gainesville, FL 32611

U. L. Larocca, Chairman

Energy Research \& Development Authority

Empire State Plaza

Albany, NY 12223 